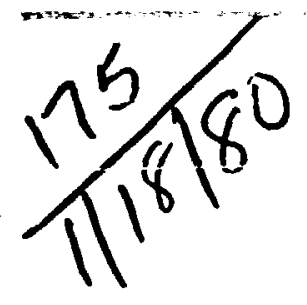

th. 528

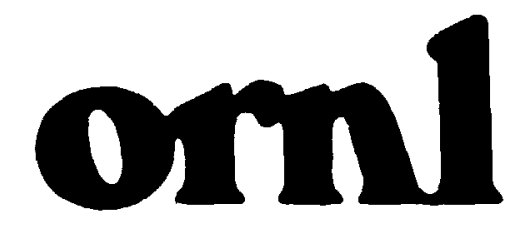

ORNL-5409/R1

OAK

RIDGE

NATIONAL

LABORATORY

UNION

CARBIDE

\title{
Safety Analysis Report for Packaging (SARP) of the Oak Ridge National Laboratory TRU Californium Shipping Container
}
W. D. Box
L. B. Shappert
R. D. Seagren:
B. B. ńlima
M. C. Jurgensen
C. R. Hammond
C. D. Watson 
ORNL-5409: RI

Dist. Category UC-7I

Contract No. W-7405-eng-26

CHEMICAL TECHNOLOGY DIVISION

\section{SAFETY ANALYSIS REPORT FOR PACKAGING (SARP) \\ OF THE OAK RIDGE NATIONAL LABORATORY \\ TRU CALIFORNIUM SHIPPING CONTAINER}
W. D. Box
L. B. Shappert
R. D. Stagren
B. B. Klima*
M. C. Jurgensen
C. R. Hammond**
C. D. Watson

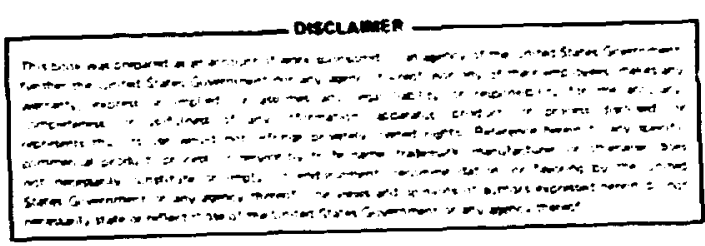

Date Published: January 1980

\footnotetext{
- Retired. Present address: Roane State Community College, Harrinan. Tennessee.

" UCC.ND Engincering.
}

OAK RIDGE NATIONAI. I.ABORATORY

Oak Ridge. Tennessec 378.30 operated by UNION CARBIDE CORPORATION

for the

DEPARTMENT OF ENERGYY 
Page'

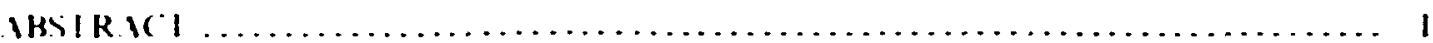

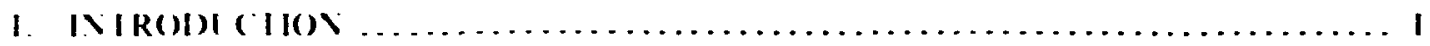

1.1 Deveripion of the Packape $\ldots \ldots \ldots \ldots \ldots \ldots \ldots \ldots \ldots \ldots \ldots \ldots \ldots \ldots \ldots \ldots \ldots \ldots \ldots$

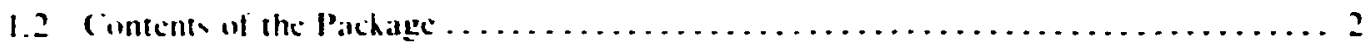

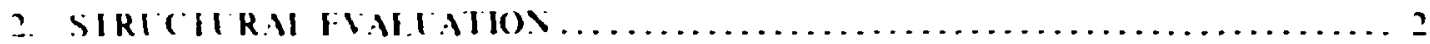

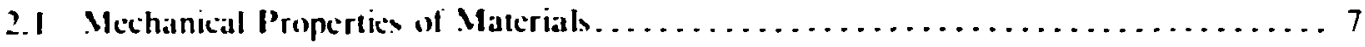

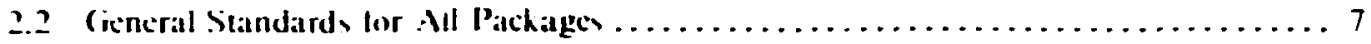

2.2 .1 Reactions betucen materials of constrtiction and package contents ..........

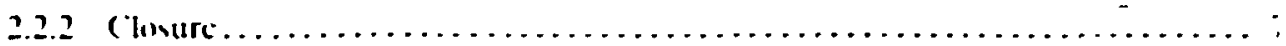

2.23 Cask-lifting derict $\ldots \ldots \ldots \ldots \ldots \ldots \ldots \ldots \ldots \ldots \ldots \ldots \ldots \ldots \ldots \ldots$

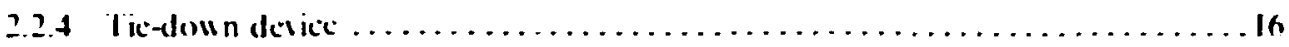

2.3 Standard, for Iype $\mathbf{H}$ and I arge (uantity Packaging $\ldots \ldots \ldots \ldots \ldots \ldots \ldots \ldots \ldots \ldots$

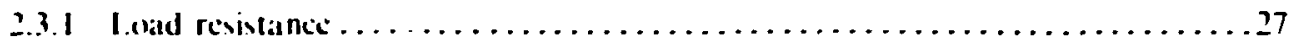

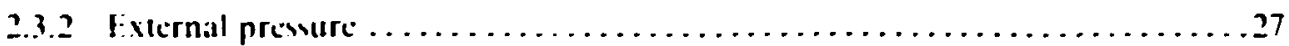

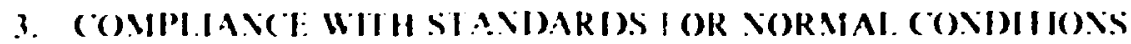

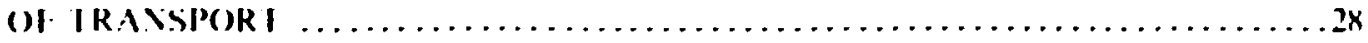

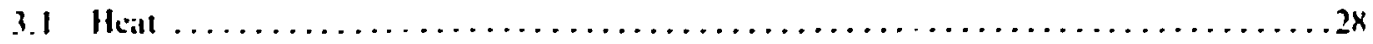

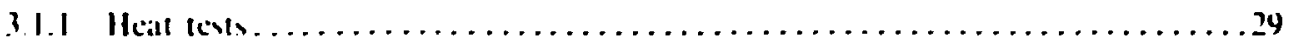

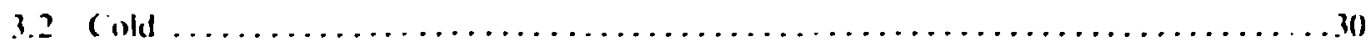

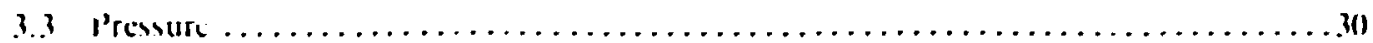

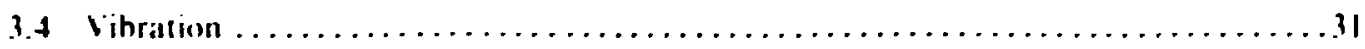

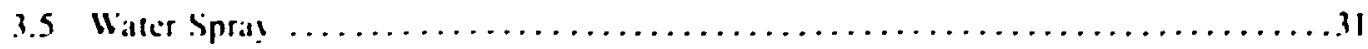

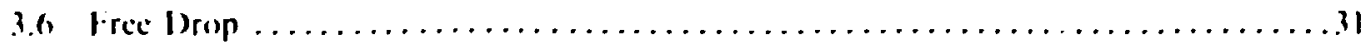

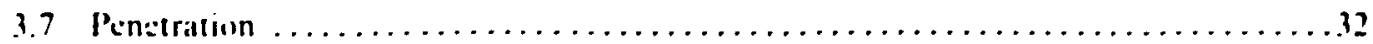

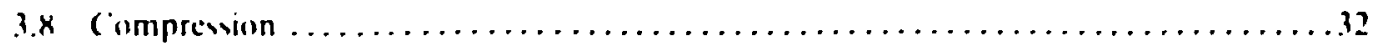

4. COMPI.IANC: WIII SIANDARISS FOR HYHOHHETICAI.

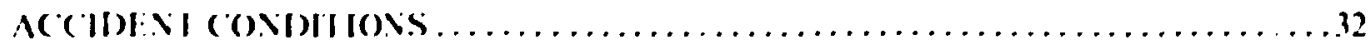

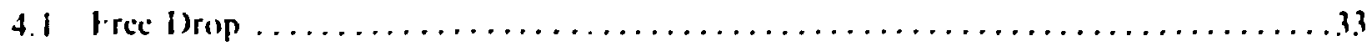

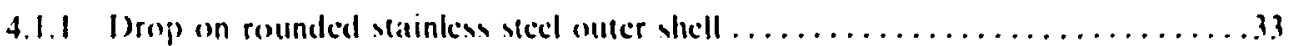

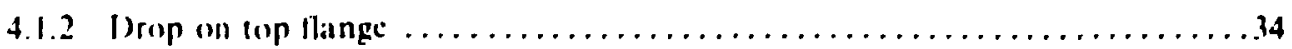

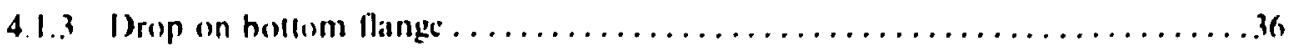

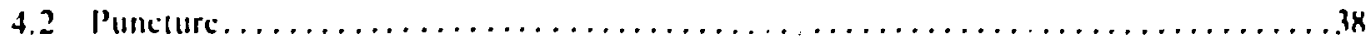

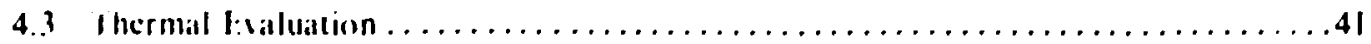

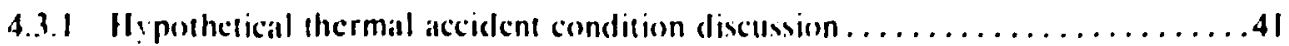

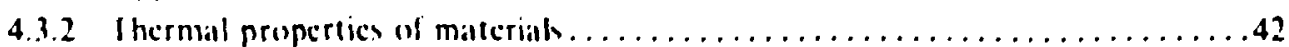

$4,3,3$ Ihermal accident analysis $\ldots \ldots \ldots \ldots \ldots \ldots \ldots \ldots \ldots \ldots \ldots \ldots \ldots \ldots \ldots \ldots$

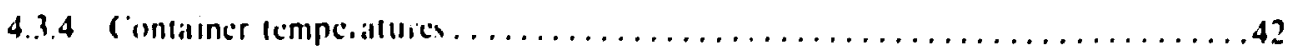




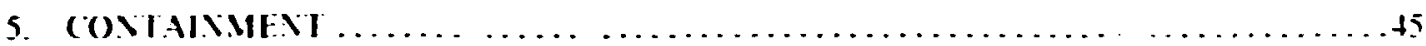

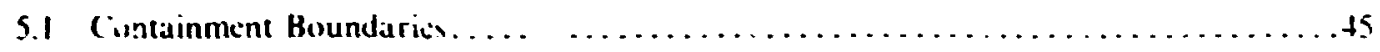

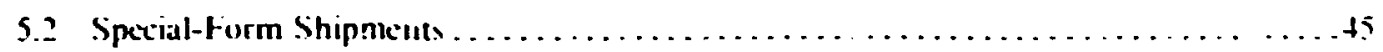

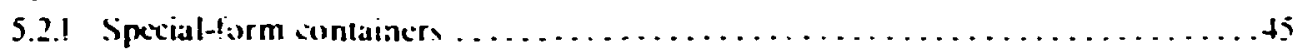

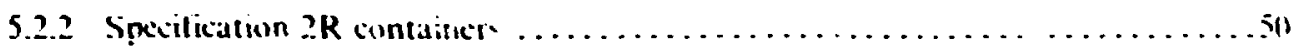

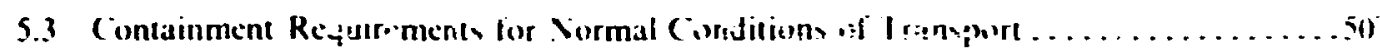

5.t Contdinment Kequirements !)ering the !lypotheticai Accideat . . . . . . . . . . . . 50)

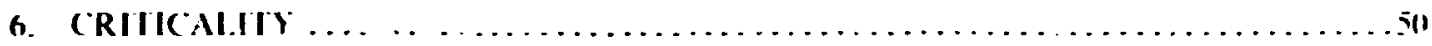

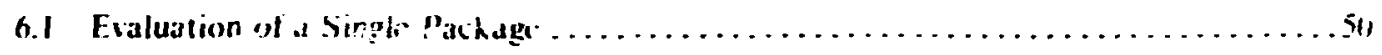

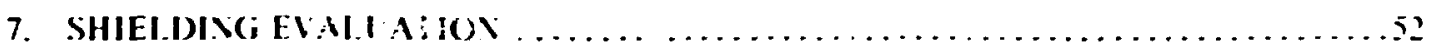

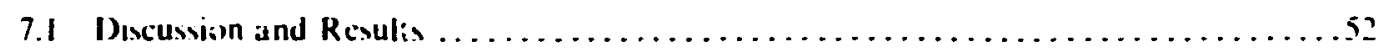

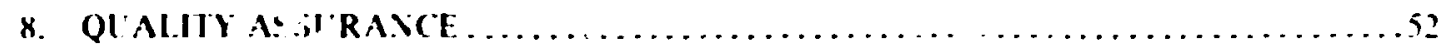

X.I Fabrication. Ia pection, at d Acceptance Tests . . . . . . . . . . . . . . . . . is

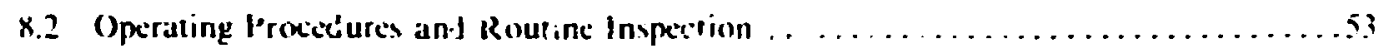

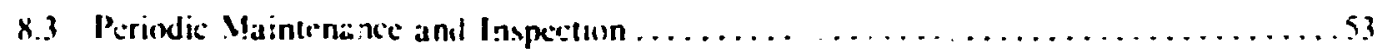

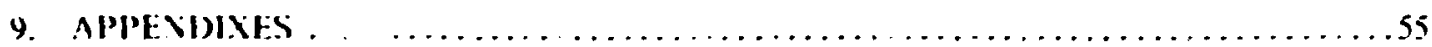

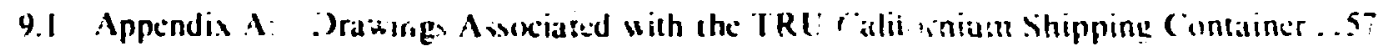

9.2 Appendix is: Appros a! Dostments. . . . . . . . . . . . . . . . . . . . 71

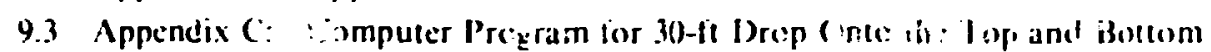

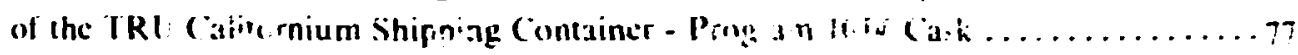

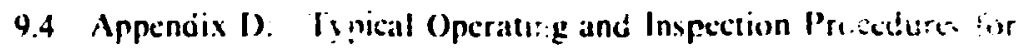

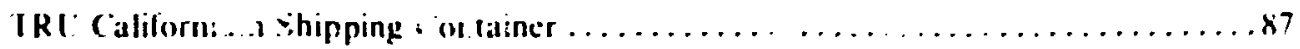

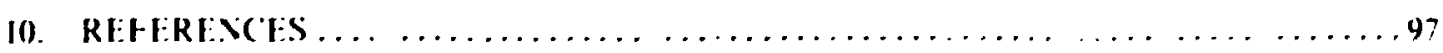




\title{
SIFET ANAIYSIS REPORT FOR PACKAGING (SARP) \\ OH IHF OAK RII)GE NATIONAL I.ABORATORY \\ IRI CAIIFORNIIM SHIPPING CONTAINER
}

\author{
W. D Box. L. B. Shappert. R. D. Seagren, B. B. Klima ** \\ M. C. Jurgensen. C. R. Hammond,** and C. D. Watson
}

\begin{abstract}
An analytical evaluation of the Oak Ridge National Laboratory TRU Californiun Shipping Container was made in order to demonstrate its compliance with the rigulations governing off-site shipment of packages that contain radioactive material. The evaluation encompassed five primary categories: structural integrity, thermal resistance. radiation shielding. nuclear criticality safety, and quality assurance. The results of this evaluation demonstrate that the container complies niti tiic applicable regulations.
\end{abstract}

\section{INTRODUCTION}

The OR.Y. TRU Californium Shipping Container was designed and fabricated at the Oak Ridge National laboratory. The design was analyzed' in 1971 and reevaluated in 1974 to demonstrate compliance with the regulations. The results of the analyses are presented in Sects. 2 through 8 of this report. The package "as inspected to ensure that it was in accordance with the drawings presented in Sect. 9.1.

The primary use of the container is 1 provide impact and thermal resistance, as well as shiclding. for its contents during both normal transport and hypothetical accident conditions. The package is shipped by truck only on its own specially designed trailer. It can be transported hy other modes if necessary. It complies with the Nuclear Regulatory Commission (NRC) regu,..tions contained in the Code of of Federal Regulations, Title 10, Part $71 ;^{2}$ DOE Manual Chapter 0529;' and all Immediate Action Directives (IAD) in effect as if this report date. The cask also compllies with U.S. Department of Transportation regulations published in the Code of Federal Regulations, Title 49, Part 173."

Calculations, enginecring logic, and all related documents that demonstrate compliance with specifications are presented in subsequent sections of this report. Copies of the approval documents are reproduced in Sect. 9.2.

One shipping container was fabricated and originally assigned ORNL No. 10-S-21-211. Later, the Department of Transportation assigned Special Permit No. 5740 to the container.

* Retircd. Present address: Roane State Community College, Harriman. Tennessee.

**U('i, ib) ing.necring. 


\subsection{Description of the Package}

T.te TRL Californium Shipping Container isee Fig. 1.1 and the enginecring drau ings in Sect 9.I) weigits $23.500 \mathrm{lb}$ and consists of two I 2-in.-thick. 66-in.-diam stainless steri hemispherical heads joined by a 6-in. cylindrical section. The cylindrical cavity is 3 in. in diameter by 6 in. long and is shielded by 30 in. of Blackburn limonitc concrete having a density of $\sim 175 \mathrm{lb} \mathrm{ft}^{\prime}$. Reinforcing steel ties the concrete to the outer shell and the central cylindrical cavity. The wall of the cavity is 1-in.-thick stainless steel. Lpper and lower ball valves located at the end of concrete-filled plugs define, isolate. and seal the cavity. The plugs, utilize $O$-ring seals, are bolted in place, and are protected with a gasketed cover nlate. Fusihle plugs. which will melt in the thermal aspect of the hypothetical accident. Will peutit steam from the concrete and gases from the cover plate to escape (see Fig. !.1). The typical hall valve. ball valve operator. and seal plug arrangement are shown in Fig. 1.2.

The top ball valve and plug may be replaced by other plugs. permitting multiple source shipments (see Fig. 1.3). Sources are contained in $2 R$ or special-form containcrs (see Sect. 5 ).

The TRU Califomium Shipping Container is shipped on its special trailer (sce Fig. 1.4). A l-in.-thick octagonal deck plate is welded to the trailer. Four chocks welded to this deck plate locate the container. The base of the container is attached to ine deck plate by eight 2-in.-diam bolts. Four of the eight lifting rijs are used as tie-down points and are attached the trailer by 7 8-in.-diam cables.

\subsection{Contents of the Packagc}

The cask is designed to transport isotopes of americium. curium. berkelium. californium. einsteinium. and fermium as a solid ieither metal. oxide. oxysulfate. or dry salt) that will be carried inside the cask in a $2 R$ or special-form capsule. The maximum yuantity of any or all radionuclides shipped will be $3 \mathrm{~g}$. which is defined as a large yuantity: The cask is designed for a maximum heat load of 5 watts $(17$ Btu hr). The quantiites shipped will be linvited b! external dose rates" and o: by internal heat loads.

\section{STRUCT!IRAI. EVAI.UATION}

The package complies with the structural requirements of the regulations (sec Sects. ? through 4). The calculations, test resu'ts. and engineering logic presented in the following sections demonstrate compliance with these performance criteria. The effects of both normal transport and specified accident conditions un the tructural integrity of the package are considered. 


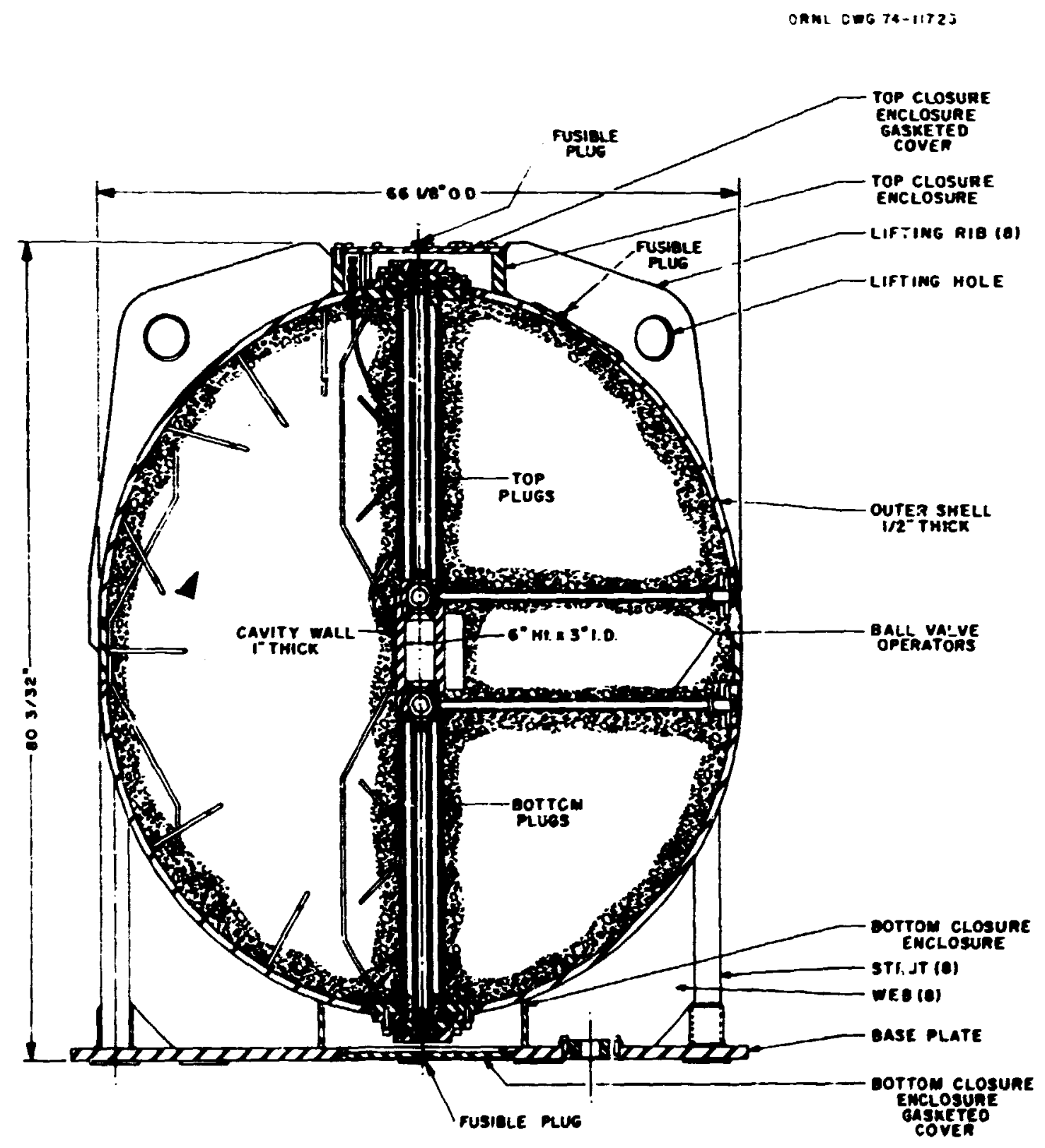

F1g. 1.1. TRU Californium Shipping Container. 


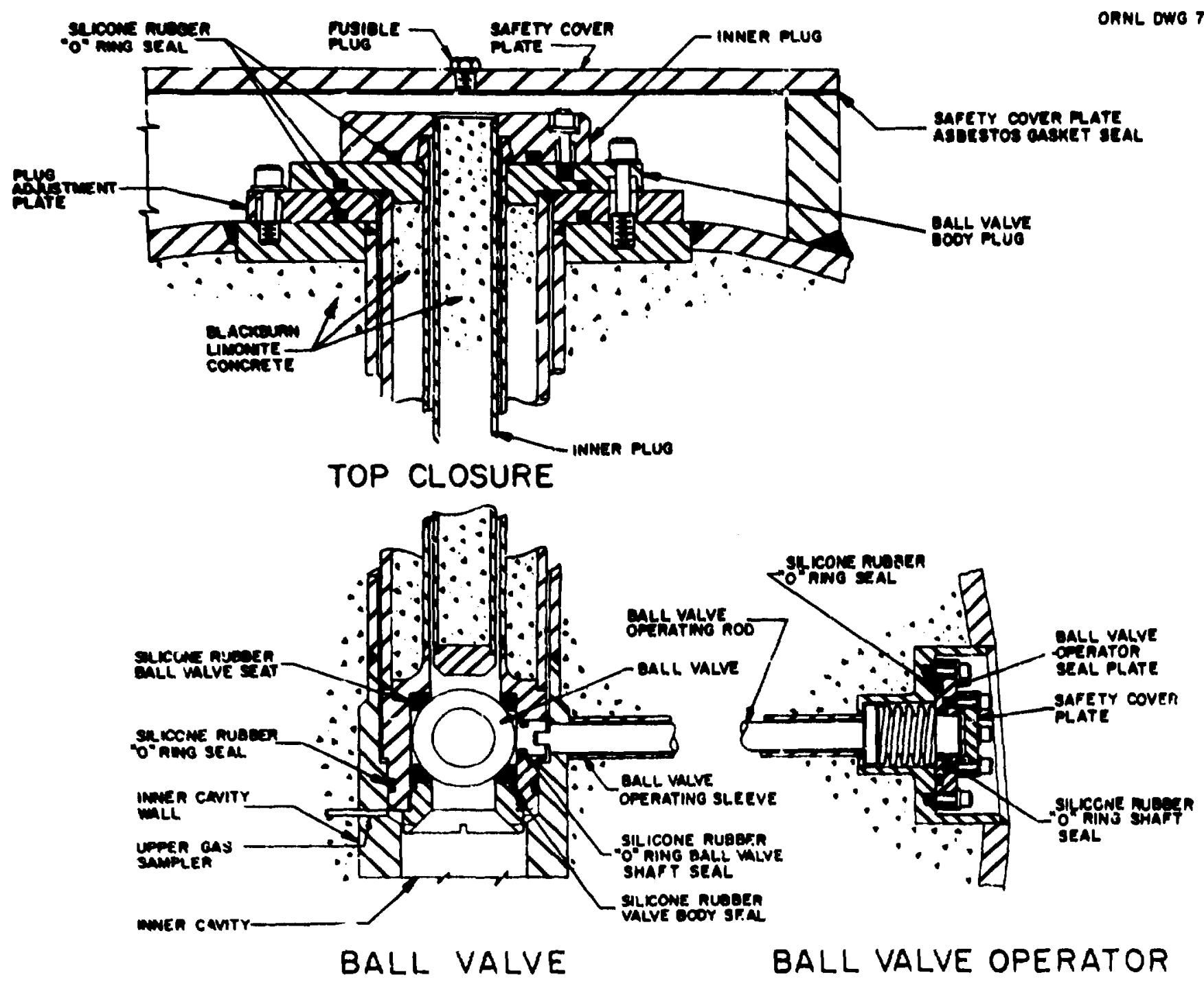

Fig. 1.2. Ball-valve upper closure for loading single-specimen shipment, showing plug and seal arrangement. 
ORML OWG 7i-85TCR3

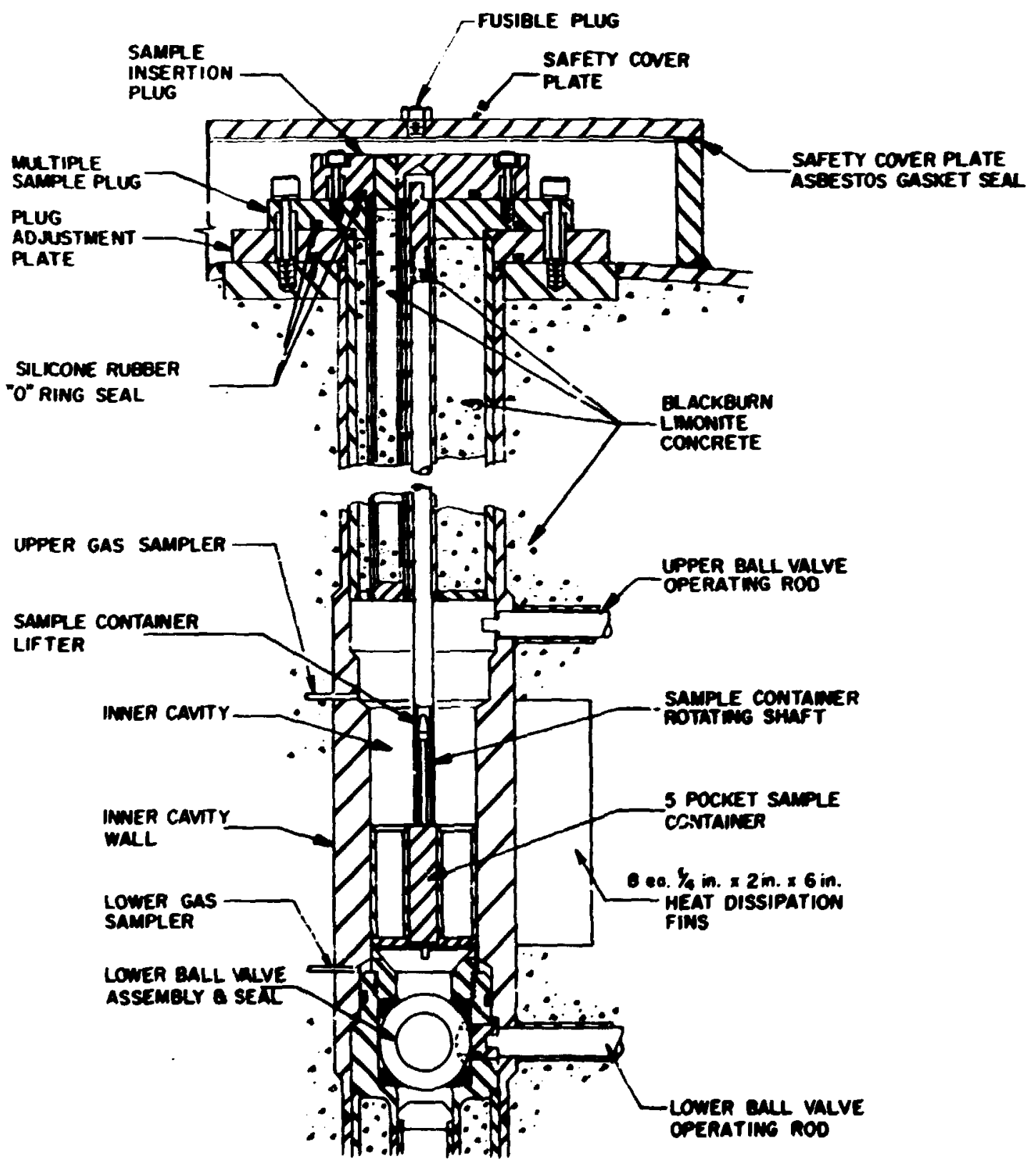

$\vec{F}$ ig. 1.3. Plug and sample container to permit multiple-specinen shipment (maximum, five specimens), showing plug and seal arrangement . 
$\bar{x}$
8
8
$\vdots$
0
0
0
0
$\frac{1}{2}$
0

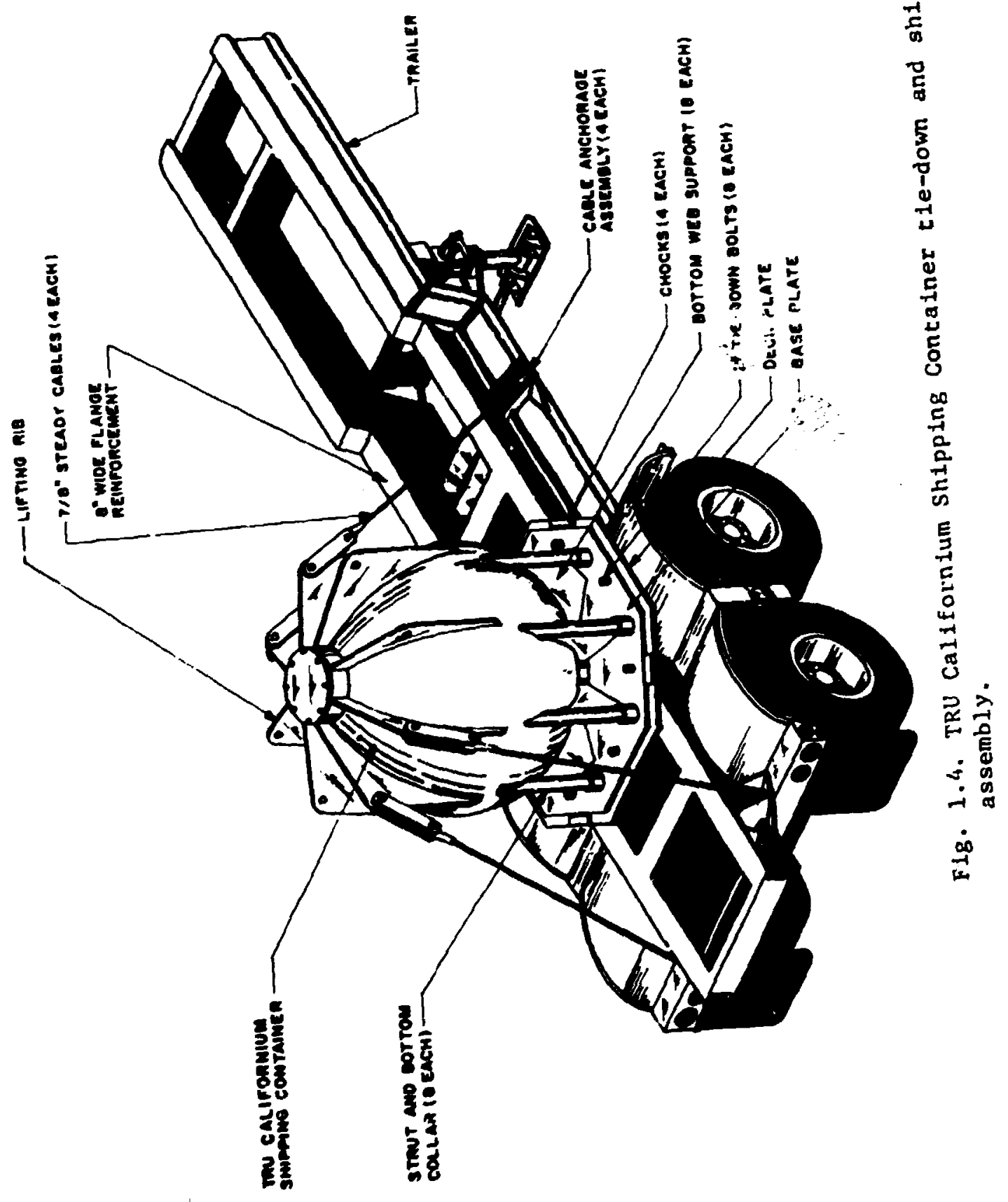




\section{I Mechanical Properties of Materiais}

The mechanical properties of $304 \mathrm{~L}$ stainless steel and limonite concrete are summarized in Table 2.1.

\subsection{General Standards for All Packages}

The general standards for all packages include an evaluation of the following: (I) the chemical and galsanic reactions between the materials of construction and the intended package contents: (2) the method used for closure: (3) the cask-lifting devices, (4) the lid-lifting devices; and $(5)$ the and tie-down devices used in securing the package to the trailer.

\section{2 .1 Reactions heru cen muterials of construction and package centents}

The container is constructed. as shown in the as-built drawing (see Fig. 1.1 and Sect. 9.1). of type 3041. staitriess stecl and limonite conerete. No evidence of any significant chemical. galtanic. or other reaction between these materials has been noi:cl: addicionally, past experience has not revealed any indication of reactions between these materials of construction and the intended package contents. Esen if the enntents vere shipped in the chloride or oxysulfate form. they uould be welded into a primary container capable of withstanding the action of these salts and thus would present no reaction problem to the cask materials.

\section{2 .2 c losure}

The cask is equipped with a positive closure consisting of two cover plates. one on the top and one on the boltom. held in place with twelve 12 -in.-diam bolts. The holts on the top plate are seal wired in place 10 indicate tampering with or opening of the cask: the bottom plate is ine ccessible in transit.

\subsubsection{Cask-liffing device}

The regulations require that if there is a system of tie-down devices which is a structural part of the package. this system must be capable of withstanding a static force applied to the center of gravity of the agckage with (1) a vertical component of two times the weighe (2W) of the package and its contents. (2) a horizontal component along the direction of travel of ter times the weight (JOW) of the package and its contents. and (3) a horizontal component in : $^{t}$. transverse direction of five times the weight (5W) of the package and its contents. This applied load shall not generate stresses in any material of the package in excess of the yield strength of that material. In addition. any tie-down device that is a structural part of the package must be designed so that failure of the device under exce sive load will not impair the ability of the package to meet other requirements of the regulations. 
Table 2.1. Mechanical properties of 304L stainless steel and limonite concrete

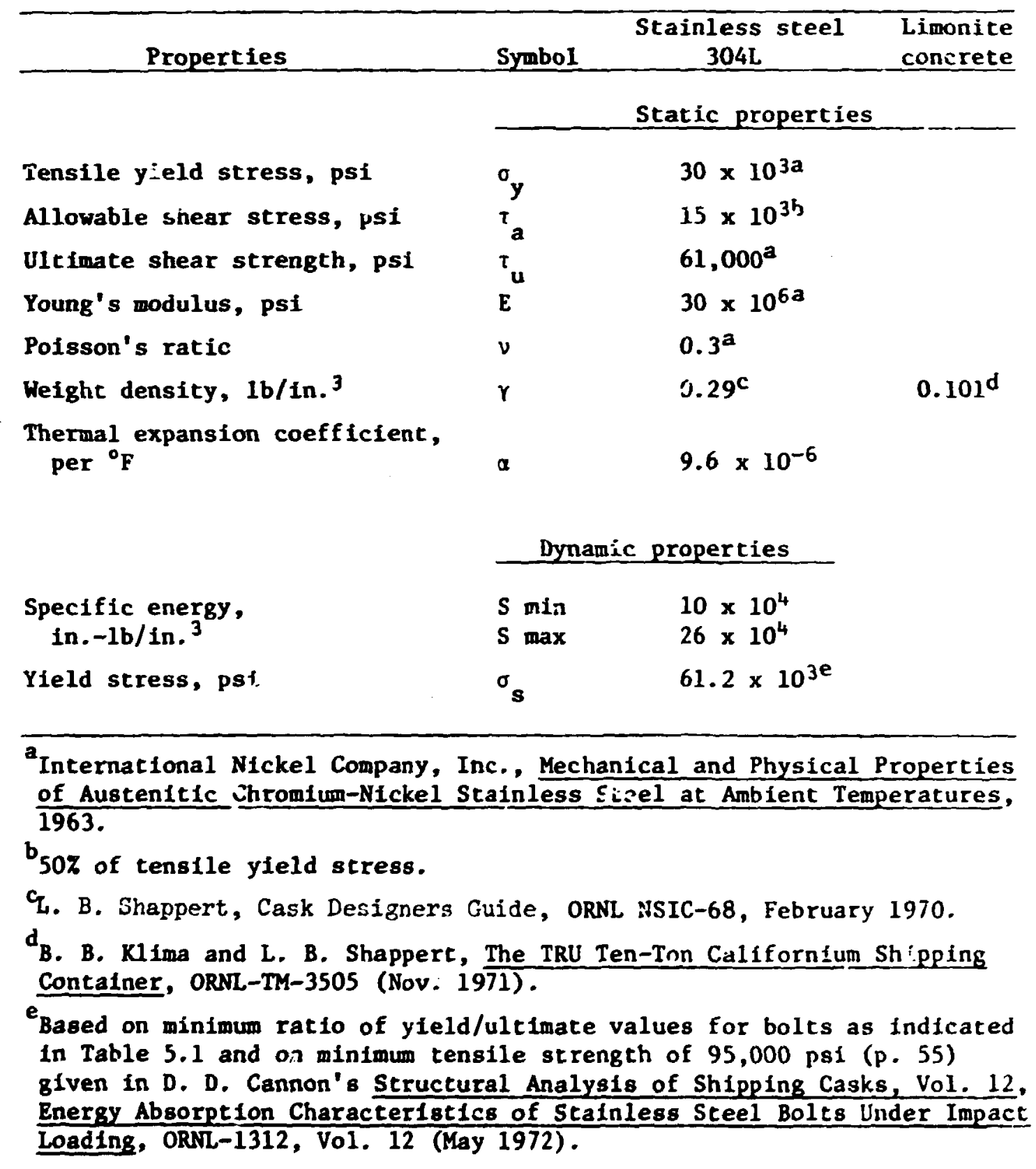




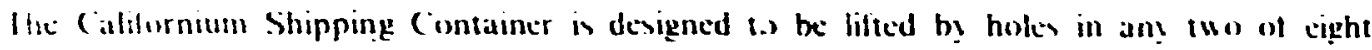
litung sib that ate smmetricalls spaced around the cask. Both the ribs and the cask bods are

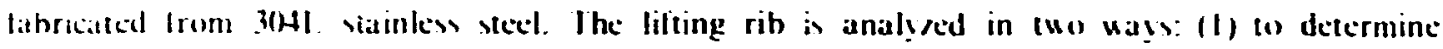
whether the streses around the liting hole are belou the tensile yield stres lor the shear gield stems of $3(141$, itinks stecl). and 12) to determine the adeyuacy of the weld betucen the rib and ask boul!

Siress around the lifting hole. Typically. the cask is lifted by two of the lifting ribs. Howeter. it is leasible to litt the cask using one of the lifting ribs: thus it will be determined whether stresses above gield are produced for one rib supporting three limes the cask weigh:. The rib is shoun in Fig. 2.1. The rib at the lifting hole is assumed to be a curved beam with fixed ends spanning the diameter of the hole. Stresses in the curved beam can be found by calculating the stresses in a straight beam with identical fixity and loads and adjusting the stresses to account for the hyperbolic distrihution of strain across a curved beam.

The maximum moment in the beam occurs when the load is centrally located. The load is assumed to act on a single line across the minimum thickness of the rib. The maximum Inoment produced by the load $3 \underline{W}$ (three times the weight of the cask) is

$$
V=\frac{3 W \mathrm{WL}}{8}=\frac{3 \mathrm{~W}(4 \mathrm{in.})}{8}=1.5 \mathrm{~W} \text { in. } \cdot \mathrm{Ib} \text {. }
$$

according to example Id from Table 3 in Roark and Young.

The maximum stress in the straight beam is $\sigma_{\max }=\mathrm{Mc} /$. The cross section of the beam under consideration is shown in Fig. 2.2 .

For convenience, the cross sectisn is represented by a rectangle with equal area.

The depth of the rectangle, $d$, is expressed as

$$
d=3 \quad 2\left|1 / 2(.25)^{2}\right|=2.9375 \mathrm{in} .
$$

The moment of inertia. I, of this representative cross section is

$$
\begin{aligned}
I & =\text { bd } 3 / 12 \\
& =1 / 12(1)(29375)^{3}=2.11 \mathrm{in}^{4} .
\end{aligned}
$$

Maximum stress on the corvex side of the straight beam is expressed by

$$
0=\frac{1.5 W(2.93375 / 2)}{2.11}=1.04 W
$$

and on the concave side the minimum stress is

$$
\sigma=1.04 \underline{\mathbf{w}} \text {. }
$$

Stress amplification factors arc taken from Example 1. Table 16 in Roark and Young." By definition, 


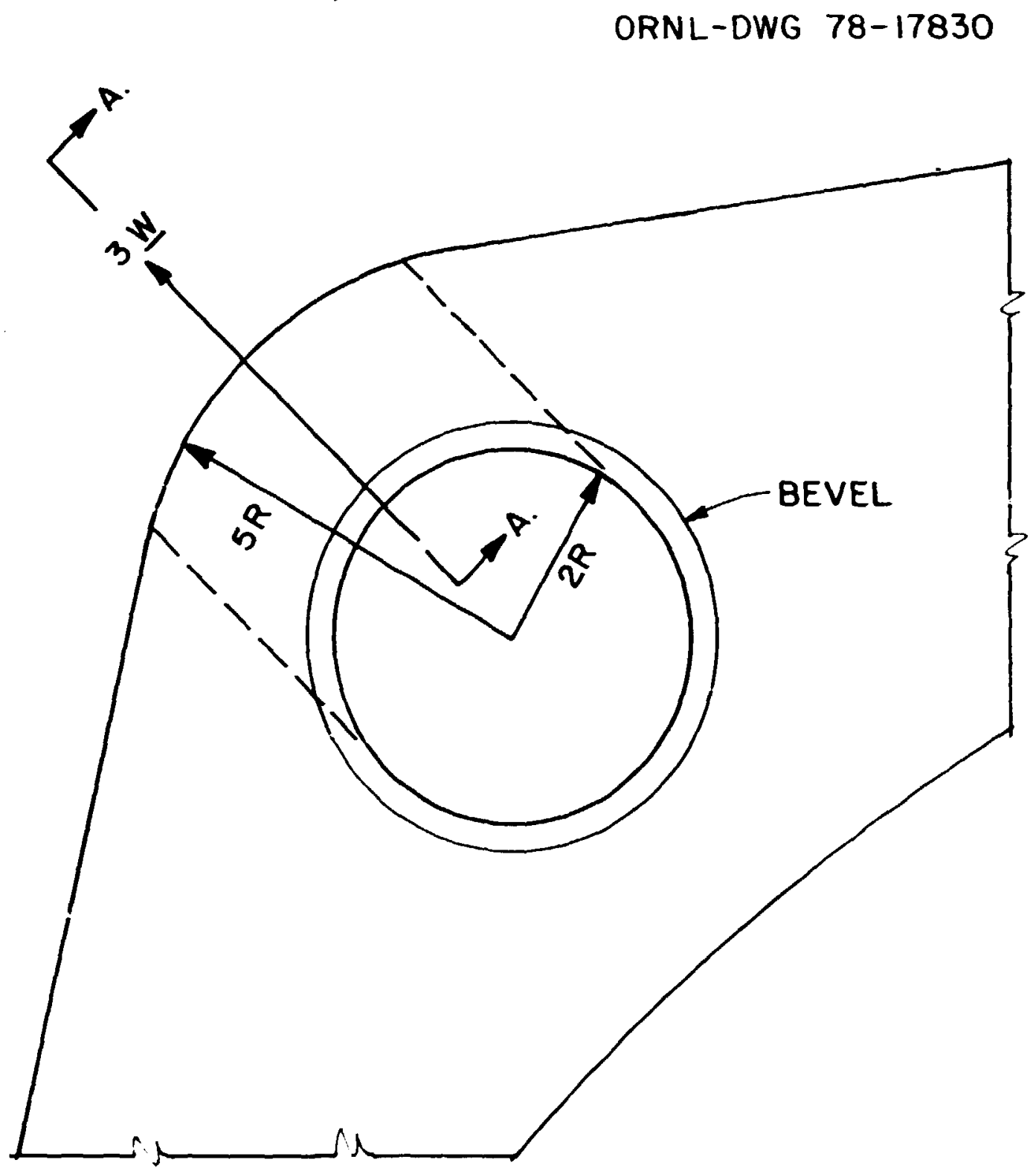

Pig. 2.1. Lifting lug eye. 


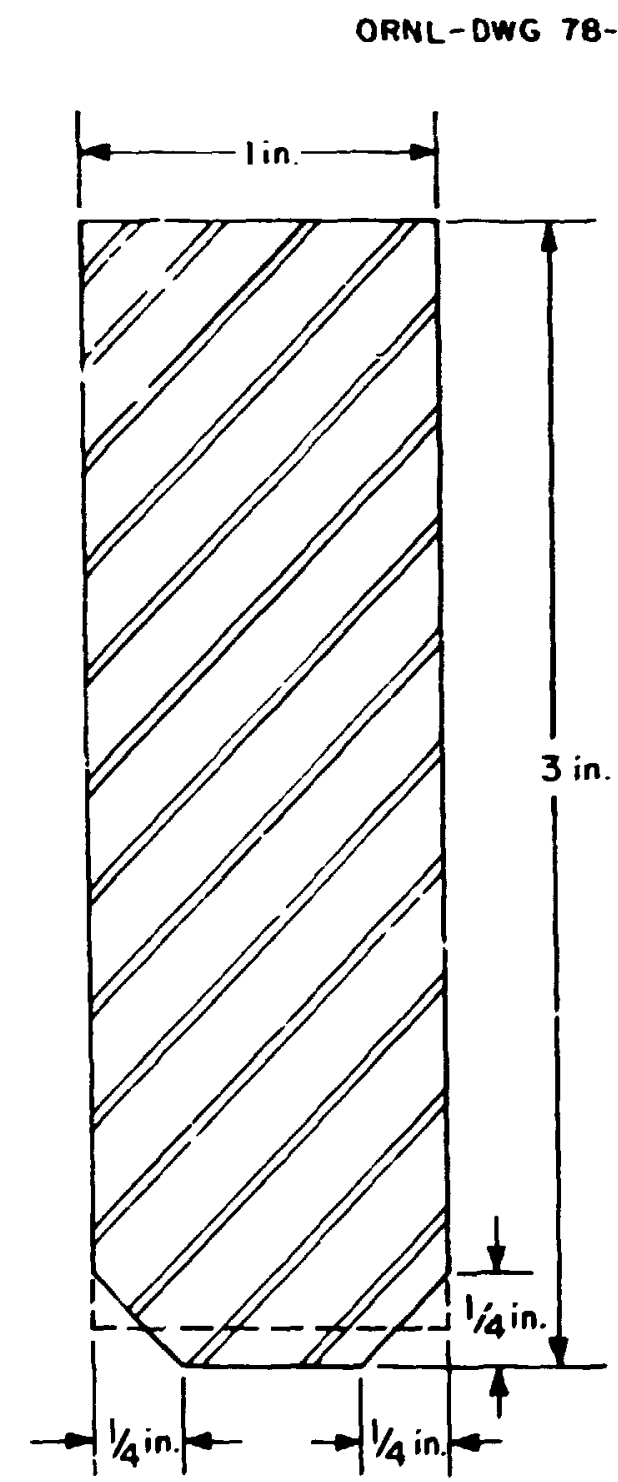

F1g. 2.2. Lifting lug cross section A.-A. of hole. 


$$
\begin{aligned}
& \sigma_{:}=k_{0} \sigma . \\
& \sigma_{0}=k_{0} \sigma .
\end{aligned}
$$

where
$0_{t}=$ actual stress on extreme fiber (concave side).
$0_{0}=$ actual stress on extreme fiber (convex side).
- = ficticious stress on comparable fiber of straight beam:

also.

$$
\begin{aligned}
& k_{i}=\frac{1}{3 h / c} \frac{1-h / c}{R / c-1} . \\
& k_{0}=\frac{1}{3 h / c} \frac{1+h / c}{R / c+i},
\end{aligned}
$$

where

$$
h / c=R / c-\frac{2}{\ln \left(\frac{R / c+1}{R / c-1}\right)} .
$$

We have

$$
\begin{aligned}
& R / c=\frac{2.0625+\frac{2.9375}{2}}{2.9375 / 2}=2.40, \\
& h / c=(2.40)-\frac{2}{\ln \left(\frac{240+1}{2.40-1}\right)}=0.15, \\
& k_{i}=\frac{1}{3(0.15)} \frac{1 \cdot 0.15}{2.40-1}=1.39, \\
& k_{0}=1 / 3(0.15) \frac{1+0.15}{2.40+1}=0.77 .
\end{aligned}
$$


Strewe, at the extreme fibers of the cuned beam are

$$
\sigma_{1} \cdot k_{i} \pi
$$

where

$$
\begin{aligned}
& n_{:}=\left(.39+1.04 \underline{w_{1}}=1.39-(.04 \times(23.500)=-34.000 \text { psi. }\right. \\
& \sigma_{n}=0.77(1.04 \underline{\underline{w}})=0.77(1.04 \times(23.500)=18.800 \text { psi. }
\end{aligned}
$$

The maximum shear in a curved bearr. is a function of the cross-sectional geometry and the initial curvature. Equation (5.13) from Oden' was used to determine shear stıess in the lug eye. The equation was programmed for a Hewlet-Packard 97 calculator, and the shear stress uas calculated at barious points across the cross section. The location of the maximum shear stres; was found to within \pm 0.025 in. At that point, the shear stress had the value

$$
r=0.57 \mathrm{~V}
$$

where

$$
v=3 \underline{\underline{W}} 2 .
$$

Substituting. we has:

$$
T_{i \ldots 0}=0.57 \frac{3 \mathrm{~W}}{2}=0.57(3 ; 2)(23.500)=20.100 \mathrm{psi}
$$

The results of this analysis indicate that if one lifting lug is used to support three times the weight of the the cask, localized yielding occurs. This loading case is a severe one for the lug since the load passes through the area of the web with least width. If the cask is lifted with two or more lugs with a standard sling or a sling with spreader bar (which is the normal method of lifting the cask), the stresses in each lug will be reduced to less than half of the stresses calculated for lifring by one lug. Yielding will not occur if two or more lugs are used to lift three times the weight of the cask.

Analysis of the weld herween the lifting lug and cask. Stresses in the weld betwcen the lifting lug and the outside shell of the cask are checked for the hypothetical case of lifting three tirses the weight of the cask with one lug. For convenience the weld is projected onto the chord of the cask as shown in Fig. 2.3. The coordinates of the end prints of the chord and of the center of the lifting eye relative to the coordinate system shown are given on the figure.

Depending on the orientation of the lifting force, 3W. differing amounts of shear and normal force in the weld are produced. Assuming that the force is parallel to the chord shown 
14

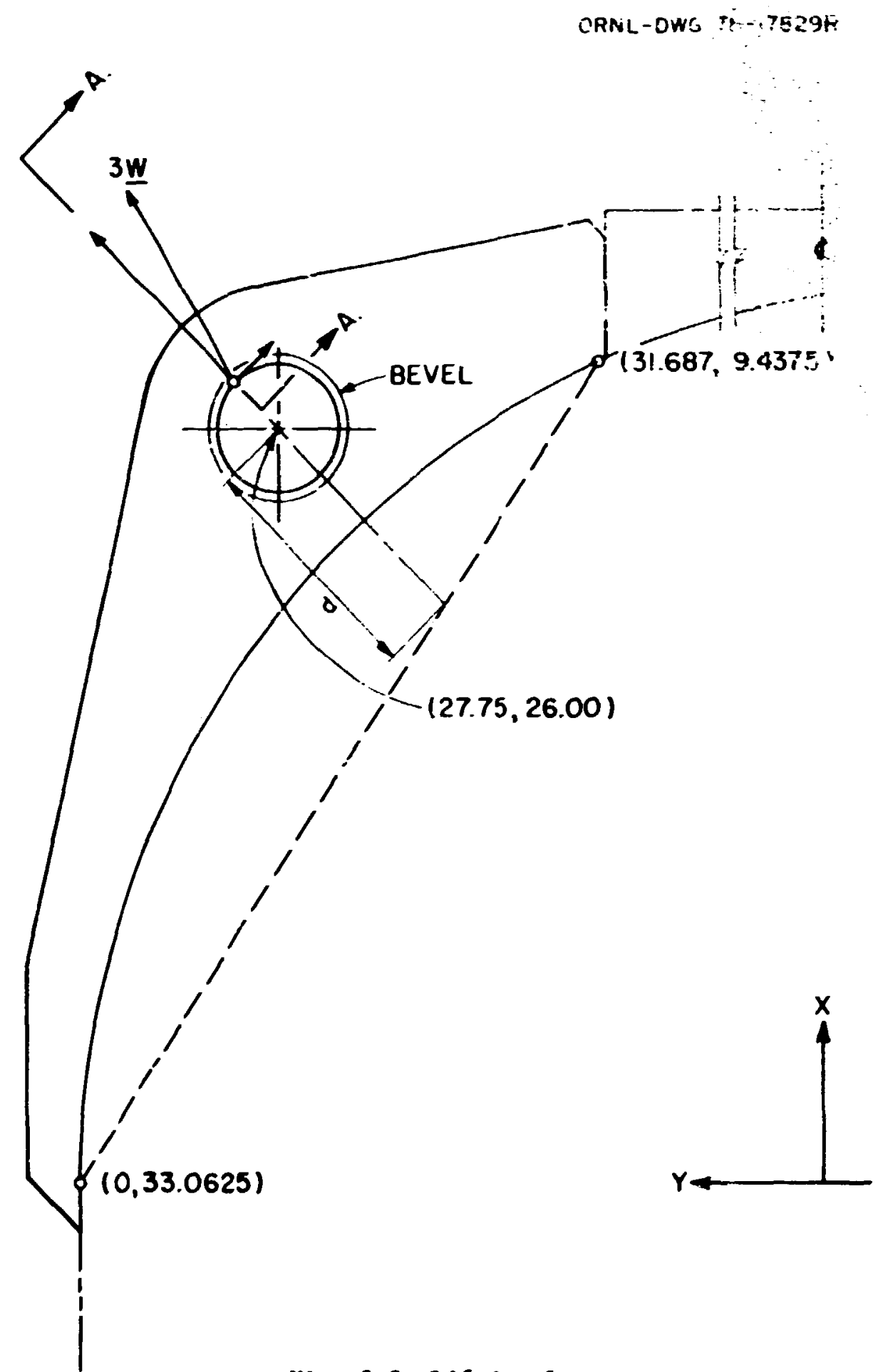

H18. 2.3. Lifting lug. 
in Fix. 2.3. mostly shear is produced. If the shear is assumed to be uniformly distributed over the projected area. the shear at any point is

$$
\begin{aligned}
& i=\frac{3 i \dot{u}}{A}=\frac{3(23.500) l b}{2\left(3 ; x !\left(\cos 45^{\circ},[31.687-0)^{2}+(9.4375-33.0625)^{2}\right]^{\frac{1}{2}}\right.} . \\
& =3360 \mathrm{psi} \text {. }
\end{aligned}
$$

where the nominal size of the fillet weld on each side of the lug is 38 in.. and the throas of the weld lies on a plane irclined $45^{\circ}$ to the lug. $f$ moment is also produced wit: the magnitude of $3 \underline{W}$ tinies the distance (d) to the chord from essentially the center of the lif:ing hole.

Assuming that the weld acts as the fixed end of a cantiliver beam. the gtresses in th: extreme tibers are

$$
\begin{aligned}
B & = \pm \frac{M_{i}}{l}=\frac{3 W(10.92}{3(1 / 12)(3 / 8) \cos 45^{\circ} \mid(31.687 / 2}, \frac{2}{2+(9.4375-33.0625)^{2} \mid} . \\
& = \pm 0.24 \mathrm{~W}= \pm 0.24(23,500)= \pm 5640 \mathrm{Fsi} .
\end{aligned}
$$

where

$$
\mathbf{d}=10.92
$$

If the load is oriented normal to the chord, shear is not produced directly, but a mornent is still produced aboul the cen'roid of the weld area projected onto the chord. The moment arm is the distance from the midpoint of the chord to the line of action of the force. This distance is

$$
\begin{aligned}
M= & \left|(27.75-0)^{2}+(26.00-33.0625)^{2}-(10.92)^{2}\right|^{1 / 2} \\
& \quad 1 / 2 \sqrt{(31.687-0)^{2}+(0.4375-33.0625)^{2}} \\
= & 6.71 \mathrm{in} .
\end{aligned}
$$

Stress in the extreme fiber, with the cantilever beam analogy, now is

$$
\sigma=\frac{3 W}{A}+\frac{3 W 6.71)}{I}
$$


or. in particuiar

$$
\begin{aligned}
& c=\frac{3 W}{338)\left(\cos 45^{\circ}+\left[(31.687-0)^{2}+(9.4375-33.0625)^{2}\right)^{1 / 2}\right.} \\
& +\frac{3 W(6.71 \text { in. }) 12}{31(12)(38) \cos 45^{2}} \frac{\left.2(31.687-0)^{2}+(9.4375-33.9625)^{2}\right)}{.} \\
& =0.289 W=0.289(-3.500)=6790 \mathrm{psi} .
\end{aligned}
$$

To coter cases between the two extremes. the absolute values of the stresses are sumned. The maximum shear stress in the weld is

$$
\begin{aligned}
\tau_{\max } & =\left[\left(\frac{6790+5640}{2}\right)^{2}+(3360)^{2}\right]^{1 / 2} \\
& =7070 \text { psi. }
\end{aligned}
$$

Since this is weil beluw the allowable shear stress of 14,000 psi, the weld is clearly adequate to support 3 times the weight of the cask.

\subsubsection{Tie-donn device}

The primary tie-down for the ten-ton TRU s.upping cask is a set of eight bolts evenly spaced on a 56-in.-diam circle. The bolts pass through the octahedral base plate of the cask and are threaded into a plate fastened to the bed of a trailer. Cables also connect the iifting flanges near the top of the cask 1 the trailer and serve to steady the cask while in transit.

The tie-down devices are required to be capable of withstanding a static for'e applitd to the center of graviiy of the package with (1) a vertical component of two times the weight of the package plus its contents, (2) a horizontal component along the direction of travel of ten times the weight of the package plus its cortents, and (3) a horizontal component in the transverse direction of five times the weight of the package and its contents. The applied load is not allowed to generate stresses in any material of the package in excess of the yield strerigth of that material. Also, any tie-down device that is a structural part of the package must be designed so that failure of the device will not inipair the ability of the package to meet other requirements of the regulation.

Anolysis. The properties of the materials are listed in Table 2.I. 
Xo credit is given to the tie-down cabies to resist the hypothetical set of forces. Figure 2.4 shows the forces that will be considered in an analysis of the bolts. The vertical (2W) force produces no moment in the bolt pattern. and it will be considered separately from the two horizontal forces. hut the effects of all the iorces will be combined bter. The horizuntal forces can be summed vectorally to p:oduce a single resultant horizontai force. P. We have

$$
\begin{aligned}
P & \left.=\left(F_{x}^{2}+F_{y}^{2}\right)^{! ! 2}=(10 W)^{2}+(5 W)^{2}\right]^{1 / 2} . \\
& =11.2 W .
\end{aligned}
$$

The center of mass of the cask is $\sim 42$ in. (d) above the bottom oi the base plate, and so the horizontal resultant produces a moment. $M$. about the base of ihe cask with

$$
\begin{aligned}
M & =d P . \\
& =(42 \text { in. })(11.2 W)=470 \mathrm{~W} .
\end{aligned}
$$

The bolts are assurned to be just snug and with no tensile preload. The moment of the horizontal forces is resisted by the eight. 2-in. bolts in tension and by some part of the contact area of the base plate. The contact area is composed of eight circuclar pads, each $S$ in. in dian.etei and spaced at the points of the octahedron on a 63-1. 8-in.-diam circle.

Figure 2.5 shows the cross section of the base of the cask. It is assumed that the distribution of internal forces in the bolts and base plate generated by the applied moment is identical to that at a beam cross section. It follows that vertical strain at the base plate is a linear function of the distance from the neutral axis acros: the cross section. Figure $\mathbf{2 . 5}$ also shnus the variation of tensile load in the bolts and the change in compressive stress in the base plate.

For the case of no applied vertical load, the vertical internal forres in the bolts must be in equilibrium with the resultant force of the stresses in the plate. The location of the neutral axis can be determined from an expression of this equilibrium. To ease computations, the circular contact pads on the bottom of the base plate are conceptually replaced by square pads of equal area. Preliminary iterative calculations using data from Table 2.2, progressively increasing the number of pads in contact per trial over the total area of the pads, indicated that two pads wnuld be in contact, and one more would be partially in contact. The first two bolts are in the compressive strain area and so are not effectsve. The final quotation for the location of the neutral axis is

$$
A_{b} \sum_{i=1}^{B}\left(b_{i} \quad a\right)=A_{p} \sum_{i=1}^{2} a_{2}\left(\frac{1}{1}\right)+\left(\frac{A_{p}}{2}\right)^{1 / 2}\left[a\left(15.49 \cdots\left(\frac{A_{p}}{2}\right)^{1 / 2}\right)\right]^{2} .
$$


OANL DNG 71 - IOB39R2
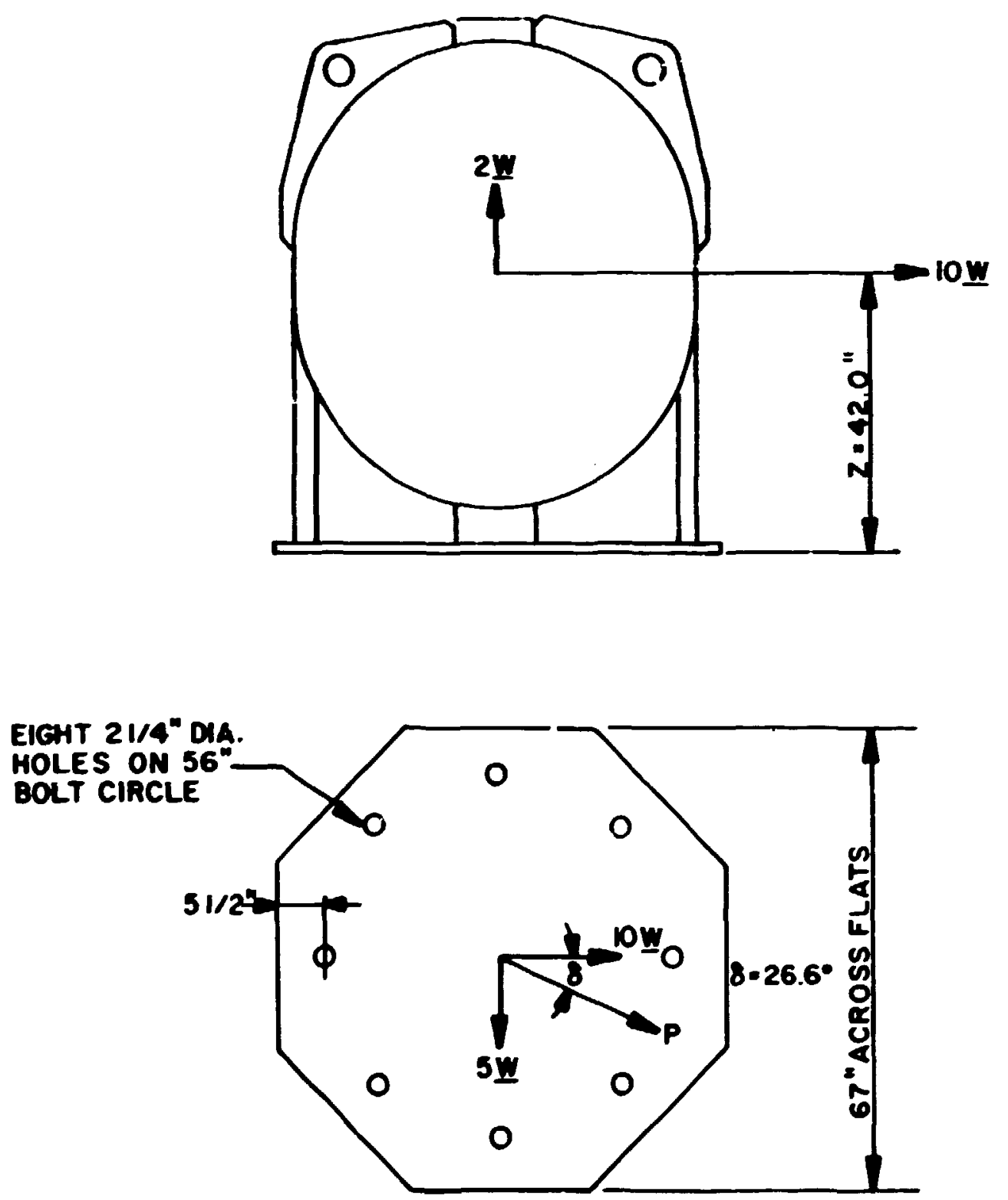

P18. 2.4. Analysis of the forces Imposed on the tie-down bolts. 


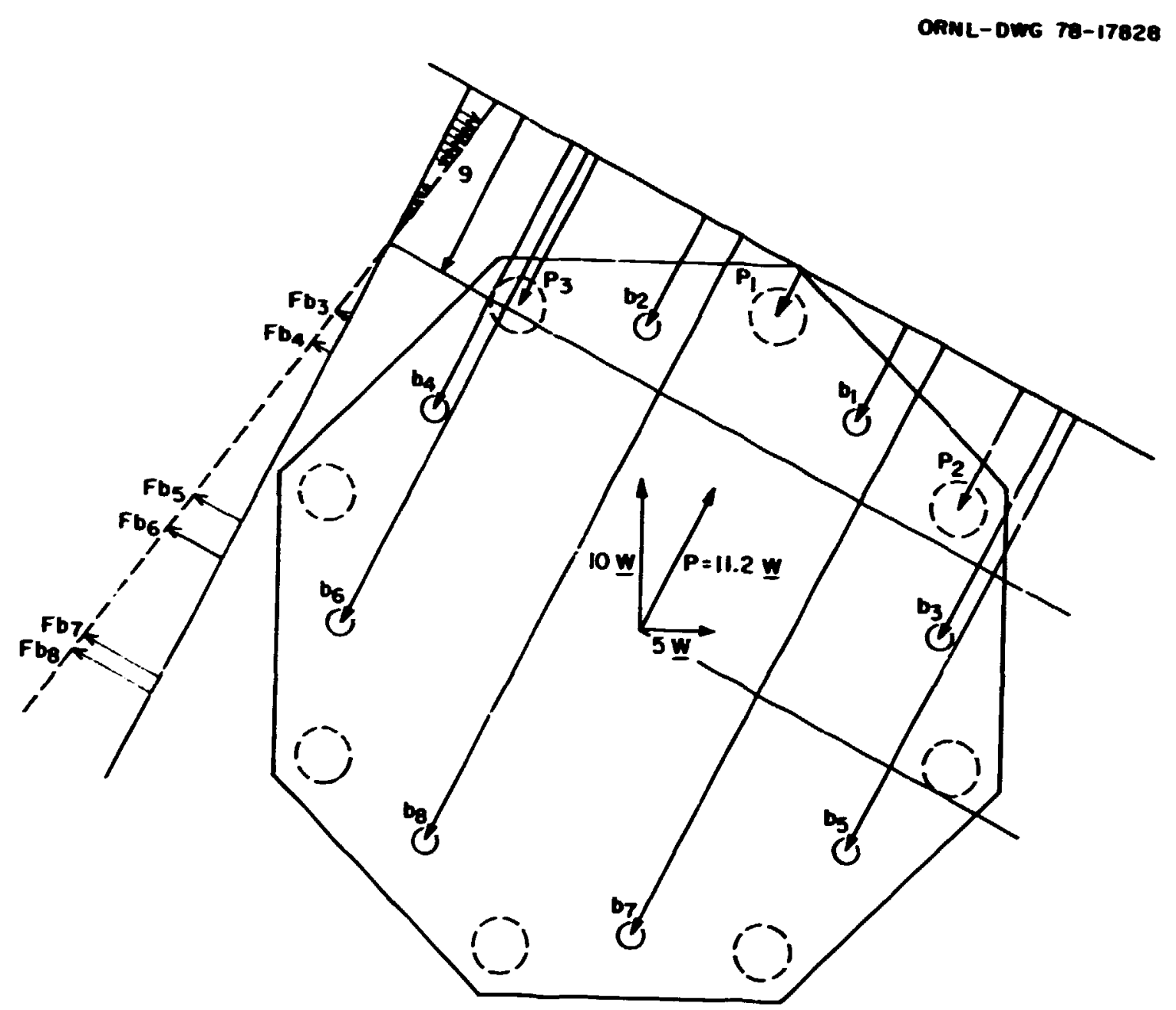

Pig. 2.5. Cark tle-down syetem. 
Table 2.2. Distances of the boits and three pads from the extreme part of the base measured parallel to the resultant force

$$
\begin{gathered}
b_{1}=36.17-28.00 \cos \left(45^{\circ}-26.57^{\circ}\right)=9.61 \text { in } . \\
b_{2}=36.17-28.00 \cos \left(0^{\circ}+26.57^{\circ}\right)=11.12 \\
b_{3}=36.17-28.00 \cos \left(90^{\circ}-26.57^{\circ}\right)=23.65 \\
b_{4}=36.17-28.00 \cos \left(45^{\circ}+26.57^{\circ}\right)=27.31 \\
b_{5}=36.17-28.00 \cos \left(135^{\circ}-25.57^{\circ}\right)=45.02 \\
b_{6}=36.17-28.00 \cos \left(90^{\circ}+26.57^{\circ}\right)=48.69 \\
b_{7}=36.17-28.00 \cos \left(180^{\circ}-26.57^{\circ}\right)=61.21 \\
b_{8}=36.17-28.00 \cos \left(135^{\circ}+26.57^{\circ}\right)=62.73 \\
P_{1}=36.17-31.56 \cos \left(26.57^{\circ}-22.5^{\circ}\right)=4.69 \pm 2.50 \\
P_{2}=36.17-31.56 \cos \left(67.5^{\circ}-26.57^{\circ}\right)=12.33 \pm 2.50 \\
P_{3}=36.17-31.56 \cos \left(26.57^{\circ}+22.5^{\circ}\right)=15.49 \pm 2.50 \\
P_{4}=36.17-31.56 \cos \left(112.50^{\circ}-26.57^{\circ}\right)=33.93 \pm 2.50
\end{gathered}
$$


where
$A_{b}=$ the bolt area $\left(2.30\right.$ in. $\left.^{2}\right)$,

$a=$ the distance from the extreme point of the octagonal base to the neutral axis.

$b_{i}=$ the distance of the $i^{\text {th }}$ bolt from the extreme point,

p. = the distance of the $i^{\text {th }}$ pad from the extreme point, and

$A_{p}-$ the area of each pad. $\left(A_{,}=19.63\right.$ in. $\left.^{2}\right)$.

From this. we get a $=\mathbf{1 7 . 2 4} \mathrm{in}$. From the analogy with a beam, and using data from Table 2 , the moment of inertia about the neutrai axis of the effective cross section can be calculated.

The moment of inertia, assuming uniform stress across each bolt, is

$$
\begin{aligned}
I= & \sum_{i=3}^{\infty} A_{b}\left(b_{i}-a\right)^{2}+2\left[\frac{\pi}{4}(2.5)^{4}\right]+\sum_{i=1}^{2} A_{p}\left(a-p_{i}\right)^{2} \\
& +\frac{(2.5)^{4}}{4}\left[\alpha \cdot \sin \alpha \cos \alpha+2 \sin ^{3} \alpha \cos \alpha-\frac{16 \sin ^{6} \alpha}{9(a-\sin \alpha \cos \alpha)}\right] . \\
= & i 7.200 \text { in. }^{4} .
\end{aligned}
$$

where

$$
\begin{aligned}
& a=\pi .2-\arcsin [(15.49-a) 2.5] \\
& a=17.24 \mathrm{in} .
\end{aligned}
$$

The vertical stress in the extreme bolt due to bending is

$$
\begin{aligned}
\mathfrak{o}_{\mathrm{y}} & =\frac{M c}{l}=\frac{M}{l}\left(\mathrm{~b}_{\mathrm{s}}-\mathrm{z}\right)=\frac{470.4 \mathrm{~W}(62.73 \mathrm{in} .-17.24 \mathrm{in} .)}{17,200} . \\
& =1.24 \mathrm{~W} \mathrm{in.}^{2} . \\
& =(1.24)(23,500 \mathrm{lb})=29,200 \text { psi. }
\end{aligned}
$$

The two horizontal loads also produce a shear across the bolts. It is assumed that the shear taken by each bolt is equal and uniform across the cross section. Then, the shear stress in any bolt is 


$$
T=\frac{11.2 \mathrm{~W}}{8 \mathrm{~A}_{\mathrm{b}}}=\frac{11.2(23,500 \mathrm{lb})}{8\left(2.30 \mathrm{in}^{2}\right)}=14,300 \mathrm{psi}
$$

The vertical force of 2 W produces an axial stress in the bolts. If the incremental load of this force is shared equally by all of the bolts, then the additional vertical stress is

$$
\sigma_{\mathrm{A}}=\frac{2 \mathrm{~W}}{8 \mathrm{~A}_{\mathrm{b}}}=\frac{2(23,500 \mathrm{lb} .)}{8\left(2.30 \mathrm{in}^{2}\right)}=2,600 \mathrm{psi}
$$

The combined effect of the three stresses on the most stressed bolt is compared to the yield strength of the bolt using the maximum shear stress theory of failuie. The maximum shear stress is found with a Mohr's circle analysis, noting that stresses normal to the vertical stress are all zero. The principal stresses are

$$
0, \text { and } \frac{(25,000+2,600)}{2} \pm\left\{\left(\frac{29,200+2,600}{2}\right)^{2}+[i 4,300]^{2}\right\}^{1 / 2}
$$

or

$$
\begin{aligned}
& \sigma_{1}=37,300 \mathrm{psi}, \\
& \sigma_{2}=0 \mathrm{psi}, \\
& \sigma_{3}=-5,500 \mathrm{psi} .
\end{aligned}
$$

The maximum shear stress in this case is

$$
\tau_{\operatorname{MAX}} \frac{\sigma_{1}-\sigma_{3}}{2}=21,400 \mathrm{psi}
$$

The specification of bolting material on UCC-ND Drawing N.. MII230-F.N-SI4-I) Iequires only steel. This is insulficient to prevent yielding. Therefore. (irade 5 bolis with a yield strength of at least $80 \mathrm{ksi}$ will be used to fasten the cask to the trailer. The tie-down procedure will limit the turque on these bolts $10230 \mathrm{ft}$.-Ibs. 
Analysis of welds between struts and strut collars. Four inches above the base plate top, support itruts of nominal 2 1/2-ir. pipe are welded to the strut collar that is attached to the base plate. Since welds at this level circumscribe the 2 1/2-in. pipe, they provide less area than welds between the 3-in. strut collar and the base plate. Further, the 3-in. pipe has a wall thickness of 0.216 in.. which reduces the effective weid thickness from the specified nominal 1:4-in.

The cross section of the cask supports 4 in. above the base plate passes through the web of the gusset plates and the inner collar, thus the full thicknesses of these components are effective. The moment of inertia of the section about a centroidal axis is the same in all directions and has the value

$$
\begin{aligned}
I= & \left.8(\pi / 4)\left[1.438+0.216 \cos 45^{\circ}\right)^{4}-(1.438)^{4}-(1.438)^{4}\right] \\
& +\pi\left[\left(1.438+0.216 \cos 45^{\circ}\right)^{2}-(1.438)^{2}\right] \\
& \times\left[2(31.563)^{2}+4\left(31.563 \cos 67.5^{\circ}\right)^{2}\right] \\
& +\pi / 4\left[(10.75)^{4}-(10.25)^{4}\right] \\
& +8 / 2(1 / 2)(1 / 3)\left((29.125)^{3}-(10.75)^{3}\right] \\
= & 21,200 \mathrm{in.}^{4} .
\end{aligned}
$$

The moment produced by the resultant force a: this section is

$$
M=(36 \text { in. }) 11.2 \mathrm{Wlb}=403.2 \mathrm{~W} \text { in. }-1 \mathrm{~b}
$$

Stress at the extreme fiber of the weld due to this moment is

$$
\begin{aligned}
\mathrm{E}_{\mathrm{B}} & =\frac{\mathrm{Mc}}{I}=\frac{403.2 \mathrm{~W} \text { in. }-1 \mathrm{~b}}{21,200 \mathrm{in}^{4}}\left[\left(31.563+1.438+0.25 \cos 45^{\circ}\right) \cos \left(26.57^{\circ}-22.5^{\circ}\right)\right], \\
& =0.63 \mathrm{~W}=0.63(23,500)=14,800 \text { psi. }
\end{aligned}
$$

The area of the cross section 4 in. above the base plate is

$$
\begin{aligned}
A= & 8 \pi\left[\left(1.438+0.216 \cos 45^{\circ}\right)^{2}-(1.438)^{2}\right]+\pi\left[(10.75)^{2}-(10.25)^{2}\right] \\
& +8(1 / 2)(29.125-10.75)=118.1 \mathrm{in}^{2} .
\end{aligned}
$$

The axial stress in the section due to thi vertical force, averaged over the area of the section, is 


$$
\sigma_{A}=\frac{2 \mathrm{H}}{\mathrm{A}}=\frac{2(23.500) \mathrm{lb}}{118.1 \text { in. }^{2}}=400 \mathrm{psi} \text {. }
$$

The total axial stress at the extreme fiber of the weld is

$$
\sigma=15,200 \text { psi. }
$$

which is well within the allowable value of 28,000 psi. Additionally. :nis cross section is not critical for shear since the shear area here is larger than at the base nlate.

Analysis of nelds betneen support struts, gussets, and collar and hase plate. The welded connections between the cask and the base plate are analyzed under the same loads applied to the bolts. The resultant of the two horizontal forces is $11.2 \underline{\mathrm{W}}$. where $\underline{\mathrm{W}}$ is the weight of the cask. This force acts about $\mathbf{4 0}$ in. above the top of the base plate and produces a moment at the top of the base plate of

$$
M=11.2 \underline{W}(40 \text { in. })=448.0 \underline{W} \text { in.-lb. }
$$

The welds resisting this moment are: (1) eight 1/4-in. fillet welds around the outer circumference of nominally 3 -in. pipe. (2) eight pairs of 3 16-in. fillet welds along 12 -in. thic! gusset plate, and (3) a full-penetration double-bevel weld flanked by 3 16-in. fillets on each side around a $1 / 2$-in. thick collar ring with a mean radius of $10.5 \mathrm{in}$. The pipe supports are located on a 63-1/8-in.-diam circle; the gusset plate welds run from the collar outward to 5 in. short of the pipe support. A view of the welds from above the base plate is shown in Fig. 2.I.

The vertical stresses due to the horizontal forces in these welds are assumed to be distributed like those at a cross section of a beam loaded by an end moment. The moment of ineria of the weld material about an axis through the centroid of the cross section is independent of the orientation of the centroidal axis since the welds are uniformly spaced in circular patterns. For convenience, an axis, $y-y$ in Fig. 2.6, through two of the struts is chosen. Also, the momeill of inerita of the gusset plate welds is calculated from the equation $I=\mathrm{J} 2$ where $I$ is a moment of inertia and $J$ is the polar moment of inertia. The area used to represent an area of fillet welds is the area of the throat of the weld which in this casc is cos $45^{\circ}$ or 0.707 times the nominal thickness times length of the weld. The moment of inertia of the weld area at the top of the base plate is

$$
\begin{aligned}
I= & 8(\pi / 4)\left[\left(1.75+0.25 \cos 45^{\circ}\right)^{4}-(1.75)^{4}\right] \\
& +\pi\left[\left(1.75+0.25 \cos 45^{\circ}\right)^{2}-(1.75)^{2}\right] \\
& \times\left[2(31.563)^{2}+4\left(31.563 \cos 67.5^{\circ}\right)^{2}\right] \\
& +{ }_{4}^{\pi}\left[(10.75)^{4}(10.25)^{4}\right] \\
& +16 / 2(3 / 16) \cos 45^{\circ}(1 / 3)\left[(25.125)^{3} \quad(10.75)^{3}\right] \\
= & 12,300 \mathrm{in} .^{4} .
\end{aligned}
$$


The stress due to bending in the weld fiber at the most distant point from the neutral axis which is orthogonal to the resultint horizontal force is

$$
\begin{aligned}
\sigma_{B}= & \frac{448.0 W \text { in. }-l \mathrm{lb} .}{12.300 \mathrm{in}^{2}}\left[\left(31.563+1.75+0.25 \cos 45^{\circ}\right)\right] \\
& \times \cos \left(26.57^{\circ}-22.5^{\circ}\right) \\
= & 1.22 W=1.22(23.500)=28,600 \text { psi. }
\end{aligned}
$$

The vertical $2 W$ force also produces a vertical stress in the welds at the base plate which is assumed to be uniformly distributed over the weld area. Total area of weld in that plane is

$$
\begin{aligned}
A= & 8 \pi\left[\left(1.75+0.25 \cos 45^{\circ}\right)^{2}-(1.75)^{2}\right] \\
& +\pi\left[(10.75)^{2}-(10.25)^{2}\right] \\
& +16(3 / 16)\left(\cos 45^{\circ}\right)(25.125-10.75)=79.8 \text { in. }^{2} .
\end{aligned}
$$

Stress at any point in the weld. due to the vertical force, then is

$$
\sigma_{A}=\frac{2 W}{A}=\frac{2(23,500)}{79.8}=590 \text { psi. }
$$

The maximum vertical stress in the weld is the sum of the two vertical stresses and is

$$
\sigma_{\max }=29,200 \mathrm{psi} \text {. }
$$

This stress is localized at the extreme fiber where shear stress is absent. The stress resulting from the hypothetical loading condition slightly exceeds the yield of 304L. stainless steel (the 300 series stainless steel with the least yield strength).

The shear stress across the base plate vields due to the horizontal resultant is zero at the extreme fibers and so must be greater than average elsewhere. Shear stress is not a serious concern for steel without a thin web, but if is it assumed that the maximum shear is twice the average shear across the cross-sectional area, then

$$
\begin{aligned}
T_{\text {max }} & =2\left(\frac{V}{A}\right) 2\left(\frac{11.2 W}{79.8 \text { in. }^{2}}\right)=0.28 W \\
& =0.28(23,500)=6600 \text { psi. }
\end{aligned}
$$




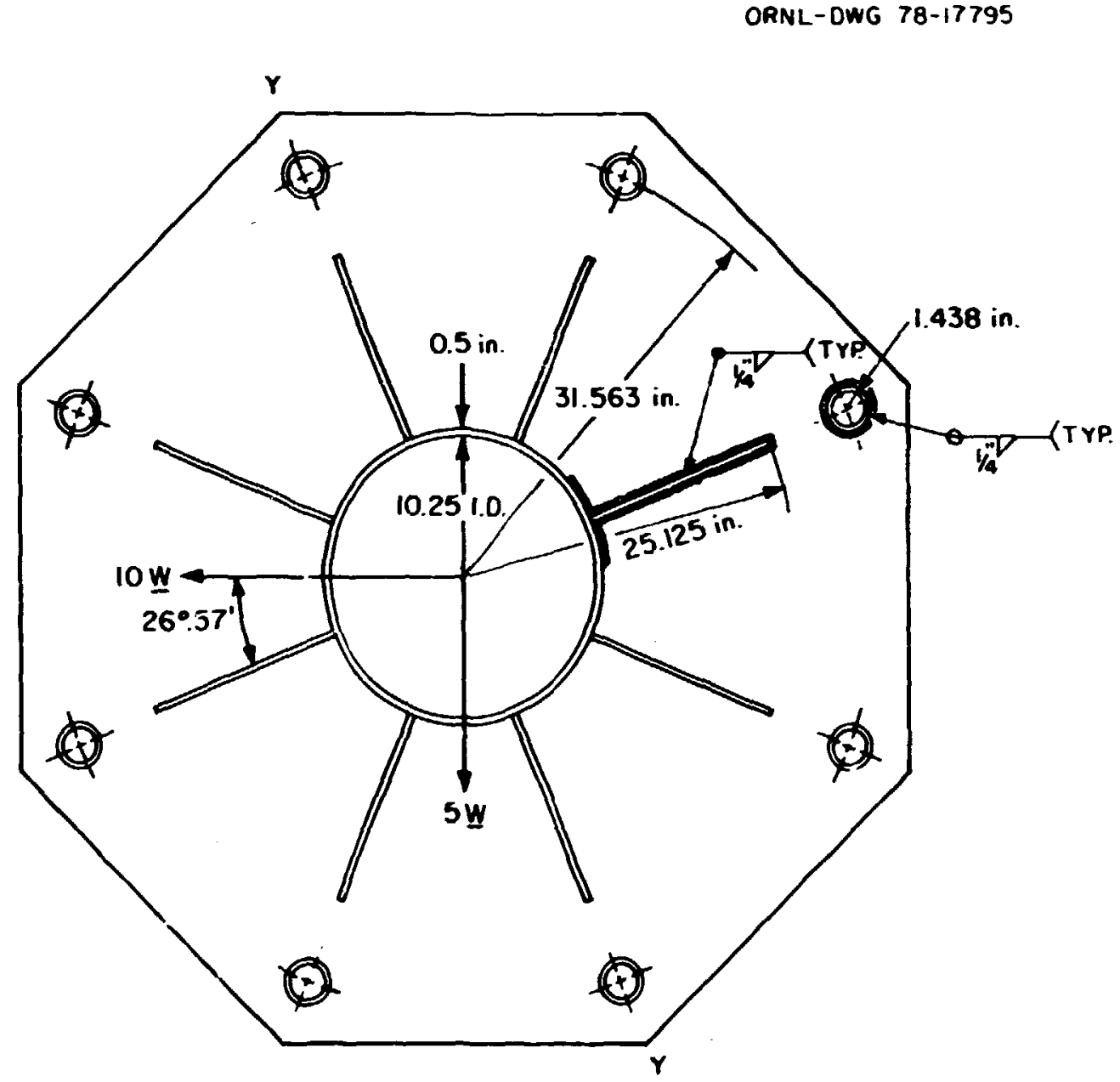

Fig. 2.6. Cross section of welds between support struts, gussets, and collar and base plate. 
This value is well within the allowable value of 14,000 psi shown in Table 2.1, which indicates that the velds are adequate.

\subsection{Slandards for Type B and Large Quantity Packagirg}

The structural standards for large quantity packaging of the regulations cover load resistance of the packaging and the external pressure which the package must withstand. Compliance of the TRU Californium Shipping Container with these requirements is discussed in the following subsections.

\subsection{Load resistance}

When regarded as a simple beam supported at its ends along any major axis, the container must be capable of withstanding a static lnad, normal to and uniformly distributed along its length, that is equal to five times its fully Iraded weight without generating stress in ar.y material of the cask in excess of the yield strength of that material. The TRU Californium Shipping Container is almost spherical; therefore, this requirement is not applicable.

\subsubsection{Exrernal pressure}

The regulations require that the design of the shipping package be adequate to ensure that the containment vessel will suffer no loss of contents if subjected to an external pressure of 25 psig.

Spherical shell. The maximum external pressure that may be withstnod by the 1/2-in-thick stainless steel spherical shell, assuming no support from the reinforcing steel or from the concrete, may be calculated (Par. UG-28(d), ref. II) as follows:

$$
P_{\text {c }}=B / r_{1} / t_{h}=10.000 / 32.5 / 0.5=154 \text { psig. }
$$

where

$$
\begin{aligned}
& P_{a}=\text { allowable working pressure, psia, } \\
& B=\text { factor, } 10,000 \text { (Fig. UNF-28.8, ref. } 11 \text { ), } \\
& r_{1}=\text { inside radius of spherical shell, } 32.5 \mathrm{in} ., \\
& t_{h}=\text { thickness of spherical shell, } 0.5 \mathrm{in} .
\end{aligned}
$$

The spinerical shell of the cask is, therefore, sufficiently thick to withstand a 25-psi external pressure; however, in addition, the internal reinforced concrete shield completely eliminates the 
possibility that the shell will buckle under external pressure.

Top and bollom closure plates. The maximum external pressure $(P)$ that may be withstood by the I 2-in.thick stainiess steel llange closure above and below the access plugs may be calculated (Par. UG 34(c)(ź). ref. II) as follows:

$$
P=S t^{2} \approx d^{2}=13.300(0.5)^{2} 0.25(16.75)^{2}=47 \text { psig. }
$$

where

$$
\begin{aligned}
& S=\text { maximum allowable stress value. } 13,300 \text { psig. (Table UHA-23, ref. } 11 \text { ). } \\
& t=\text { thickness of cover, } 0.5 \text { in.. } \\
& c=\text { attachment factor. } 0.25 \\
& d=\text { diameter of the bolt circle. } 16.75 \text { in. }
\end{aligned}
$$

The top and bottom closure flange is, therefore, stifficiently thick to withstand an external pressure of 25 psig.

All openings to the cask cavity are gasketed and are not expected to leak under an external pressure of 25 psig. Hence the regulations are met.

\section{COMPLIANCE WITH STANDARDS FOR NORMAL CONDITIONS OF TRANSPORT}

The regulations stipulate that a single package must be able to withstand the normal conditions of transpon without substantially reducing the effectiveness of the package and without releasing radioactive material from the containment vessel. The contents of the container are limited such that the package will contain no gases or vapors that could reduce the effectiveness of the packaging. No circulating coolant other than atmospheric air is used, and no mechanical cooling device is required or provided. The TRU Californium, Shipping Container and its inner containers are designed so that the contents will not be vented to the atmosphere under normal conditions of transport. These normal conditions include the effects of heat, cold, pressure, free drop, and penetration.

\subsection{Heat}

Tne cask must be so designed and constructed that if it were subjected to direct sunlight at an ambient temperature of $130^{\circ} \mathrm{F}$ in still air, its effectiveness would not be reduced. In addition, the temperature of the accessible external surfaces of the cask shall not exceed $122^{\circ} \mathrm{F}$ in the shade when fully loaded, assuming still air at ambient temperatures. If the cask is transported in a vehicle assigned for the sole use of the consignor, the maximum accessible external surface temperature shall be $180^{\circ} \mathrm{F}$. 


\section{1 .1 Hew iests}

Io $\therefore$ aluate the adequacy of the Californium cask under normal operating conditions. heat transler tests were conducted both in the shade and in direct sunlight.

The cask was lirst placed in the crane bay of a building where the ambient temperature uas controlled at $70^{=} \mathrm{F}$. The temperature of the cask was measured witt thermocouples and recorded over a four day period to ensure equilibrium conditions.

The results of these tests extrapolated to $100^{\circ} \mathrm{F}$ are presented in Table 3.1 It is apparent that should the ambient temperature reach $100^{\circ} \mathrm{F}$ in the shade. the maximu.n surface temperature should not be greater than about $10^{\circ} \mathrm{F}$ higher than this.

The cask uas next placed outside on a bitumenous surface for a period of eight days in the middle of May. During the test. the weather was clear and mild with bright. sunny days. A thermocouple was attached to the top cupola and another was attached to the side of the cask 45 from the center line and midway between two of the extcrnal ribs.

In full sunlight with an ambient temperature of $130^{\circ} \mathrm{F}$, the surface temperature should not exceed approximately 165 . The inclusion of a $5 W$ heat source in the cavity of the cask would not be expected to raise these projected temperatures a measurable amount because of the large surface area oser which this heat will be dispatched. Thus, the cask meets the conditions specified in Sect. 3.1.

Table 3.1. Cask temperatures

\begin{tabular}{lcc}
\hline Location & $\begin{array}{c}\text { Cask in shade } \\
{ }^{{ }^{\circ} \mathbf{F}}\end{array}$ & $\begin{array}{c}\text { Cask in sun } \\
{ }^{{ }_{0}} \mathbf{F}\end{array}$ \\
Top of cask & 107 & 162 \\
Side of cask & 110 & 160 \\
Ambient & 100 & 130 \\
\hline
\end{tabular}




\subsection{Cold}

The shipping package must be able to withstand an ambient temperature of $-40^{\circ} \mathrm{F}$ in still air and shade.

Taking $T_{1}=-40^{\circ} F\left(420^{\circ} R\right)$ and assuming no internal heat load. the final or maximum pressure $\left(P_{y}\right)$ in any cavity sealed at a pressure of 14.7 psia and a temperature of $70^{\circ} F\left(530^{\circ} R\right)$ is

$$
P_{:}=\left(P_{1} T_{2}\right) T_{1}=11.65 \text { psia. }
$$

The resulting pre sure differential is less than the 25-psig differential pressure investigated in Sect. 2.3.2. A temperature of $-40^{\circ} \mathrm{F}$ is within the operating temperature range of the seals and the stainless steel cladding, structural components, and fasteners. Brittk fracture of these components under the stipulated cold condition is unlikely because the temperatures of these components are above their ductile-10-brittle transition temperatures.

The above considerations indicate that the stipulated cold conditions will not reduce the effectiveness of the packaging, and that the container conforms to the requirements for the cold condition of normal transport.

\subsection{Pressure}

The regulations for normal conditions of transport specify that the package be able to withstand an atmospheric pressure of 0.5 times the standard atmospheric pressure, the resulting pressure being 7.35 psia.

When the model is under full heat load, trapped air in all sealed cavities will expand and exert internal pressures. Assuming assembly at $70^{\circ} \mathrm{F}$ and 14.7 psia, the resulting pressure of any trapped air is

$$
P_{2}=\left(P_{1} T_{2}\right) / T_{1}=(14.7)(590) / 530=16.4 \text { psia. }
$$

where

$$
\begin{aligned}
& P_{1}=\text { assembly pressure, } 14.7 \text { psia, } \\
& T_{1}=\text { assembly temperature, } 530^{\circ} R, \\
& T_{2}=\text { assumed cask surface temperature, } 590^{\circ} \mathrm{R} .
\end{aligned}
$$


The internal heat load (5W) is expected to contribute nothing to the cask surface temperature. The increase in pressure is therefore calculated by Eq. (SO) and is 16.4 psia (1.7 psig). The maximum differential pressure expected actoss the cavity seals is therefore $23.7 \mathrm{psia}$ (9.0 psig).

The cask and its silicone rubber seals (see Figs. 1.2 and 1.3) will be able to withstand these pressures without damage or reduction in the effectiveness of the packaging. Therefore. the container conforms to the requirement for the reduced pressure condition of normal transport.

\subsection{Vibration}

The container is of welded construction, and vibrations received in transit are not expected to affect the integrity of the weldment. All fasteners are equipped with lock washers and are not expected to loosen during such vibrations.

In addition. the cask. Juilt several yea: ago. has operated in the transportation environment. suffering no ill effects as a result of vibrations encountered.

\subsection{Water Spray}

The containment capabilities of the TRU Californium Shipping Container are not compromised by water spray since all external surfaces are of staintess steel. The closure seal is impervious to water.

\subsection{Free Drop}

The regulations for normal conditions of transport require that a package weighivg more than 20,000 lb be capable of withstanding a free drop through a distance of 2 ft onto a flat. essentially unyislding, horizontal surface. striking the surface in a position in which maximum

damage is expected to result. A free drop of the TRU Californium Shipping Container through a distance of $2 \mathrm{ft}$ is expected to produce a denting of the outside steel shell and possibly some slight tracturing of the concrete. Any concrete that might be fractured will be contained, and no reduction in effectiveness of the package or loss of contents is expected to occur due to the 2-ft free drop. Analysis of the hypothetical accident 30-ft free drop (Sect. 4.1) indicates that damage (if any) from a 2-ft drop will be insignificant. 


\subsection{Penctration}

The regulations for normal conditions of transport stipulate that the package must be capable of withstanding the impact of the hemispherical end of a vertical steel cylinder which weighs $13 \mathrm{lb}$. has a $1-1$ 4-in. diam. and is dropped from a height of $40 \mathrm{in}$.. typically onto the exposed surface of the package that is expected to be the most vulnerable to puncture.

The maximum energy imparted to the cask is 520 in.-lb. Approximately 50.000 in.-Ib is required to deform I in.' of stainless steel: therefore. the energy of impact would deform about 0.0104 in.' of material. If the hemispherical head of the impactor struck the stainless steel shell. the depth of penetration would not exceed the depth of a spherical sector having a volume of 0.0104 in.". The volume of a spherical segment of one base is

$$
V=(13) \min \left(3 h-h^{2}\right)
$$

where

$$
\begin{aligned}
& h=\text { height of segment (or depth of penetration). in.., and } \\
& r=\text { radius of sphere. } 0.625 \text { in. }
\end{aligned}
$$

The preceding equation becomes

$$
h^{3}-1.875 i^{2} .9 .93 \times 10^{\prime}=0 \text {. }
$$

This gives a maximum depth of penetration of 0.074 in. Damage of this magnitude would not reduce the effectiveness of the cask. This actual test was performed on the cask and no damage resulted to it.

\subsection{Compression}

Since the weight of the TRU Californium Shipping Containet exceeds 10.000 th. this section is not applicable.

\section{COMPLIANCE WITH STANDARDS FOR HYPOTHETICAI. ACCIDENT CONDITIONS}

The standards for the hypothetical accident conditions stipulate that a container used for the shipment of fissile or large quantities of radioactive material shall be designed and constructed in such a manner and its contents limited so that, if it is subjected to the specified free-drop. puncture, thermal, and water-immersion conditions, the following requirements would be met: 
1. The reduction in shiclding would not be sufficient to increase the externai radiation fose rate to more than $1000 \mathrm{mR} \mathrm{hr}$ at a distance of $3 \mathrm{ft}$ from the outside surface of the package.

2. So radioactive material would be released from the package except for gases containing total radioactivity not to exceed 0.15 of the total radioactivity of the contents of the package.

3. The contents would remain subcritcal

\section{I Free Drop}

The first in the sequence of hypothetical accident conditions to which the cask must be subjected is a free drop through a distance of $30 \mathrm{ft}$ onto a Rat. essentially unyielding. horizontal surface. striking the suriace in a position in which the maximum damage is expected to occir. Since the cask is essentially a sphere, three orientations will be considered: (1) a random drop on the rounded stainless steel outer shell, (2) a drop on the top to test the bolis hokding the top plugs. and (3) a drop on the bottom to test the bolts holding the bottom plugs.

\subsection{Drop on rounded slainless steel outer shell}

When the TRU Californium Shipping Container is dropped on the rounded outer stainless steel shell. the energy will be absorbed by bending the outer shell and crushing or cracking the concrete.

Very little information is available in the literature concerning the impact of heavy concrete pieces on essentially unyielding stationary objects. However, a series of tests were performed at the Brookhaven National Laboratory, with three unencased reinforced concrete waste shipping containers. These containers, which weighed $\sim 10$ tons, were dropped 30 ft onto a IO-in.-thick slab of armor piate." These containers had wall thicknesses of 6 in., 12 in., and 17 in. Containers that had wall thicknesses of 12 in. or 17 in. passed the drop test, with the latter one showing only hairline cracks and essentially no loss of shielding.

The Californium Shipping Container is shielded with 30 in. of reinforeed concrete completely encased in a $1 / 2$-in.-thick staintess steel outer shell and weighs 11.75 tons. Thus this container weighs approximately the same as the concrete waste shipping containers that were tested, has almost twice the shielding thickness, and has a thick outer steel shell that will help spread the impact forces over a broad area of the cask surface. It is, therefore, concluded that the Californium Shipping Container will suffer only localized damage to the outer shell and concrete at the point of impact and that no significant cracks will occur in the shielding. Hence the cask dropped in this manner will meet the hypothetical accident requirements of a 30-ft drop.

Should the impact occur in the region of the actuator stems, the force is likely to be transmitted to the valve mechanism shown in Figs. 1.2 and 1.3 which could result in a loss of the seal. The ball valve will physically remain in place. 
Even thcugh the cask seal is lost, the primary line of containment will remain the welded container, described in Sect. 5 . Thus no loss of radioactive material is expected from an impact on the side.

\subsubsection{Drop on cop flange}

Th: possibility of failure of the bohs which hold the top concrete shielding plugs in the cask was investigated. It was assumed that the cask was dropped, upside down. on its top lange, from a height of $30 \mathrm{ft}$ onto a solid, essentially unyieiditig surface. Under these conditions the wall of the cupola (to which the top flange is bolted) and the I-in.-thick lifting ribs would deform, absorbing the kinetic energy of the cask. An analysis was made using the equations given in Sect. 9.3.

Results indicate that the cupola would crush approximately 1 in. before all kinetic energy would be absorbed. This is not possible, because after collapsing 0.5 in. the top flange would come in direct coniact with the bolted plug tanges. At this time of contast, the number of $g$ 's experienced by the cast would rapidly increase, the cask would come to rest in less than the remaining 0.5 in. predicted in the analysis, and the plug flanges would be driven back into the body of the cask. The predicted $g$ loading of the cask, shown in Fig. 4.1 as a function of deformation, should be realistic up to the point at which the top flange encounters the plug flanges. Under these conditions the bolts holding the plugs in place will have to resist about $425 \mathrm{~g}$ 's before the plugs are driven back into the cask body. Therefore, the force to be resisted by the bolits becomes

$$
\mathbf{F}=\mathbf{m a} \text {, }
$$

where

$$
\begin{aligned}
& m=\text { mass of the plugs, } 3.60 \text { slugs, } \\
& a=\text { maximum acceleration experienced by the plugs, ft } / \sec ^{2}, 425 \mathrm{~g} \text {. }
\end{aligned}
$$

Substituting, the applied load is

$$
F=(3.60)(425)(32.2)=49,200 \mathrm{lb} .
$$

The area of metal in tension by this force is the stress area of the eight bolts. The area of the bolts under stress is

$$
A=N A=(8)(0.122)=0.976 \text { in. }^{2} \text {. }
$$

where

$$
N=\text { number of boles, } 8 \text {, }
$$




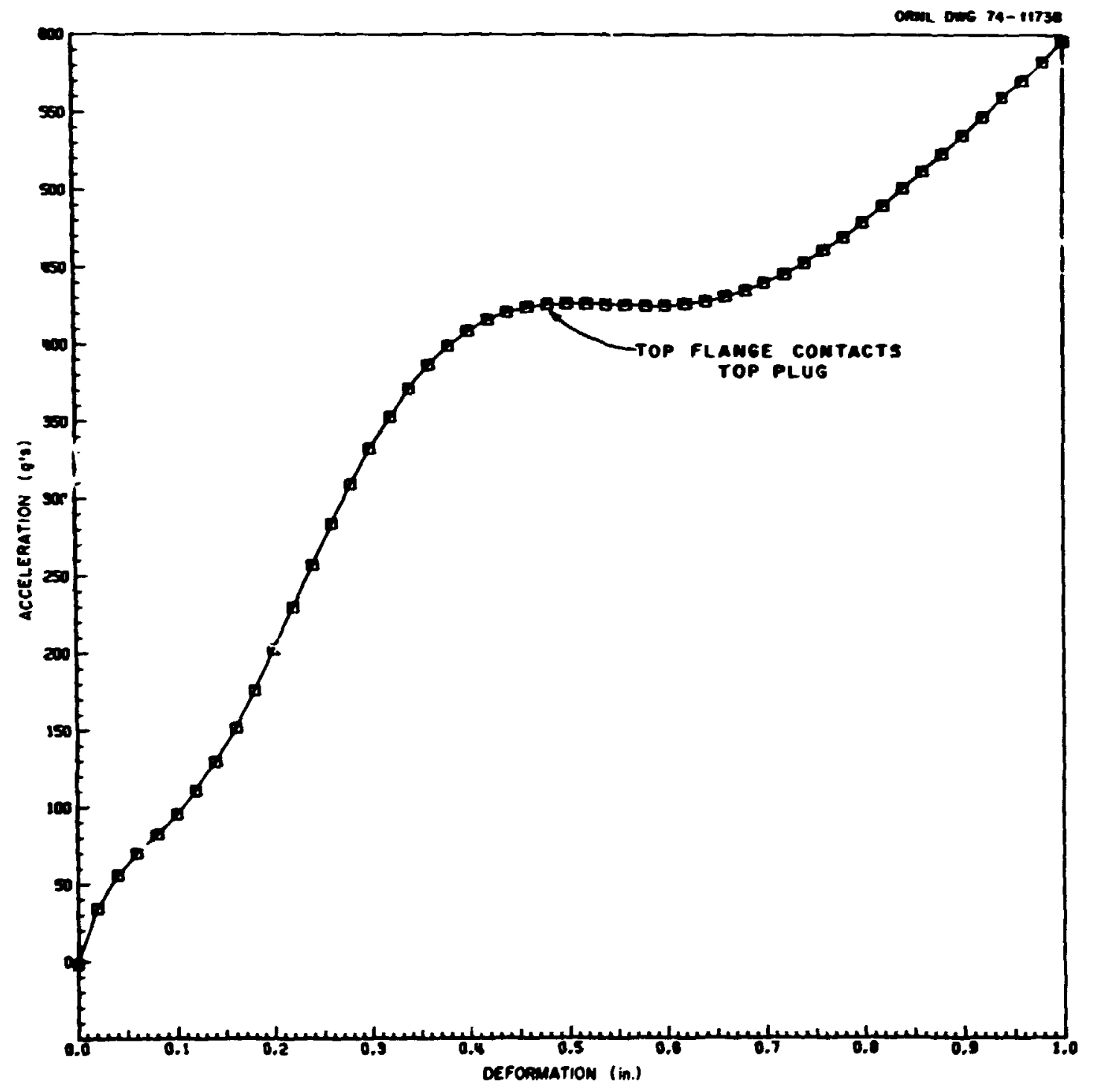

Fig. 4.1. Acceleration vs deformation as a result of computer analysis of $30-\mathrm{ft}$ drop on top flange. 


$$
A=\text { area of bolt. } 0.122 \text { sq in.'.* }
$$

The total load-bearing capacity of the bolts is determined from

$$
\mathrm{F}_{\max }=\mathbf{A o}_{3}
$$

where

$$
\begin{aligned}
\sigma_{s} & =\text { yield strength of stainless steel, 61,200 psi (see Table } 2.1 \text { footnote e) } \\
F_{\max } & =(0.976)(61,200)=59,700 \mathrm{lb} .
\end{aligned}
$$

Since $F_{\text {mer }}$ is greater than the applied load, the plugs will remain attached to the cask, and the contents will remain in the cavity.

\subsubsection{Drop on bottom flange}

The possibility of failure of the bolts which hold the bottom shielding plugs in the cask was investigated. It was assumed that the cask was dropped base down from a height oi $30 \mathrm{ft}$ onto a solid, essentially unyielding surface. Under these conditions, the waiis of the cupola, the base plate (to which the bottom flange is bolted), the eight I-in.-thick webs, and the eight struts-all would be deformed, absorbing the kinetic energy of the cask. An analysis was made using the equations given in Sect. 9.3.

Results indicate that the cupola would crush approximately 0.6 in. before all the kinetic energy would be absorbed. The relationship between acceleration and deformation for the drop onto the bottom flange is shown in Fig. 4.2. There is additional clearance at the bottom flanges due to the offset bottom cupola cover. Under these conditions, the bolts holding the plugs in place will have to resist about $1000 \mathrm{~g}$ 's. Therefore, the force to bi resisted by the bolts is

$$
F=\mathbf{m a},
$$

where

$$
\begin{aligned}
& m=\text { mass of the plugs, } 3.60 \text { slugs, } \\
& a=\text { maximum acceleration experienced by the plugs, } \mathrm{ft}^{\prime} \mathrm{sec}^{2}, 1000 \mathrm{~g}
\end{aligned}
$$

Substituting,

$$
F=(3.60)(1000)(32.2)=115,900 \mathrm{lb}
$$

\footnotetext{
Body of bolt turned down to a 0.394 -in. diam. or 0.122 in. $^{2}$.
} 


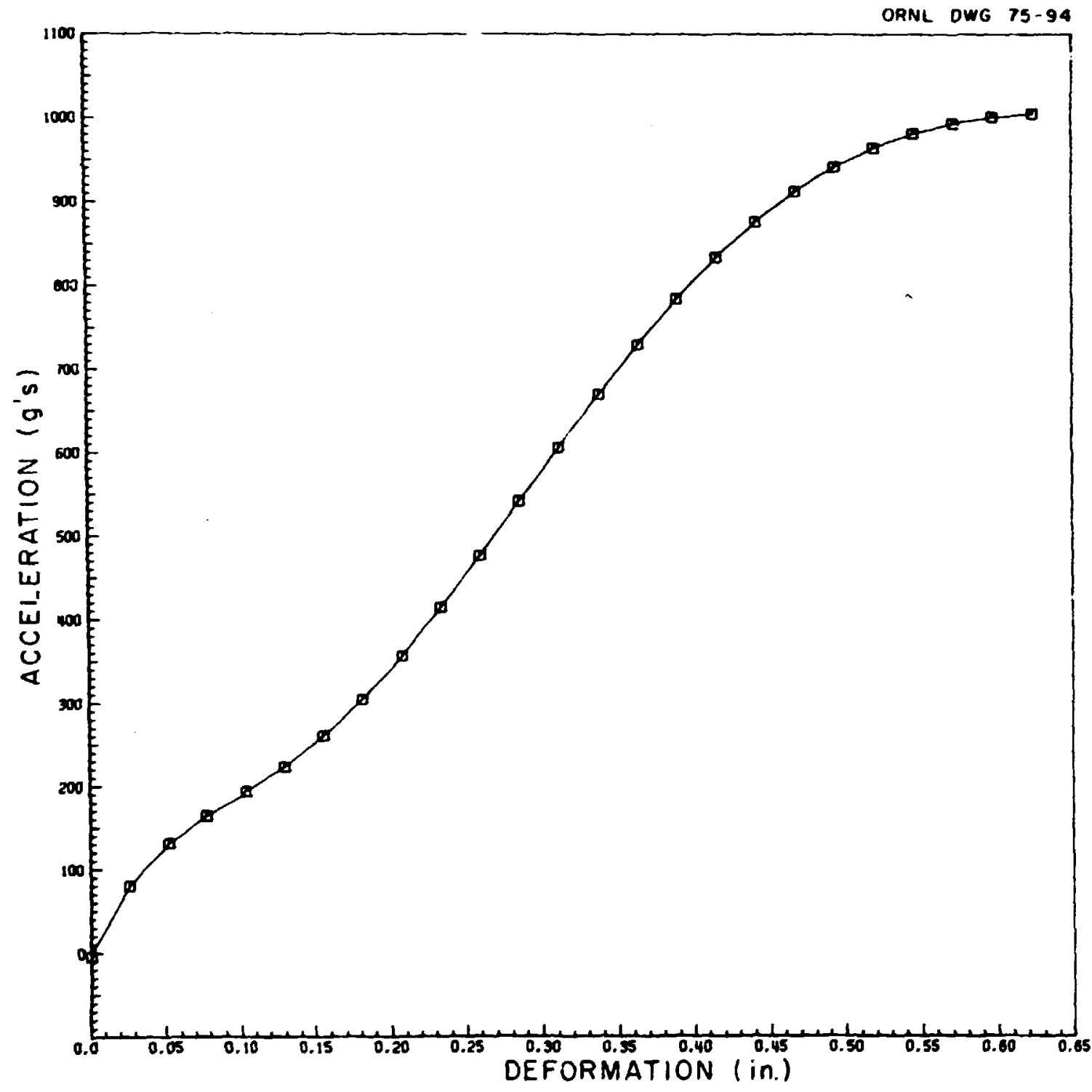

Fig. 4.2. Acceleration vs deformation as a result of computer analysis of 30-ft drop on bottom flange. 
The area of metal in tension by this force is the stress area of eight turned down 12 -in. bolts. The area of the bolts under stress is 0.976 in. $^{2}$, as indicated in Eq. (SS).

The total load-bearing capacity $\left(F_{\text {max }}\right)$ of the bolts was determined to be $59.700 \mathrm{lb}$. as indicated in Eq. ( 56 ). Since $F_{\text {max }}$ is less than the applied load. the bolts will fail and the ends of the plugs will drop into the bottom closure cover (see Fig. 1.1).

The bottom cover plate is retained by twelve 1:2-in. cap screws which have the following load-bearing capacity:

$$
F_{\max }=\mathrm{NAO}_{s}=12(0.142)(61,200)=104,300 \mathrm{lb} .
$$

where

$$
\begin{aligned}
& N=\text { number of bolts, } 12, \\
& A=\text { area of bolts, } 0.142 \text { in. }^{2} \text { (ref. 10), } \\
& a_{s}=\text { tensile strength of stainless steel, } 61,200 \text { psig (see Table 1). }
\end{aligned}
$$

The load bearing capacity of these bolts will hold the plugs from further travel. The bottom closure cover is a gasketed sealed cavity, and the inner container upon which containment depends is still retained in the cavity essentially without movement. No loss of containment or appreciable loss of shielding is anticipated.

\subsection{Puncture}

The second in the sequence of hypothetical accident conditions to which the cask must be subjected is a free drop through a distance of $\mathbf{4 0}$ in. to strike, in a position in which maximum damage is expected, the top end of a vertical mild-steel bar mounted on an essentially unyielding, horizontal surface. The mild-steel bar shall have a diameter of 6 in. with the top horizontal and its edge rounded to a radius of $1 / 4$ in., and the bar shall be of such length that it will cause maximum damage to the cask but not less than 8 in. long. The long axis of this bar shall be normal to the surface of the cask upon impact.

To analyze the puncture accident, a rather conservative model can be used which considers all the energy absorbed by the cask is absorbed by the outer stainless steel shell with no consideration given to the concrete shielding.

The energy of impact will be absorbed by the 6-in.-diam mild-steel bar and the 1/2-in.-thick cask outer shell. Figure 4.3 illustrates the configuration for this computational model. The absorbed energy $U=W h=(23,500)(40)=940,000$ in.-lb, and

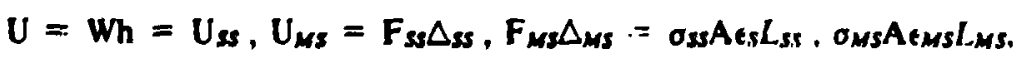

where 
ORNL DWG 74-12623

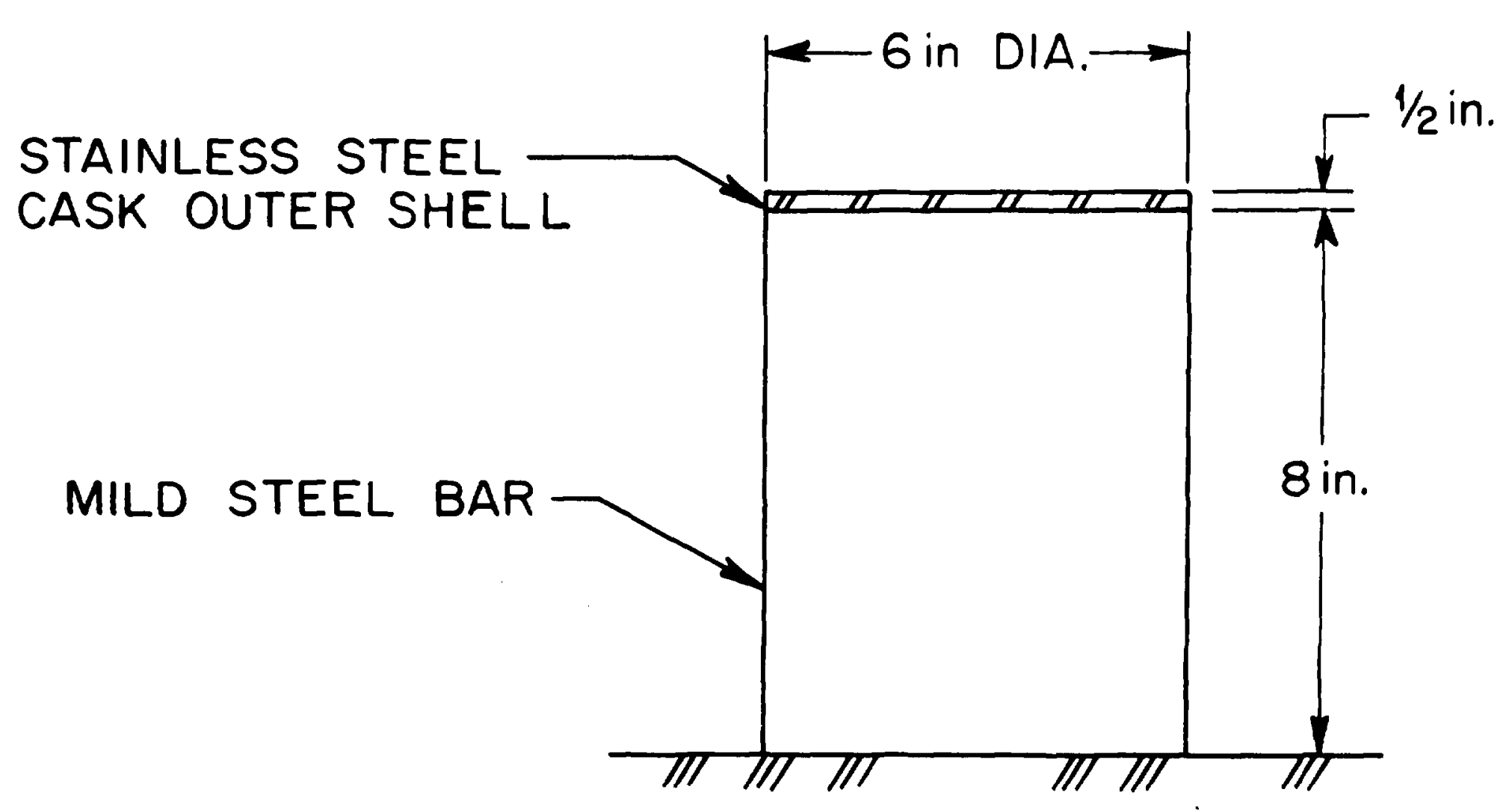

F18. 4.3. Model used for puncture analysis. 


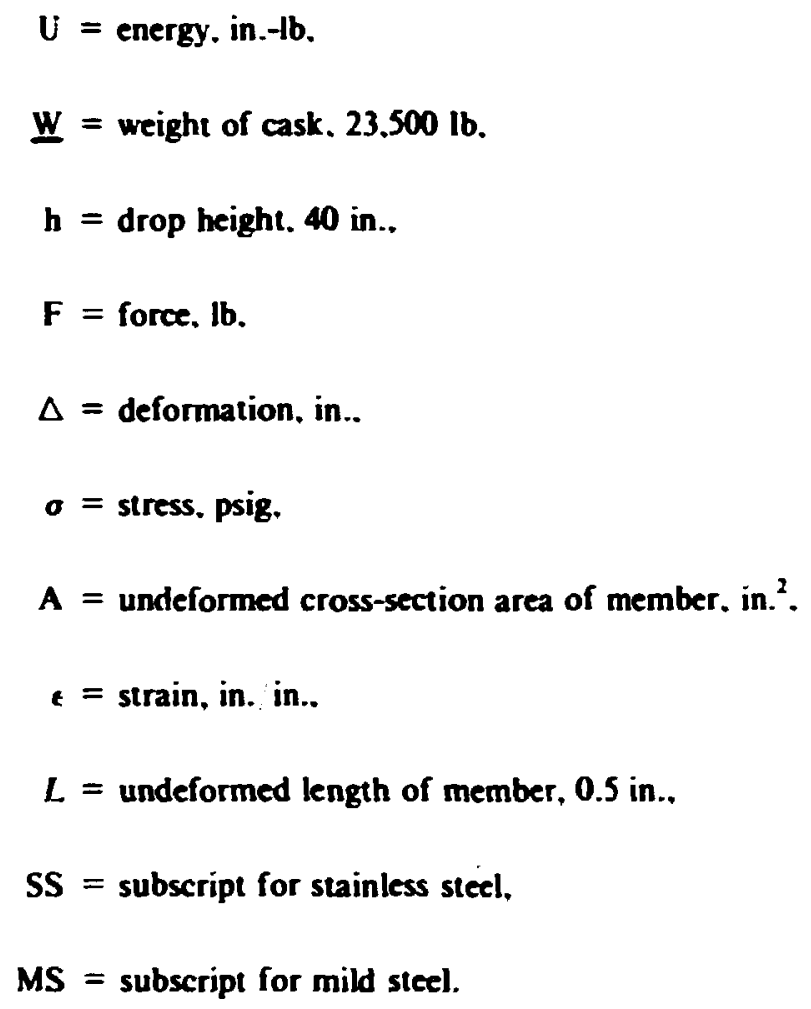

Since the force is the same in both members, we can write

$$
\sigma_{S S A}=\sigma_{M S} A,
$$

and since the areas are the same,

Then Eq. (60) becomes:

$$
\sigma_{S S}=\sigma_{M S}=\sigma
$$

$$
U=\sigma A\left(e_{s s} L_{s s} \cdot\left(\mathrm{ms} L_{\mathrm{ms}}\right) .\right.
$$

For plastic deformation of stainless steel and mild steel, simple stress-strain relations can be written as ${ }^{14}$

$$
\sigma_{s s}=\left(4.33 \times 10^{5}\right) \epsilon s, 60,000
$$

and

$$
\sigma_{M S}=\left(2.56 \times 10^{5}\right) \epsilon_{W J}, 60,000 \text {. }
$$

Rearranging yields the following result: 


$$
e_{s s}=\left(\sigma_{s s}-60,000\right) \cdot\left(4.33 \times 10^{9}\right)
$$

and

$$
e_{w s}=\left(\sigma_{s s}-60,000\right)\left(2.56 \times 10^{5}\right)
$$

Substitution of Eqs. ( 65$)$ and ( 66 ) into Eq. (62) and eliminating the material subscripts yields a quadratic eupuation as follows:

$$
\sigma^{2}-\left(6.0 \times 10^{4}\right) \sigma-\left(1.694 \times 10^{7}\right)=0 .
$$

which yields the result $\sigma=60.281$ psig.

The strain on the stainless steel cask shell is

$$
c s=(60.281-60,000)\left(4.33 \times 10^{5}\right)=0.00065 \text { in. in. }
$$

and the deformation is

$$
\Delta \mathrm{ss}=t L=(0.00065)(0.50)=0.000325 \text { in. }
$$

From Newton's second law. the peak acceleration is

$$
a_{\text {max }}=F m=F_{g} W=\sigma A_{g} W=-(60.281)(\pi)(6)^{2}(g):-(4)(23.500)=72.5 \mathrm{~g} .
$$

This acceleration is less than that associated with the end impact resulting from the 30-ft free drop discussed in Sect. 4.1, and it is therefore concluded that the inner container will continue to provide containment under the puncture accident condition.

The stainless steel outer shell will defo:!: plastically; however, because of the support from the concrete. it will not rupture. Impact-induced cracks that may occur in the concrete shielding material ... in intergranular in nature, thus offering a labyrinth path for radiation without reducing the shielding properties.

\subsection{Thermal Evaluation}

\subsubsection{Hypothetical thermal accident condition discussion}

The third in the sequence of hypothetical accident conditions specified by the regulations to which the cask must be subjected is a 30-min exposure to a source of radiant heat having a temperature of $1475^{\circ} \mathrm{F}$ and an emissivity coefficient of 0.9 or equivalent. For calculational purposes, it shall he assumed that the package has an absorption coefficient of 0.8 . The package shall not be cooled artificially until after the 30 -min test period and the temperature at 
the center of the package has begun to fall, or until $3 \mathrm{hr}$ following the test period.

A computer program. HEATING-3. which has been modified to evaluate the phase change of materials and is applicable to the IBM 360 compu:er. was used to determine the temperature distribution when exposed to these thermal environments.

It was assumed that the container was loaded with a decay heat load of $50 \mathrm{~W}$. a factor of 10 higher that will be used in this package (see Sect. 1.2). which will therefore provide an upper limit on the expected cask temperatures under the hypothetical thermal accident condition. The temperature distribution from $100^{\circ} \mathrm{F}$ ambient condition and a $50 \mathrm{~W}$ source was input as starting temperatures for the accident (fire) calculation.

The damage from the free drop and puncture portions of the hypothetical accident would not adversely affect the performance of the container in the hypothetical thermal accident. Hence the undamaged configuration was assumed.

\subsubsection{Thermal properties of materials}

The thermal properties of materials used to compute the temperature distribution under steady-state and transient conditions are listed in Table 4.I

\subsubsection{Thermal accident analysis}

The computational model representing the TRU Carrier is illustrated in Fig. 4.1. The contents were modeled as a homogenous cylinder with the decay-heat generation rate of $50 \mathrm{~W}$ uniformly distributed throughout the volume.

As the HEATING-30 ${ }^{10}$ code cannot be used to model a sphere, the exterior surface was modeled using a group of concentric cylinders whose outside surfaces approximated the surface of a sphere. The radius and length of these cylinders were chosen so that the resulting surface had the same surface area as that of the actual cask. Natural convection heat transfer coefficients for a sphere were used for the exterior of the cask.

Convection. radiation, and conduction were assumed to transfer heat across large air gaps in heat transfer model, except in cases where. because of the combination of narrow gaps and small temperature differences, it can be shown that heat convection contributes essentially nothing to the heat transfer process.

\subsubsection{Container temperatures}

The results of the computer analysis are presented graphically in Fig. 4.4. Cask temperatures are followed for $3 \mathrm{hr}$ after the conclusion of the fire since regulations specify that the cask cannot be artificially cooled prior to this time unless the temperatuse in the center of the cask has begun to fall. 
Table 4. Thermal propertles of materials used to compute temperature distribution

\begin{tabular}{|c|c|c|c|c|}
\hline Materlal & $\begin{array}{c}\text { Temperature } \\
\left({ }^{\circ} \mathrm{F}\right)\end{array}$ & $\begin{array}{l}\text { Thermal conductivity } \\
\text { Btu } h r^{-1} \mathrm{ft}^{-1}\left({ }^{\circ} \mathrm{F}\right)^{-1}\end{array}$ & $\begin{array}{l}\text { Density } \\
\text { Ib in. }-3\end{array}$ & $\begin{array}{c}\text { Heat } \\
\text { capacity } \\
\text { Btu } 1 b^{-1}\left({ }^{\circ} \mathrm{F}\right)-1 \\
\end{array}$ \\
\hline Fuel & & 6.62 & 0.0978 & 0.214 \\
\hline Seal & & 0.143 & 0.0347 & 0.469 \\
\hline SST 304L & $\begin{array}{r}32.0 \\
212.0 \\
932.0 \\
1292.0 \\
1472.0\end{array}$ & $\begin{array}{r}7.736 \\
9.428 \\
12.571 \\
14.989 \\
15.000\end{array}$ & 0.282 & 0.130 \\
\hline Air & $\begin{array}{r}32.0 \\
212.0 \\
392.0 \\
572.0 \\
752.0\end{array}$ & $\begin{array}{l}0.017 \\
0.018 \\
0.022 \\
0.026 \\
0.029\end{array}$ & $4.11 \times 10^{-5}$ & 0.240 \\
\hline Concrete & - & 0.600 & 0.090 & 0.21 \\
\hline
\end{tabular}




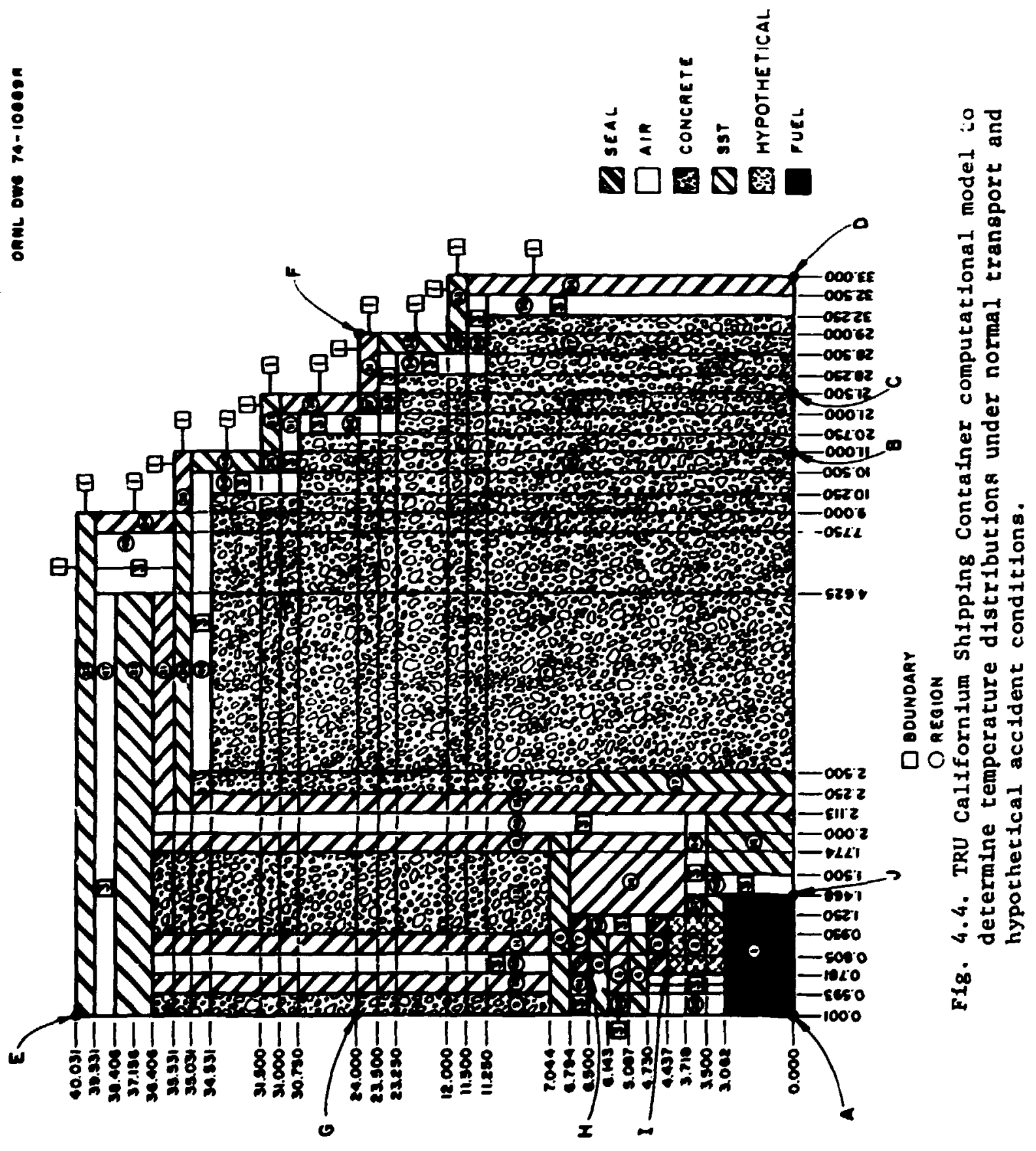


Throughout the entire test period. the mid-point temperature of the cask remained almost constant. Following the fire. the outer parts of the cask cooked rapidly: after $3 \mathrm{hr}$. the maximum calculated tenperature in the cask was $345^{\circ} \mathrm{F}$. located approximately in the top inner plug platc. It is apparent that the inner container fuel contents will remain at its equilibrium temperature which. from Table 3.2 would be about $110^{\circ} \mathrm{F}$. Such temperatures will cause no problems to the contents: nor will it have any significant (degrading) effect on the seals of the inner containers. Consequently. if the cask is subjected to the high-temperature thermal environment. it is capable of withstanding it with no loss of contents and. therefore. tueets this part of the regulations.

\section{CONTAINMENT}

Sources and other shipments are confined inside the inner cavity of the TRU Californium Shipping Container in either a special-form or a $2 R$ container. These containers-their uses and inspections-are described below.

\subsection{Containment Boundaries}

The containment boundaries for the shipping options available with the Californium cask are (a) the cask cavity seaked by its gaskets (Figs. 1.2 and 1.3 ) and (b) ar inner container that meets either $2 R$ specifications or special form requirements. Any material carried in a $2 R$ container will be enclosed in a welded capsule. In all cases. there will be at least one welded seal between the source and the cask cavity.

\subsection{Special-Form Shipments}

The welded encapsulation provides primary containment for all special-form shipments (see Figs. 5.1 - 5.3) for examples of special-form encapsulations). If the material is doubly encapsuiated. the outer welded capsule provides secondary containment. Visual inspection of these lines of containment are peiformed on a routine basis. and the welds are radiographed. The cask seals form an additional line of containment. The cask is equipped with gasketed closures which are teak-tight during normal transpor. An accident might result in a rupture of the seals, but the contents in their primary containers would remain in the cavity.

\subsubsection{Special-form ronntainers}

The ORNL Operations Division is authorized by Laboratory management to certify that a mat: rial conforms to the special-form requirements of Appendix D of 10 CFR Pan 71. ${ }^{\text {is }}$ The tests prescribed have been performed on a number of capsule designs. When a capsule is similar in design to a capsule previously tested (i.e., in relation to size, mass. wall thicknesses. materials, weld, etc.), the design is certified as passing the special-form requirements based on previous test results. If this similarity does not exist, it is required that a prototype be tested as prescribed. 


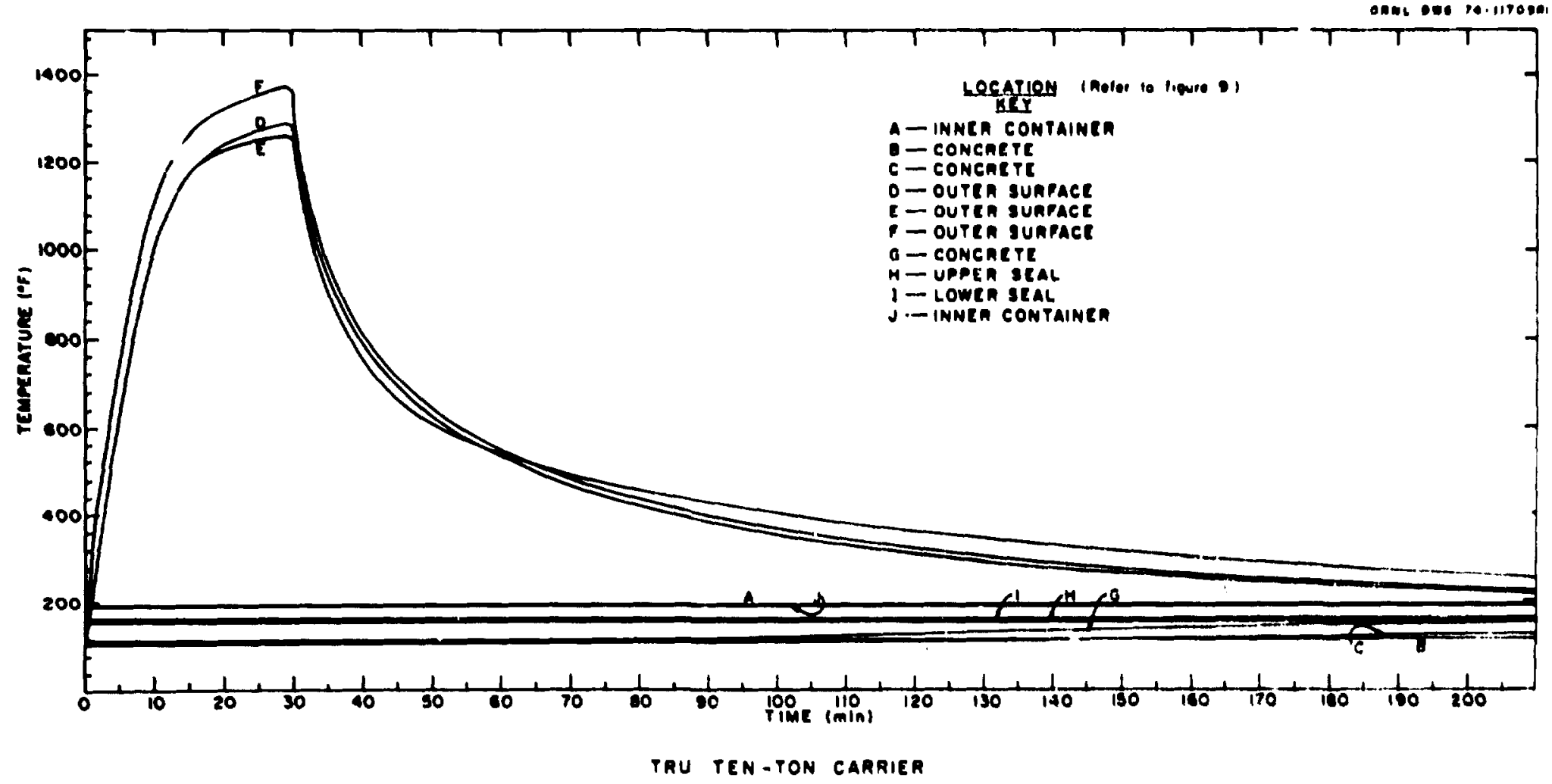

F18. 4.5. Temperature distribution in the TRU Californium shipping Container during and after the thermal portion of the hypothet ical accident. 


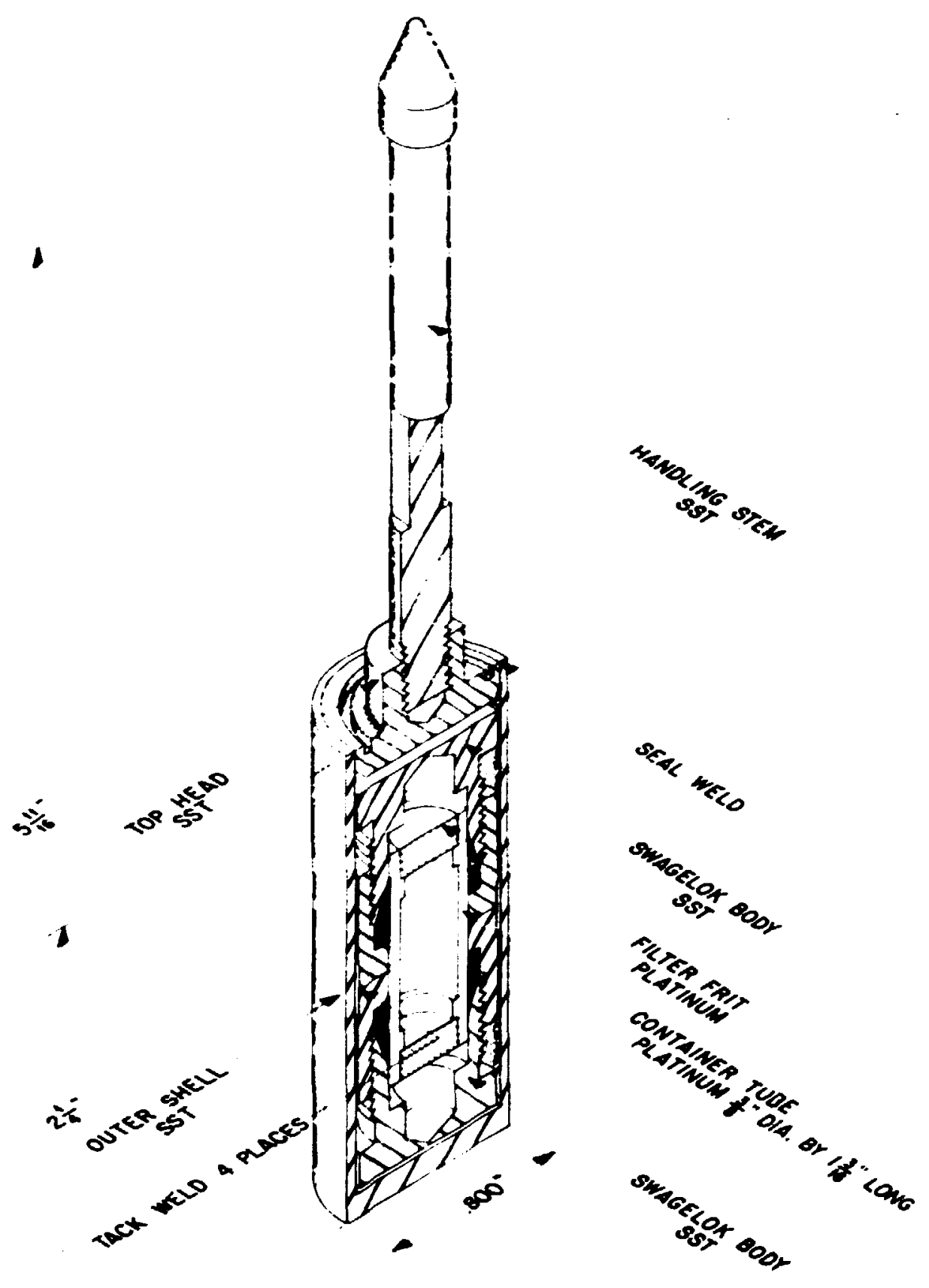

1

ASSEMBLY FOR TRU SHIPMENT OF ${ }^{252} \mathrm{Cl}$

(FOR DETAILS SEE DRAWING $M-12175-C P-335-D$ )

Fig. 5.1. As8embly for TRU shipment of ${ }^{252} \mathrm{Cf}$ (for detalls see Drawing M-12175-CP-335-D) - a typlcal speclal-form inner contalner. 


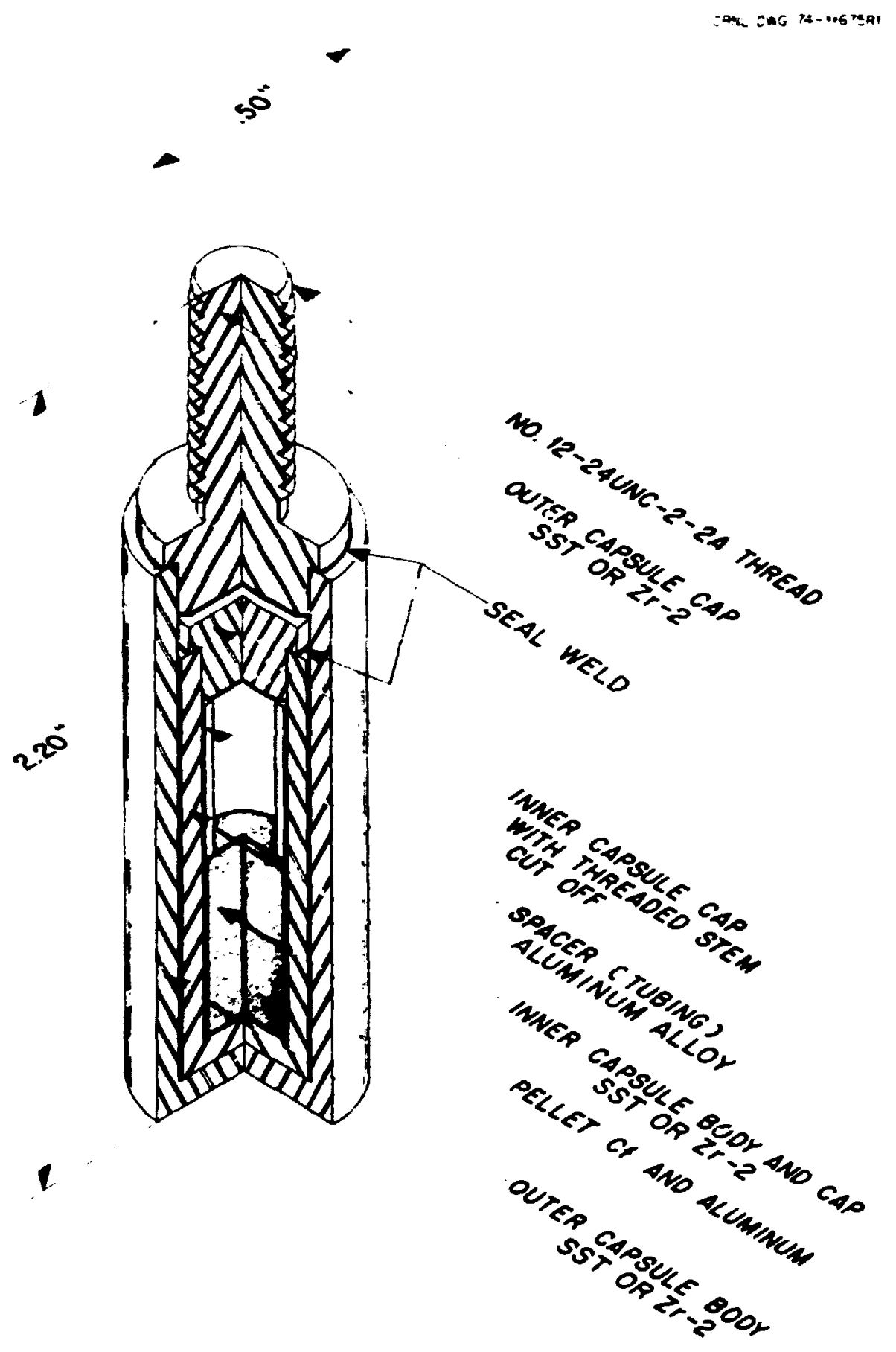

STANDARD NEUTRON SOURCE CONTAINER

( FOR DETAILS SEE DRAWIH,G $\mathrm{m}$-12175CP-636-D)

Fig. 5.2. Standard neutron source container (for detalls see Drawing M-12175-CP-636-D) - a typical special-form inner container. 
ORNL DWG 74-11668R2

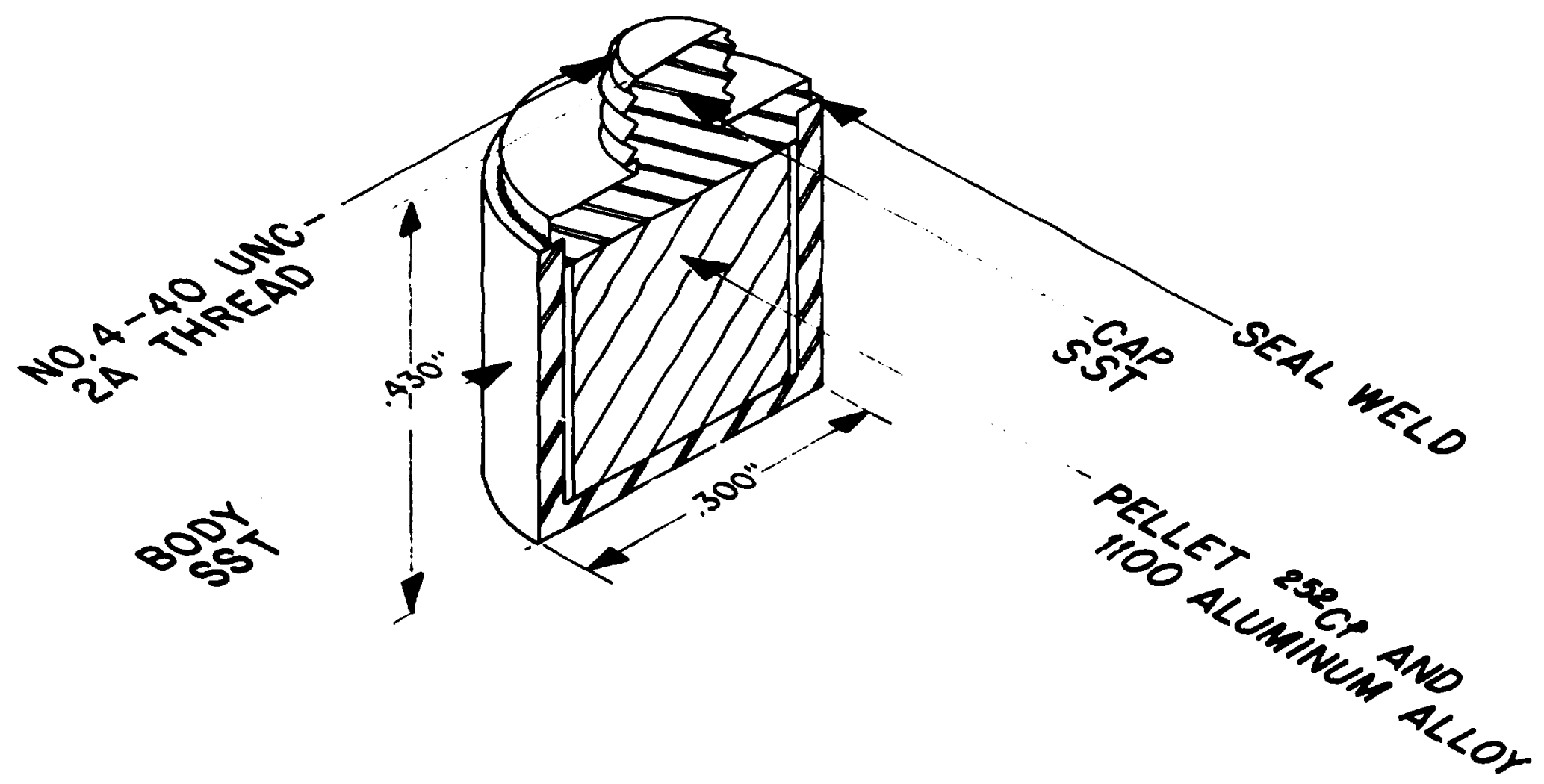

SPECIAL NEUTRON SOURCE CAPSULE - NS - 65 (FOR DETAILS SEE DRAW M-12175-CP-637-D)

Fig. 5.3. Special neutron source capsule - NS-65 (for details see Drawing $M-12175-C P-637-D)$ - a typical speclal-form inner container. 


\subsubsection{Specification $2 P$ containers}

Specification $2 R^{16}$ inner containers (shown in Fig. 5.4) may be used with the TKI Californium Shipping Container. These will be made from pipe and pipe fittings or tube and tube fittings. Wall thicknesses and closures will be made in accordance with Specification $2 R$.

Fabrication will be in accordance with ORNL Quality Assurance Procedures. Applicable approved ORNL procedures will be used for welding. All welds will be appropriately inspected in accordance with approved ORNL weld inspection procedures.

\subsection{Centainment Requirements for Normal Conditions of Transport}

The test sequence for containers of special-form materials is more severe than for those with normal conditions of transpon. The pressure increases that are encountered will be less than those experienced in the thermal test for special-form materials. No loss of primary coolant (air) is expected.

The $2 R$ containers, housing a welded capsule, are designed for pressures and temperatures in excess of those encountered in normal transport. No releasi of radioactive material. loss of coolant (air), or contamination of coolant should occur.

\subsection{Containment Requirements During the Hypothetical Acciden:}

The test series for special-form containers demonstrates that special-form encapsulation will not fail or leak contents as the result of the free falls. The thermal test temperatures of special-form containers exceed those experienced by the inner cavity contents during the hypothetical accident (see Sect. 4.3.3); hence no release will occur during the thermal exposure. The water immersion test for special form is identical to that specified in the hypothetical accident conditions.

The $2 R$ containers, housing a welded capsule, are designed for pressures and temperatures in excess of those encountered in the hypothetical accident.

\section{CRITICALITY}

The analysis for the single container given below is adequate for an infinite array of similar containers because the concrete shielding assures essentially no interaction.

\subsection{Evaluation of a Single Package}

A study" has been made of the criticality of californium and other transuranium elements under conditions of optimum moderation and wates reflection. Californium-251 had the smallest critical mass $(10 \mathrm{~g})$. The quantity of isotopes to be carried by this cask is limited in 3 8. Approval of the use of this cask for that quantity of fissile material has been granted hy Nuclear Safety Review 750 (see Sect. 9.2). 
ORNL Dwg 74-11718

R-I

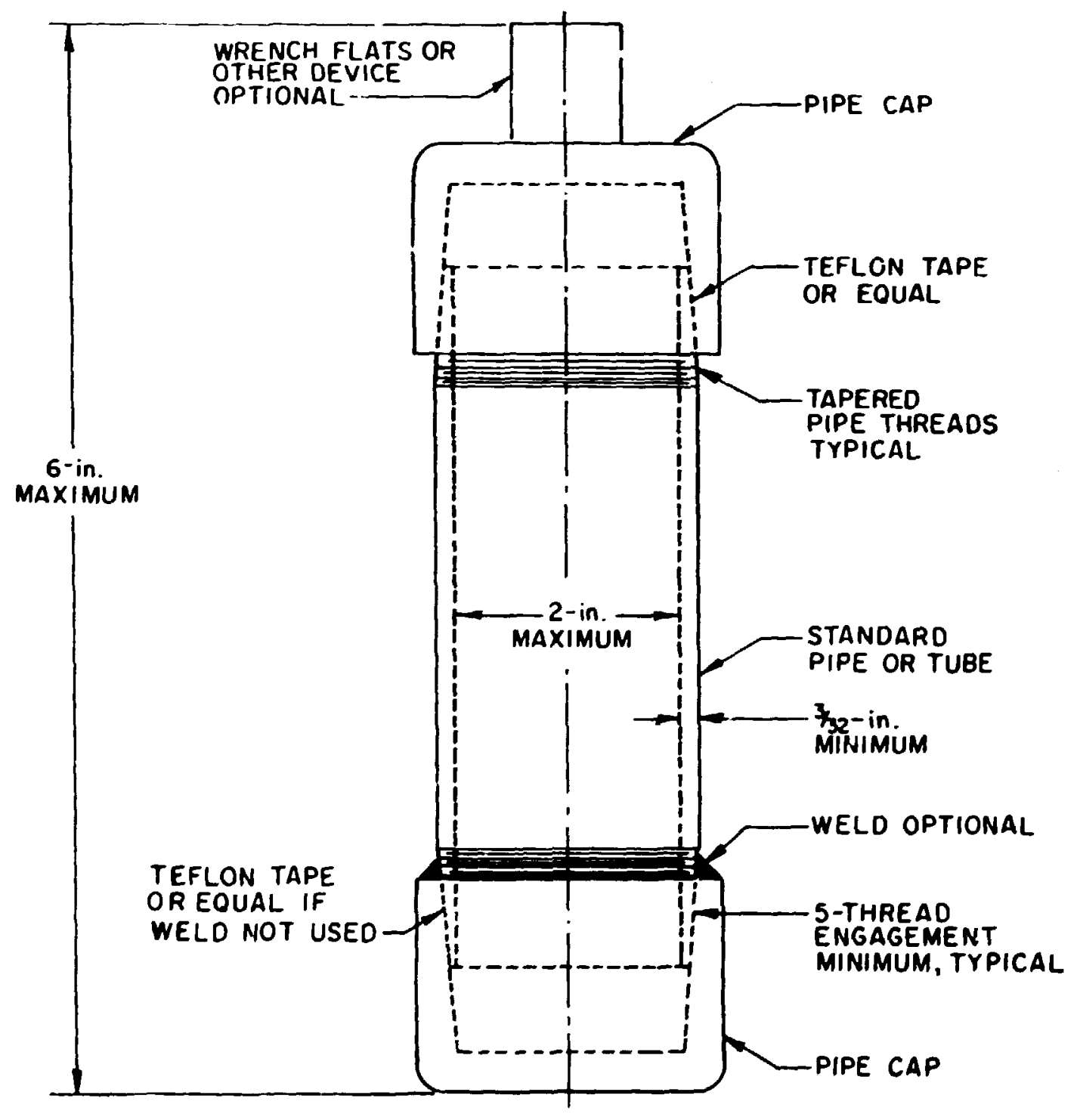

F18. 5.4. Typical pipe-element Specification 2R inner container. 
Since the quantites of fissionable isotopes carried is below all minimum critical masses for these isotopes under optimum moderation and reflection, and since the cask effectively isolates the contents from neutron interaction with packages of similar design. unlimited numbers could be stacked together without creating a criticality problem. Thus the package is adequate for Fissile Class I shipments.

\section{SHIELDING EVALUATION}

\subsection{Discussion and Results}

The TRU Californium Shipping Container is designed with its cavity surrounded by a l-in. thickness of stainless steel and a 1/2-in.thick outer spherical shell. The shielding cavity between the two is filled with limonite concrete to a nominal thickness of $30 \mathrm{in}$. The shielding effectiveness has been checked with transuranium sources and found to be adequate. A 44-mg (1.7-W) ${ }^{252} \mathrm{C}$, source produced a reading of $7 \mathrm{mrem} / \mathrm{hr}$ gamma at a distance of $6 \mathrm{ft}$ from the cask surface. In this case, the drivers compartment registered tess than $1 \mathrm{mrem} / \mathrm{hr}$. The cask contents will be limited to the source that will not exceed the allowable radiation dose limits of the DOT regulations. The shielding effectiveness will not be reduced by the hypothetical 30-ft drop accident, concrete fractures in an intergranular manner providing a labyrinthine pathway for radiation, allowing no possibility of radiation streaming.

\section{QUALITY ASSURANCE}

\section{I Fabrication, Inspection, and Acceptance Tests}

The fabrication of this container was performed in the shops of the Oak Ridge National Laboratory in accordance with normal shop fabrication procedures and prior to the adaption of a formal quality assurance program by the DOE and ORNL. Material was specified on the original drawings as "304L SST." Material was withdrawn from Bill of Materials Stores stock. The casks were inspected by ORNL Shop Inspection Department personnel for conformance to the drawings, quality of workmanship, and compliance with welding requirements when fabricated. In the opinion of the inspecting personnel, the weldments were made in accordance with the drawings and specifications. This is further supported by the fact that the casks have operated for 6 years without failures or loss of effectiveness. The routine operating inspeciion procedures specify periodic weld inspections to verify weld integrity.

A formal quality assurance program has now been prepared" and future shipping containers will be constructed in accordance with provisions set forth in this program. 


\subsection{Operating Procedures and Routine Inspection}

The Transuranium Processing Plant. Chemical Technology Division, has established operating and routine inspection procedures and standard checklists to ensure that all shipments are safe and that they comply with DOE regulations as well as all ORNL procedures and regulations. A copy of typical procedures and checklists are presented in Sect. 9.4 .

\subsection{Periodic Maintenance and Inspection}

Inspections are required prior to each shipment or biennially (see Sect. 9.4). Maintenance will be required only when routine inspections indicate damage. 
9. APPENDIXES 
9.1 Appendix A: Drawings Associated with the TRU Californium Shipping Container

Title

Drawing No.

Page

Shipping Carrier Assembly

M-11230-EN-001-D $\quad 58$

Shipping Carrier Velment

M-11230-EN-002-D 59

Shipping Carrier - Detail Sheet No. 1 M-11230-EN-003-D 60

Shipping Carrier - Detail Sheet No. 2 M-11230-EN-004-D 61

Shipping Carrier - Detail Sheet No. 3 M-11230-EN-005-D 62

Shipping Carrier - Detail Sheet No. 4 M-11230-EN-006-D 63

Shipping Carrier - Detail Sheet No. $5 \quad$ M-11230-EN-007-D 64

Shipping Carrier - Detail Sheet No. 6 M-11230-EN-008-D 65

Shipping Carrier Trailer Modification M-11230-EN-012-E Assembly

Shipping Carrier Trailer Modification Tie Down Details

M-11230-EN-014-E 67

Modified Plug to Handle Multiple Items

M-11230-EN-017-D 68

Shipping Carrier Trailer Modifications Radioactive Sign Mounting Bracket

$M-11230-E N-018-E \quad 69$

TRU Ten-Ton Californium Shipping

Container

M-12166-CD-019-D

70 


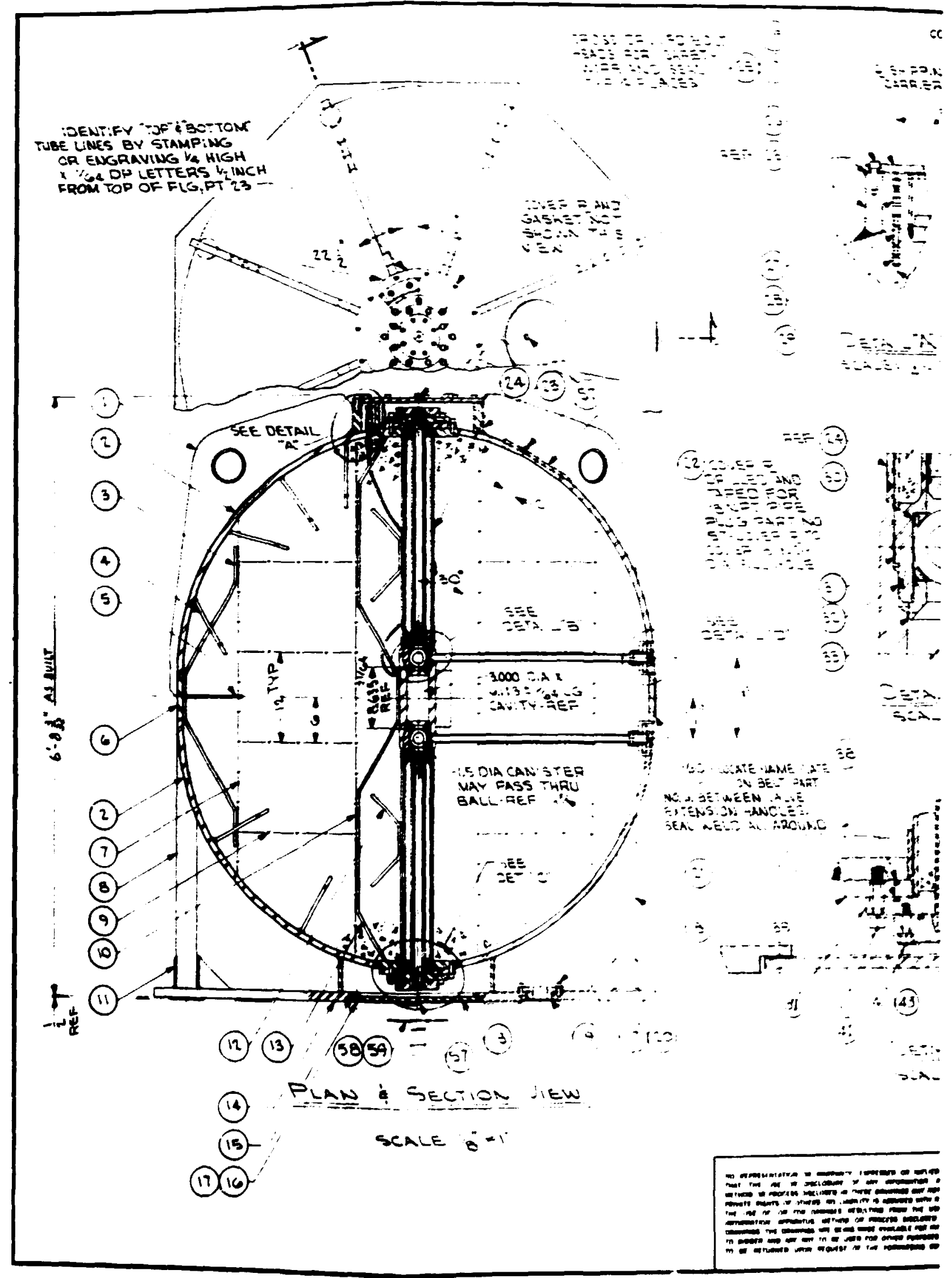




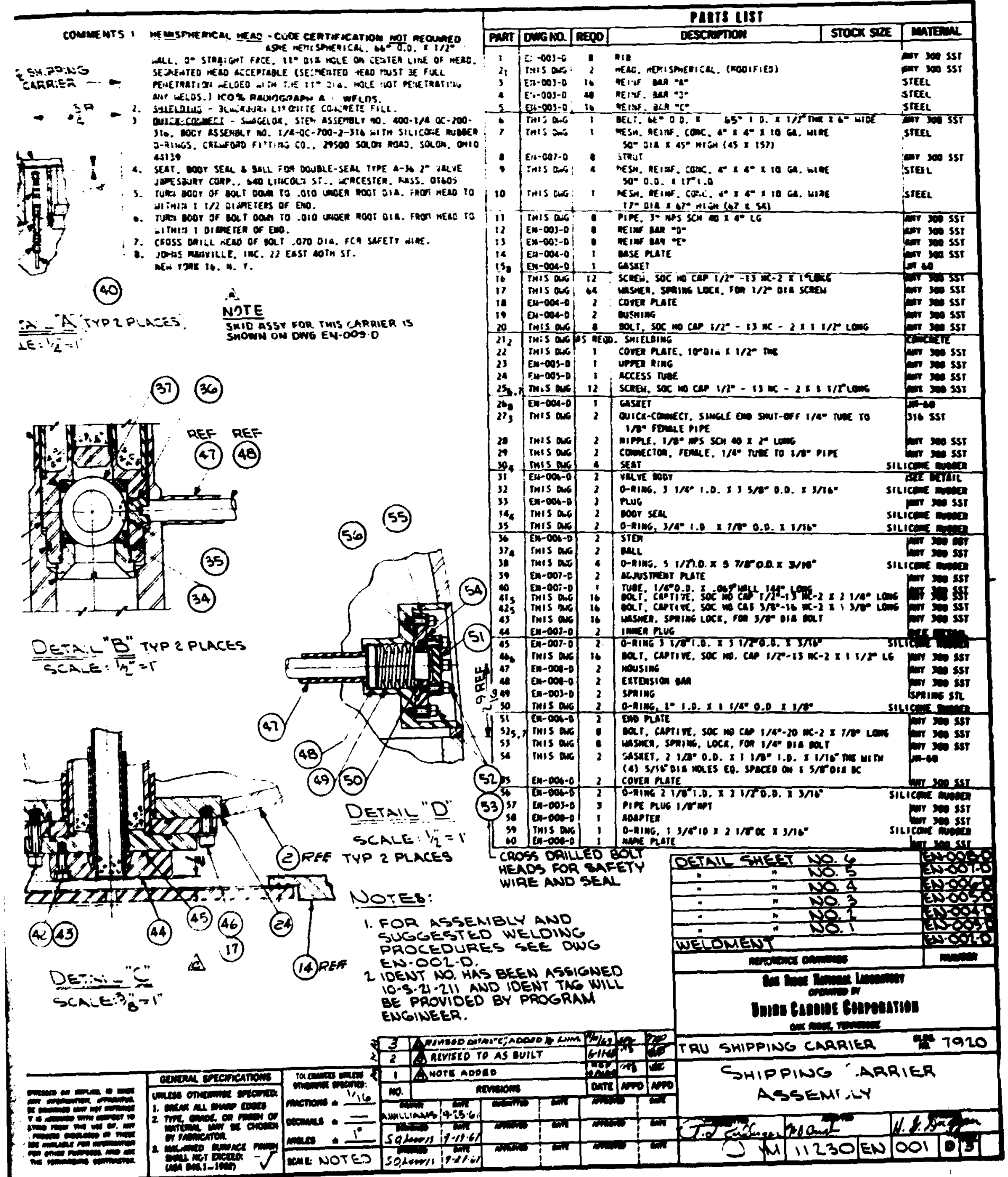




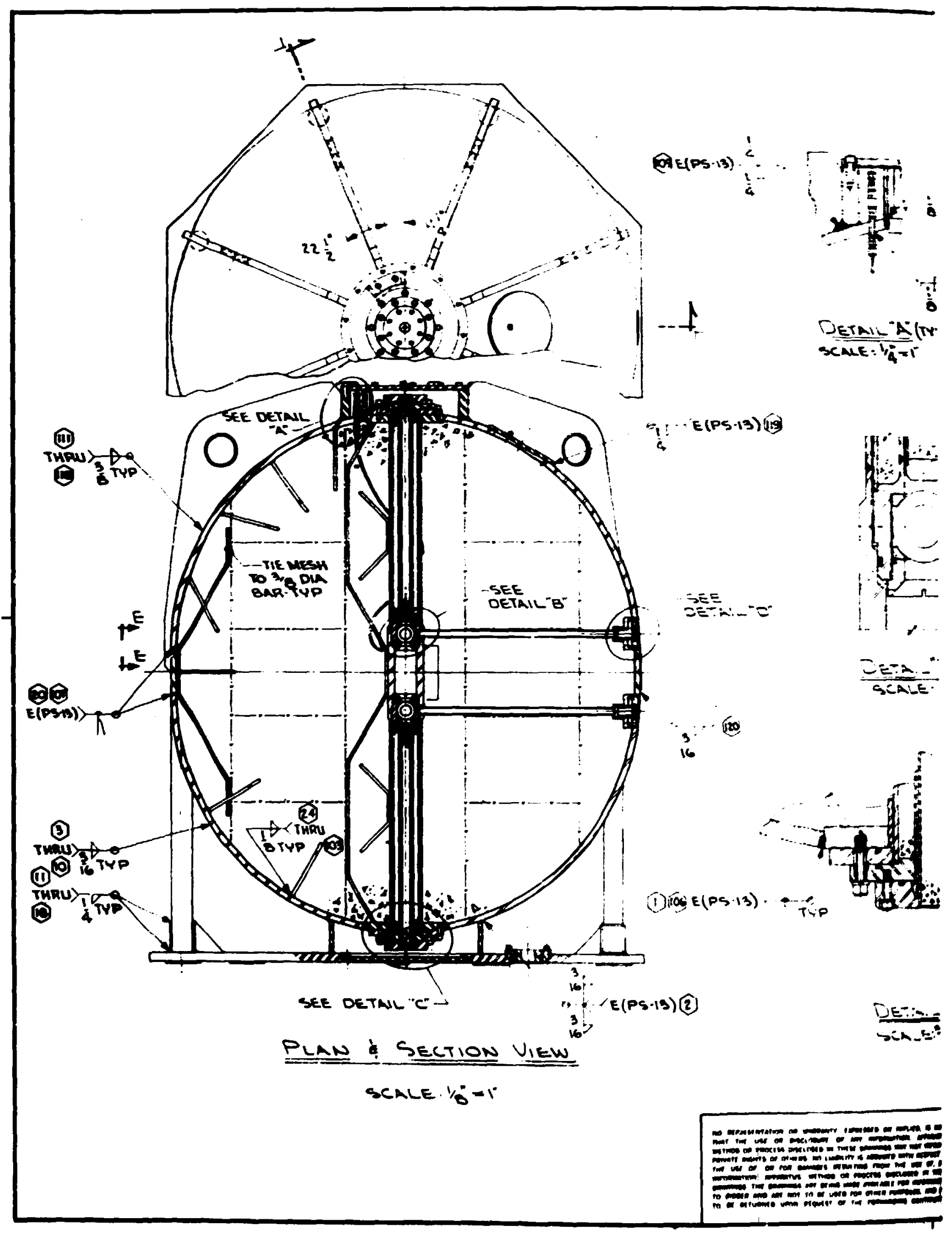




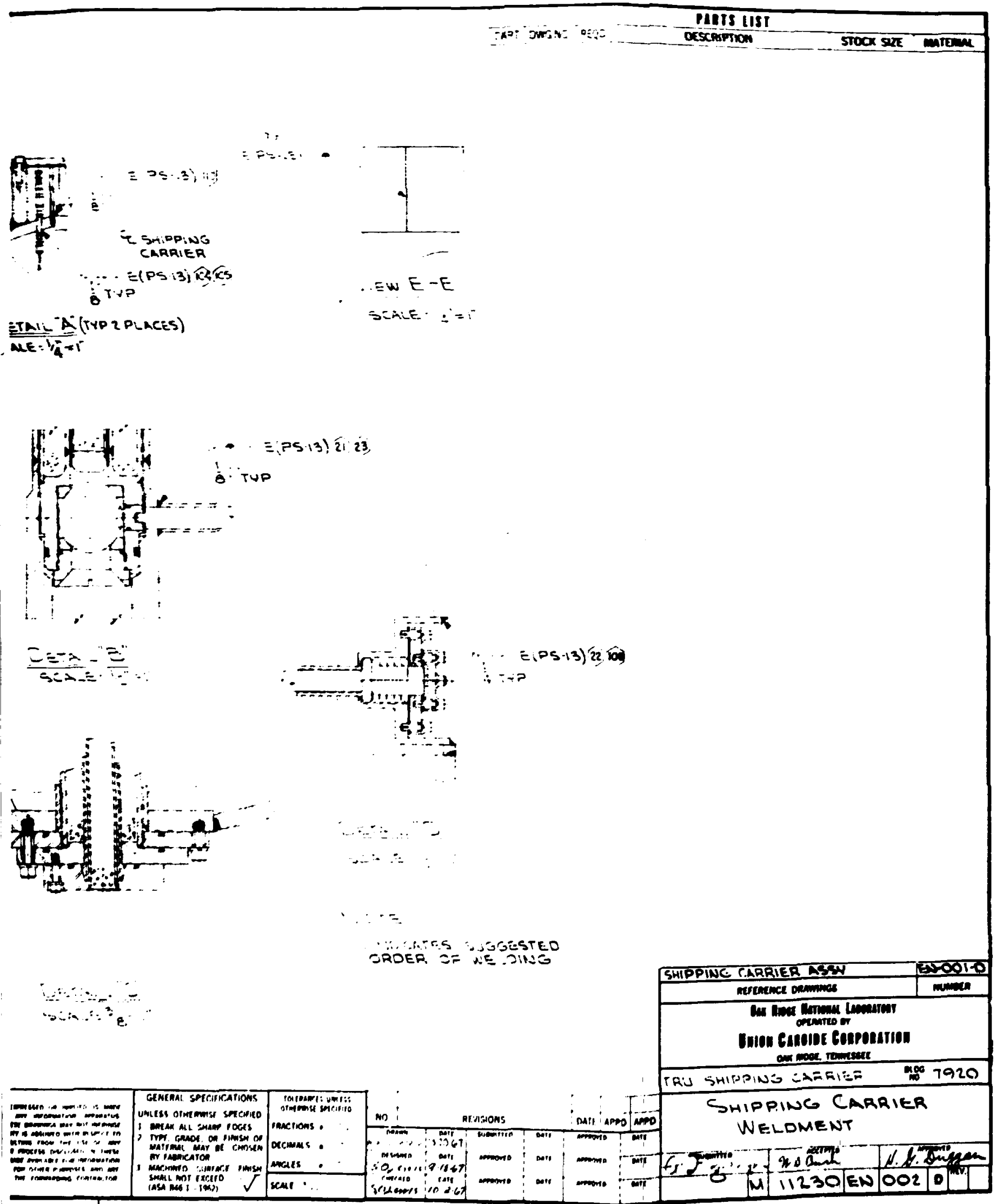




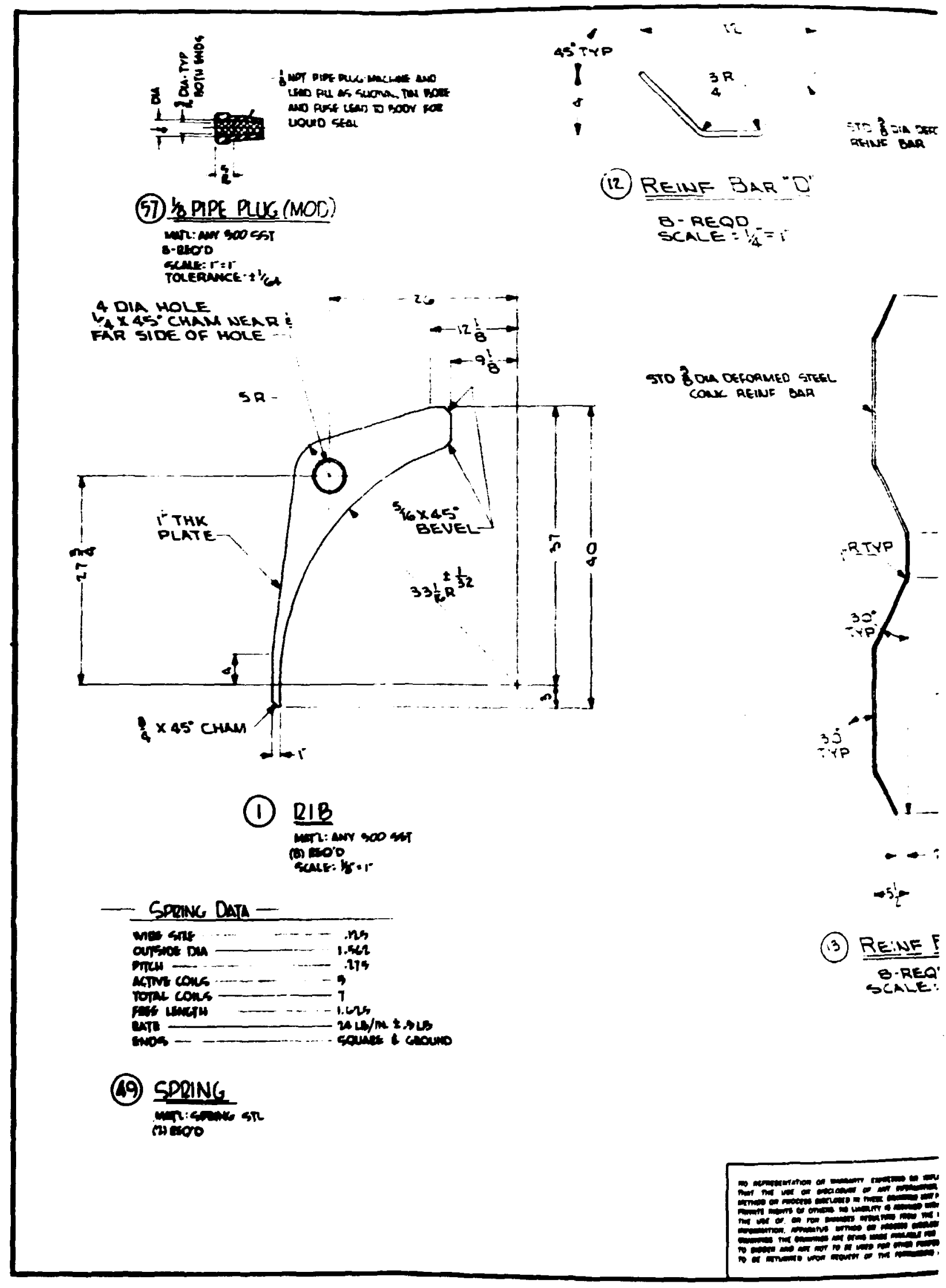




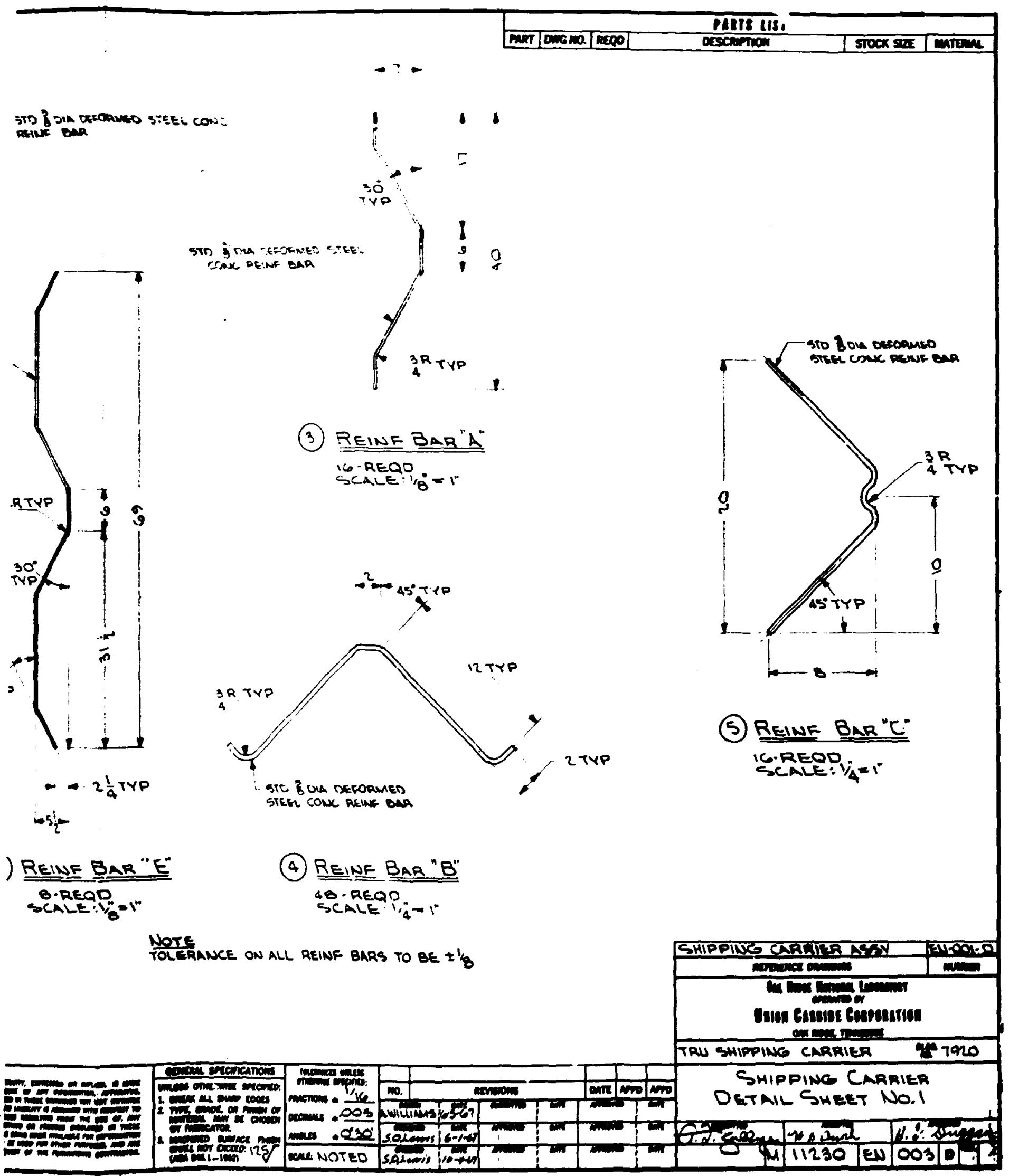




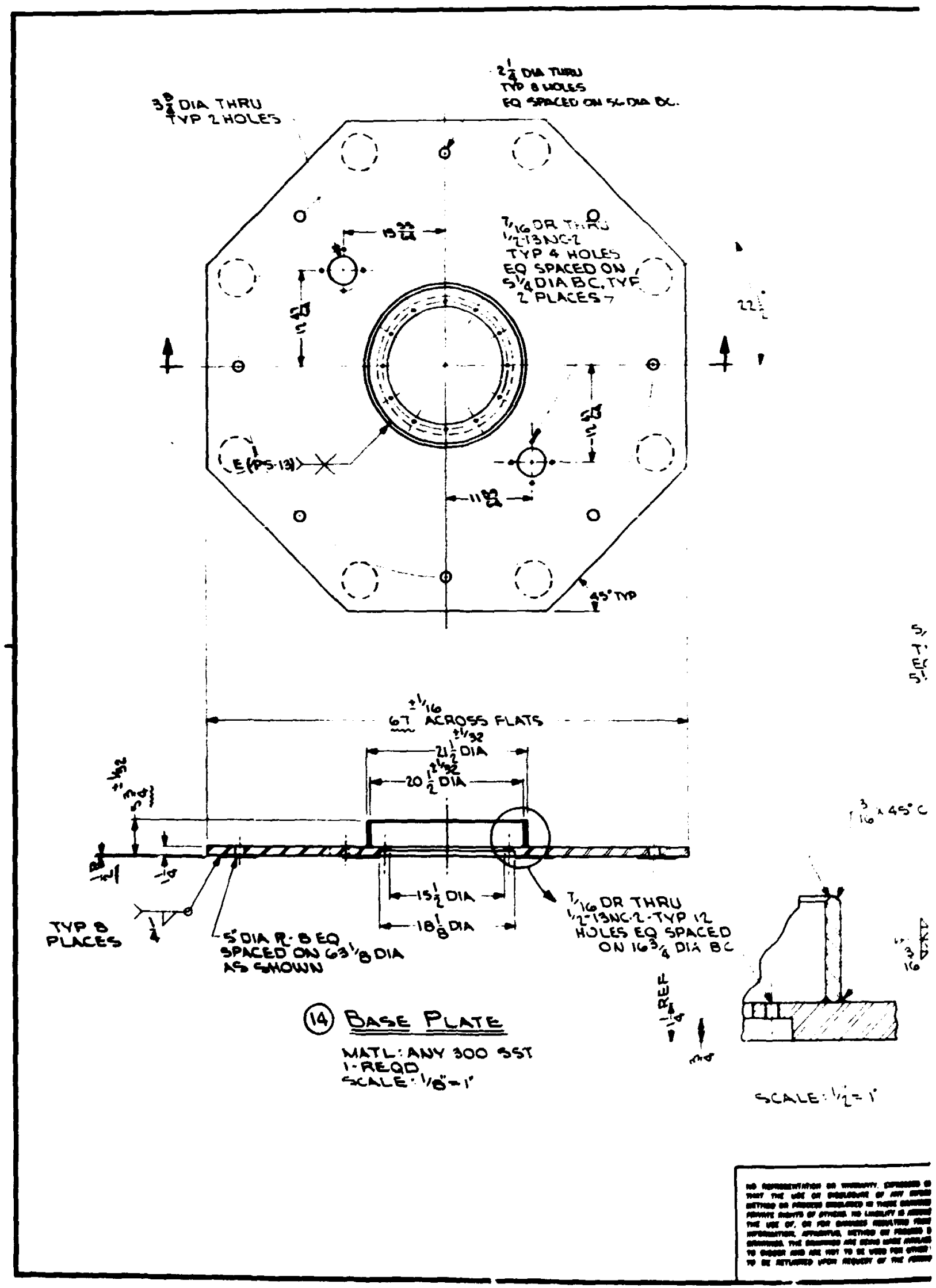




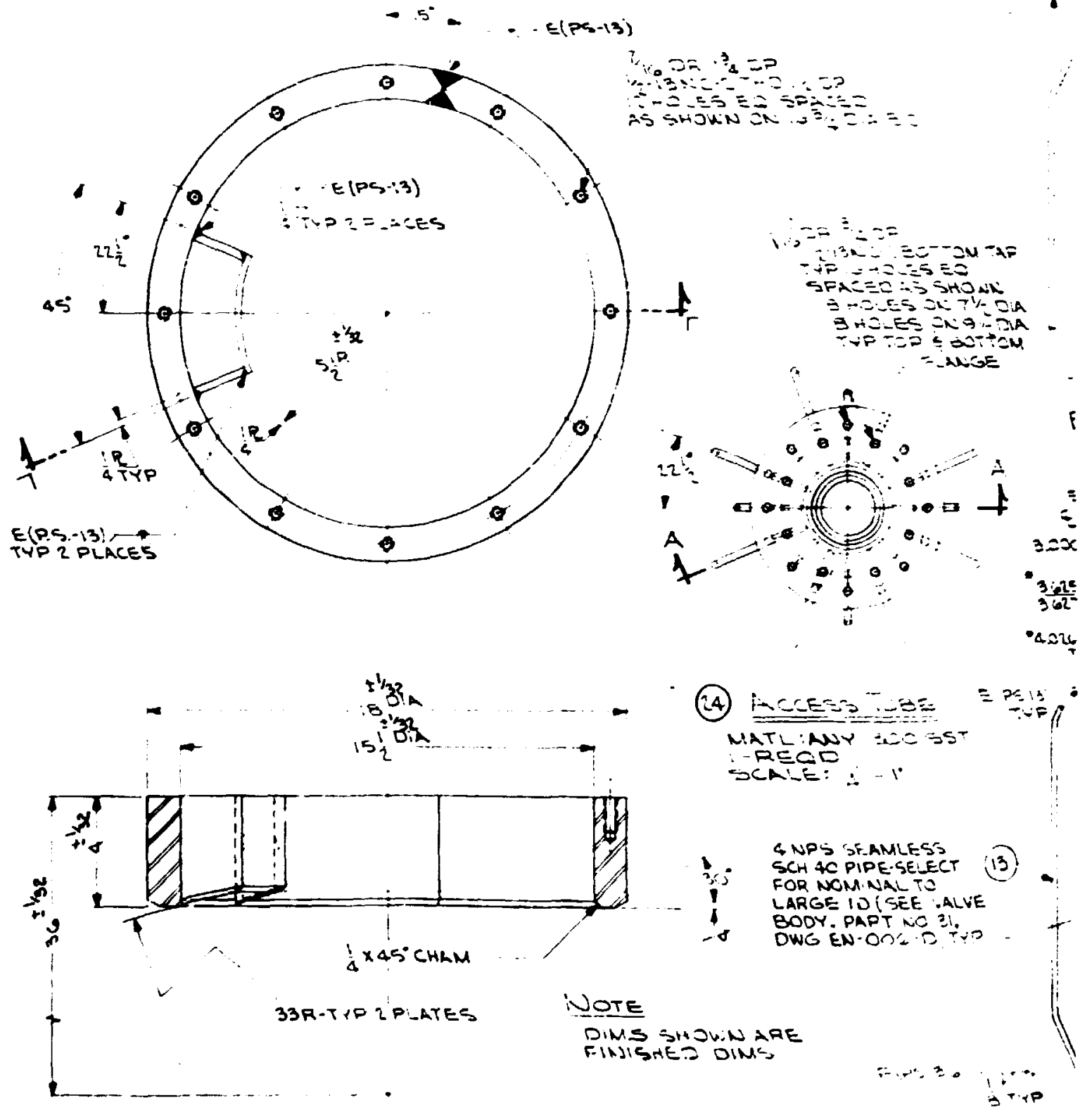

(23) UPRER Rine MATL:ANY 300 SST I.REOD

SCALE $3 / 8 \%=1$ 


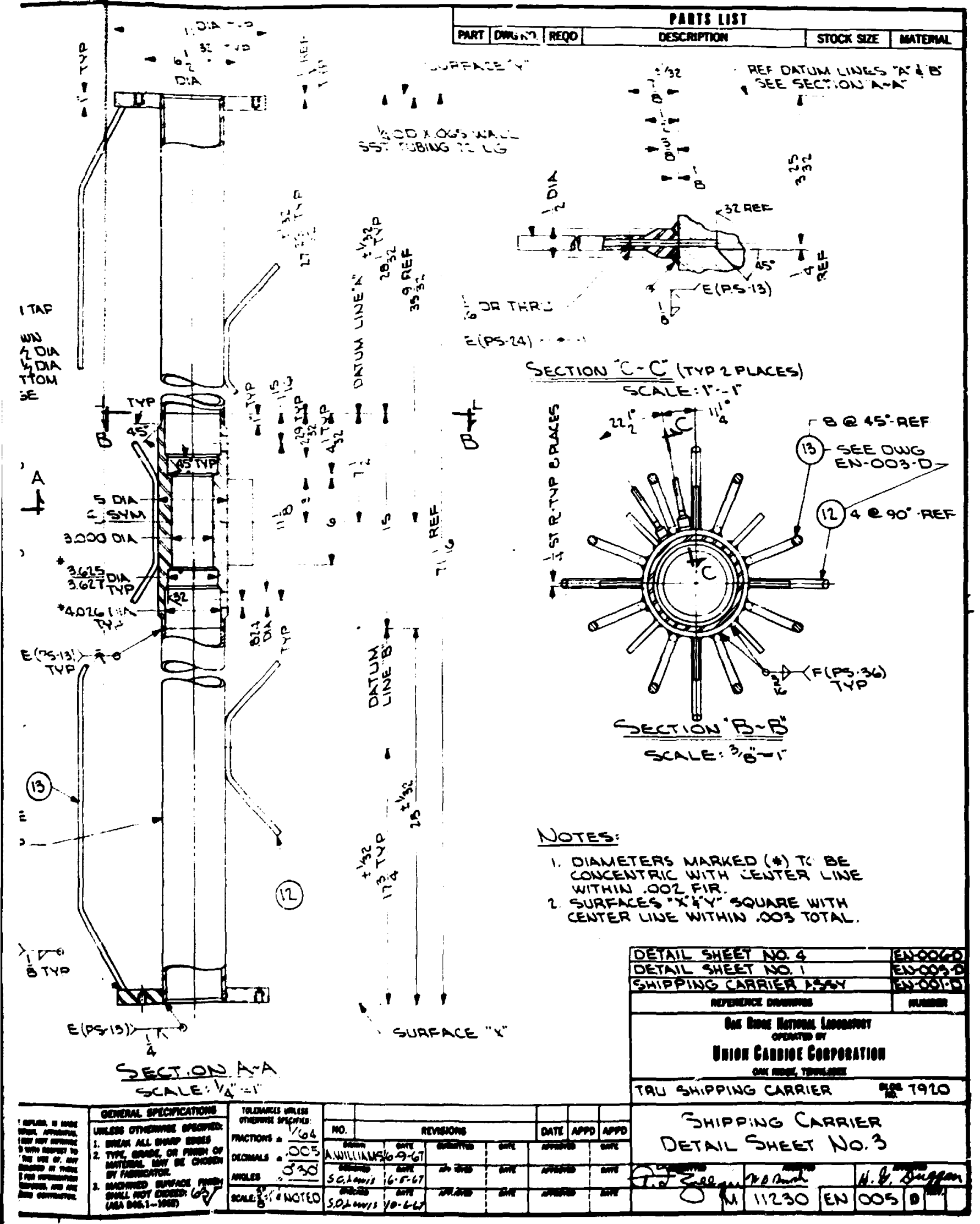




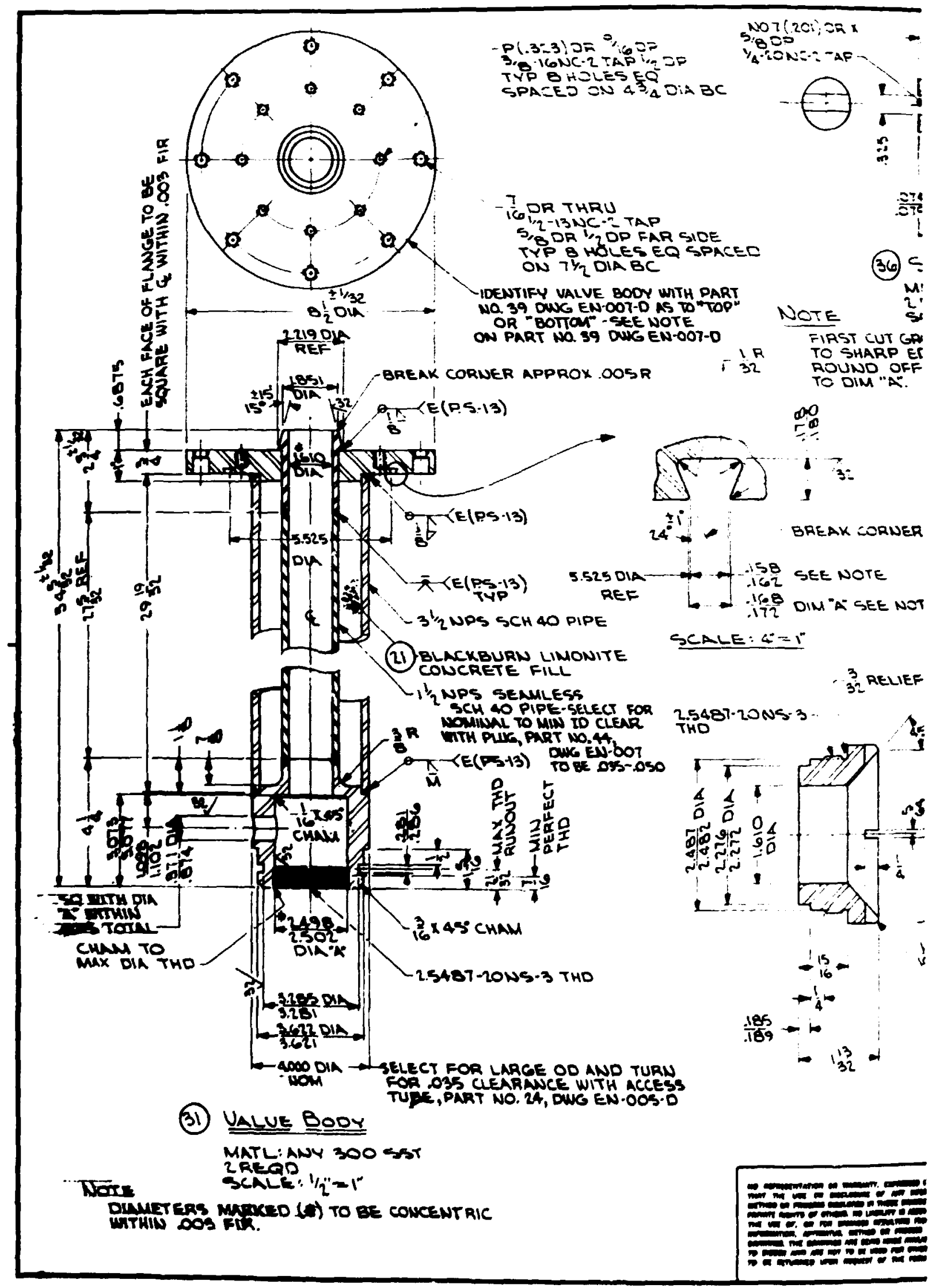




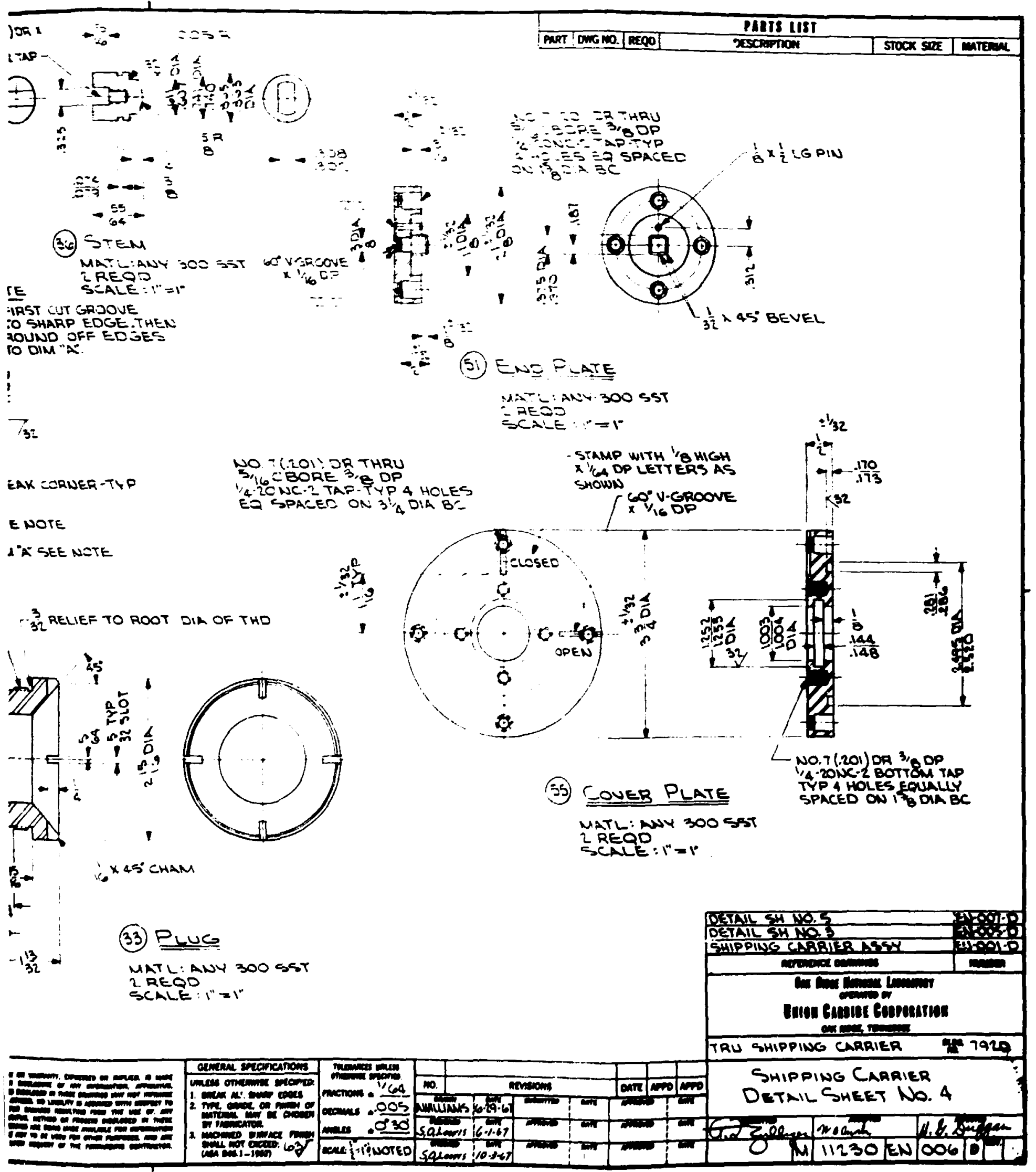




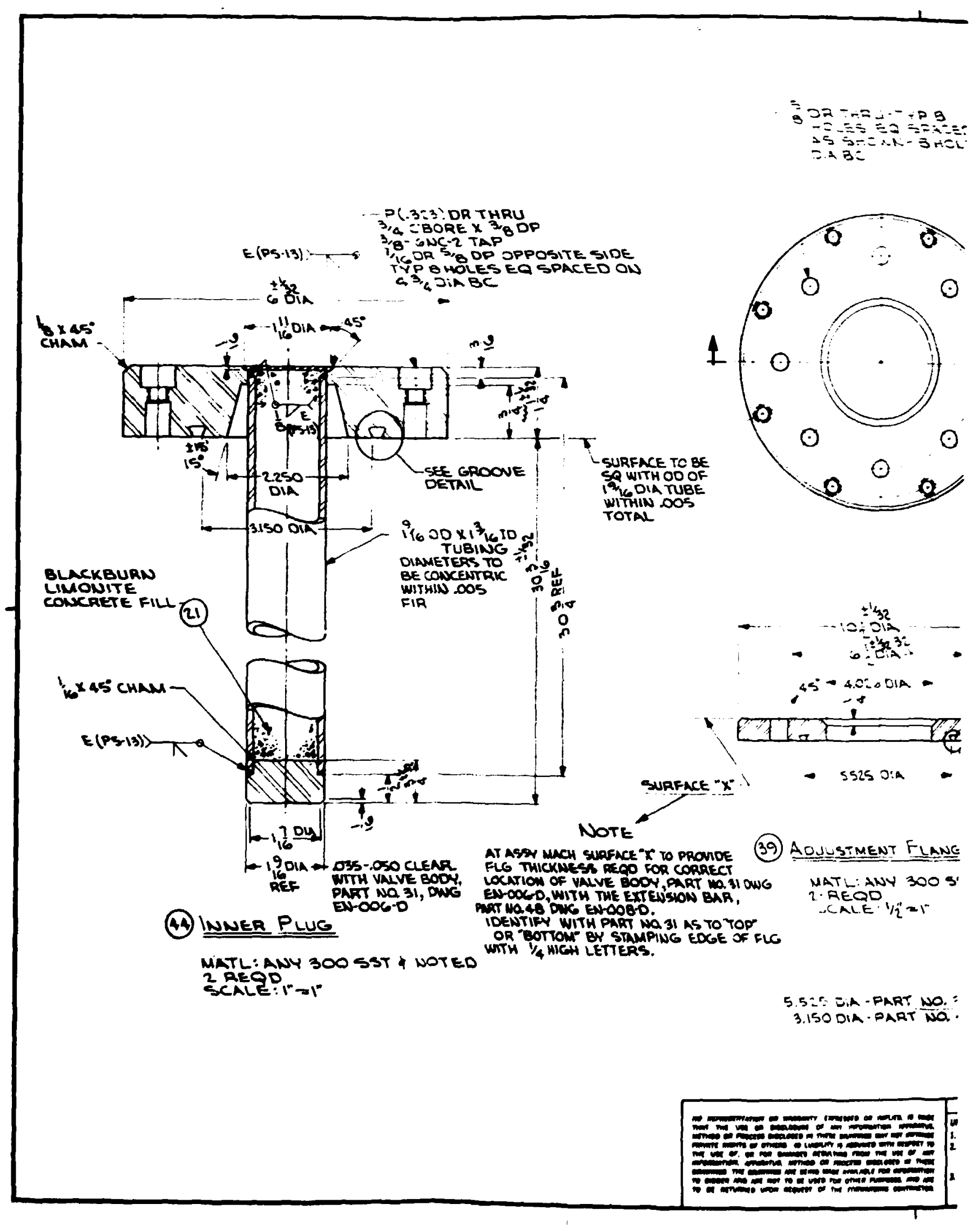




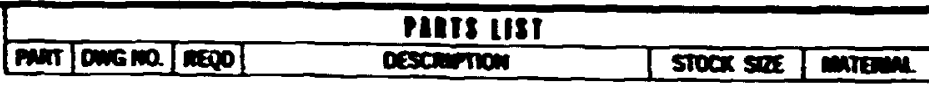

RU-TYPE

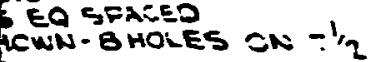

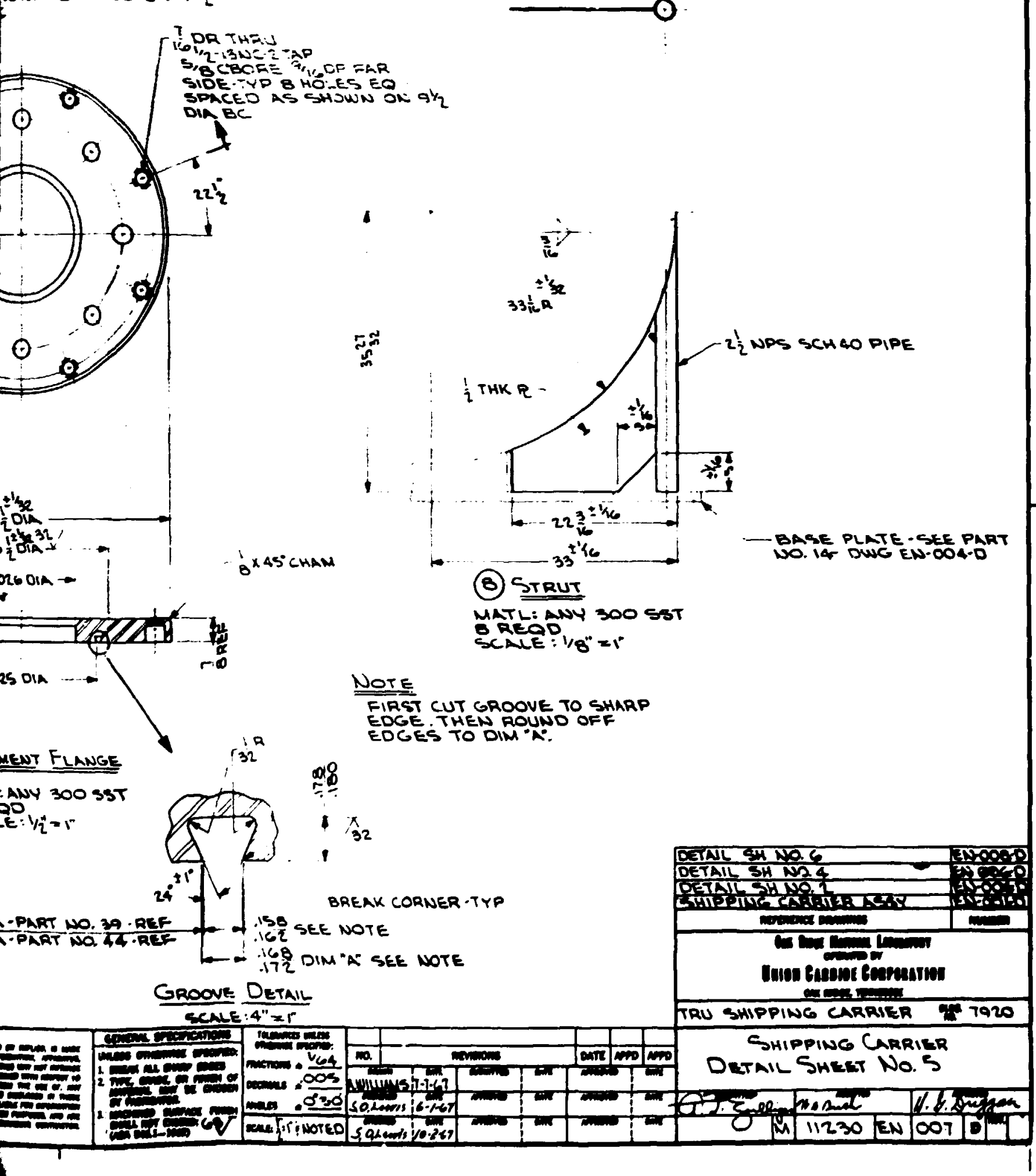




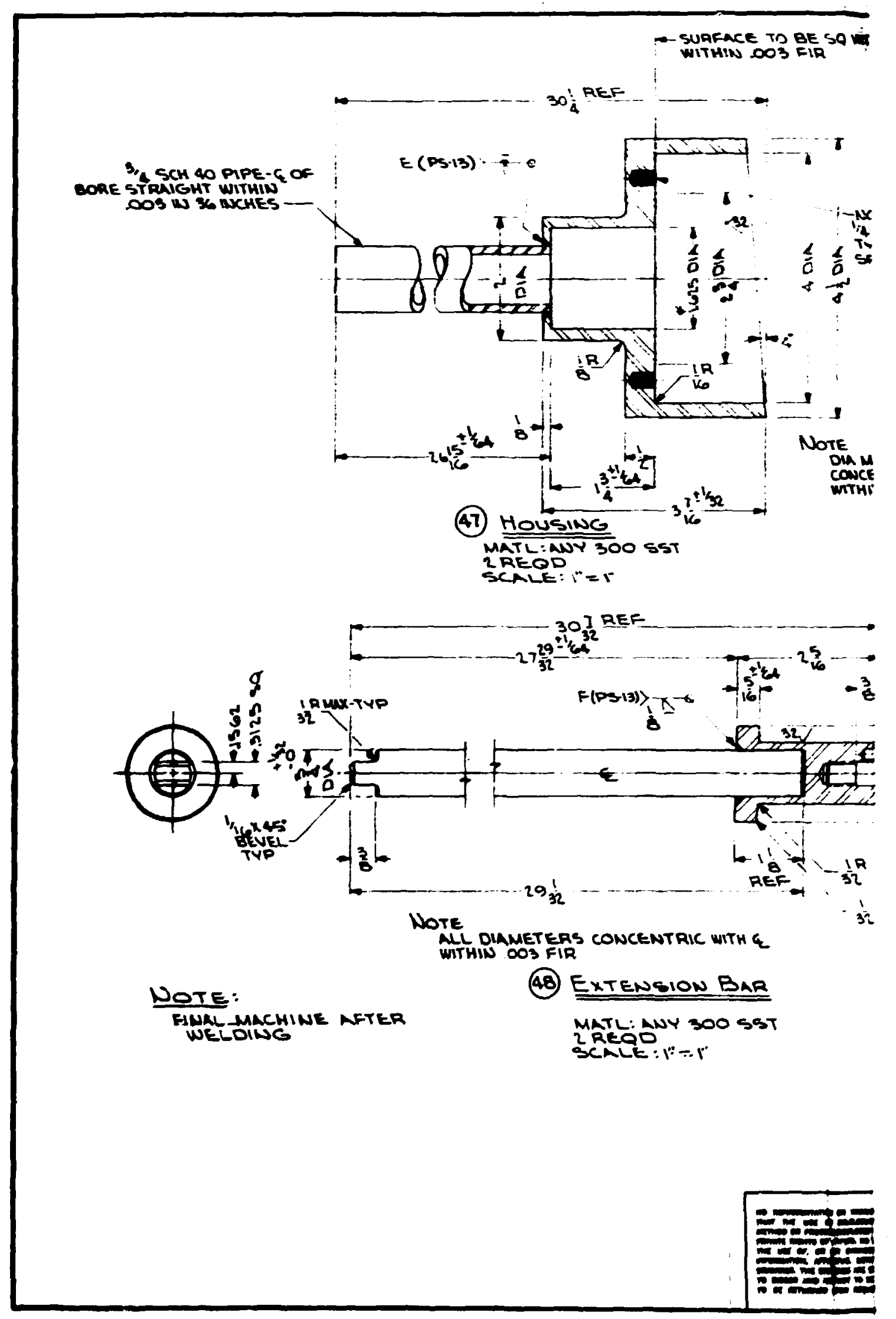


${ }_{n=1 R} B E \leq=w . T+t$

$=1$

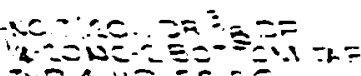

$1 \quad V=44=-\equiv S E=$

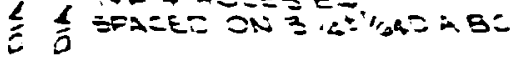
$2 \frac{1}{8}$

6

$-1$

Note

DA MAAKED (4) TO BE

CONCENTRIC WITHE

WTHM) .003 FIR
RIRTS IIST

oescreption stock Ste mane
OETAIL "A"

SCALE:I" $=r$

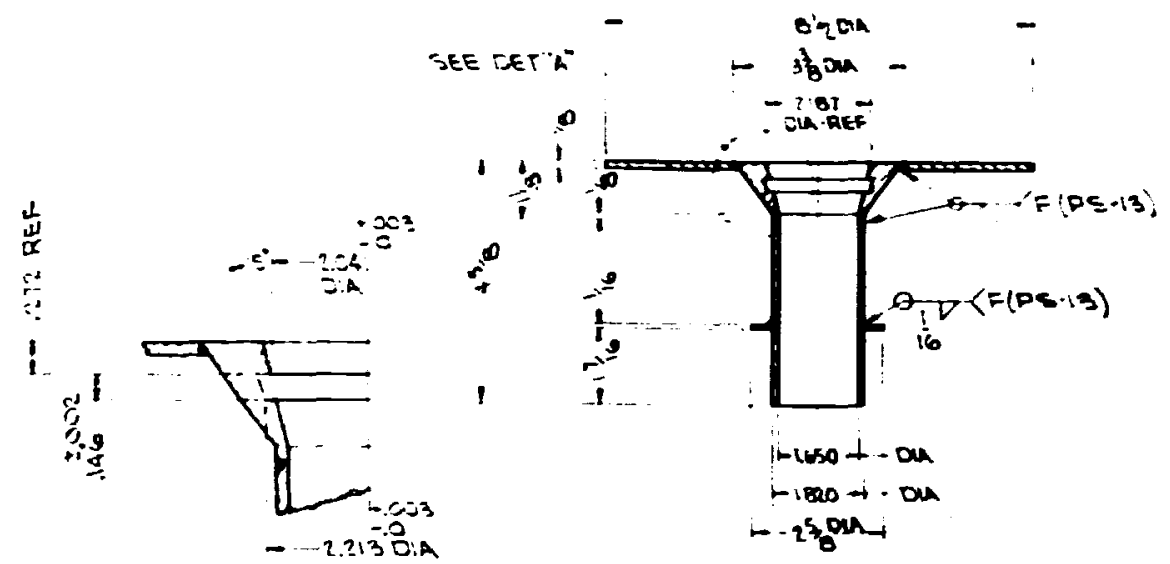

(58) ADAPTER

MATL: ANY 300 SST

1.REQO

SCALE: $1 / 2=1$
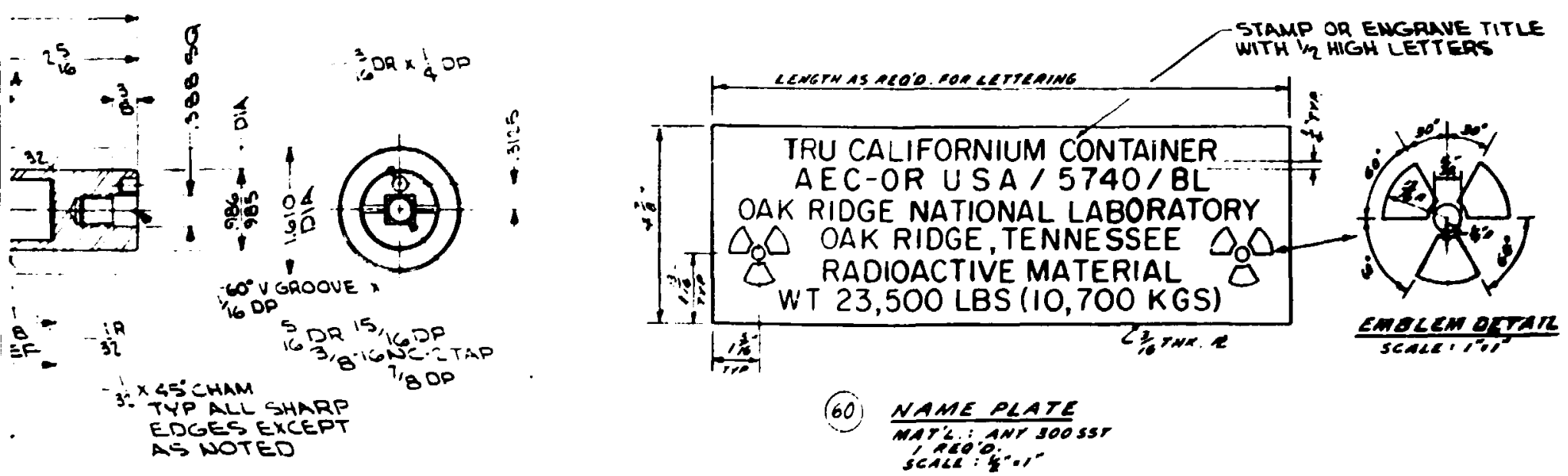

$\vdots$

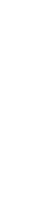




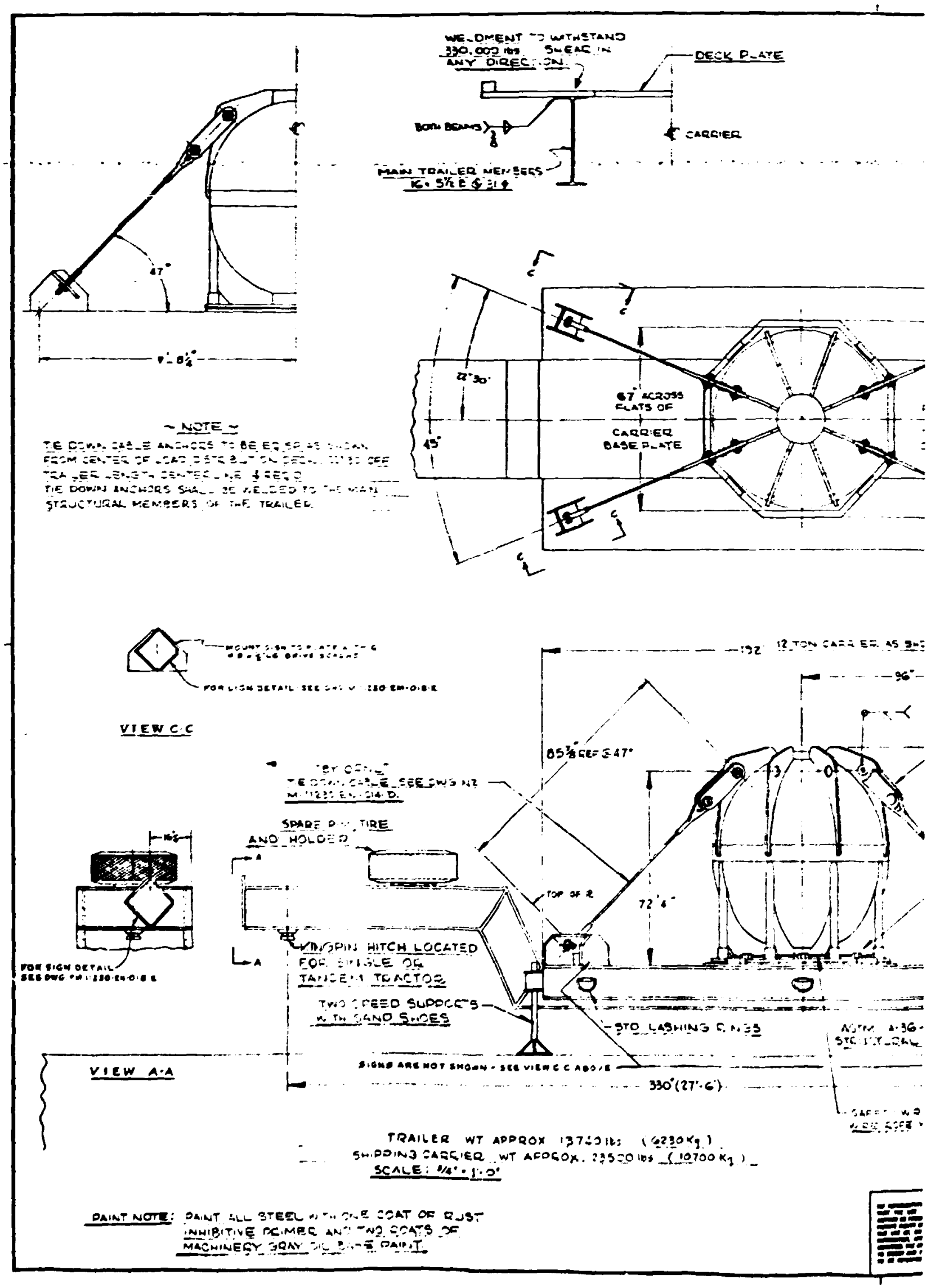


* MOIE: FOQ CETKLLS OK TQALER JEK PATE-

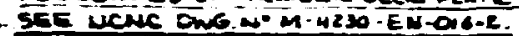

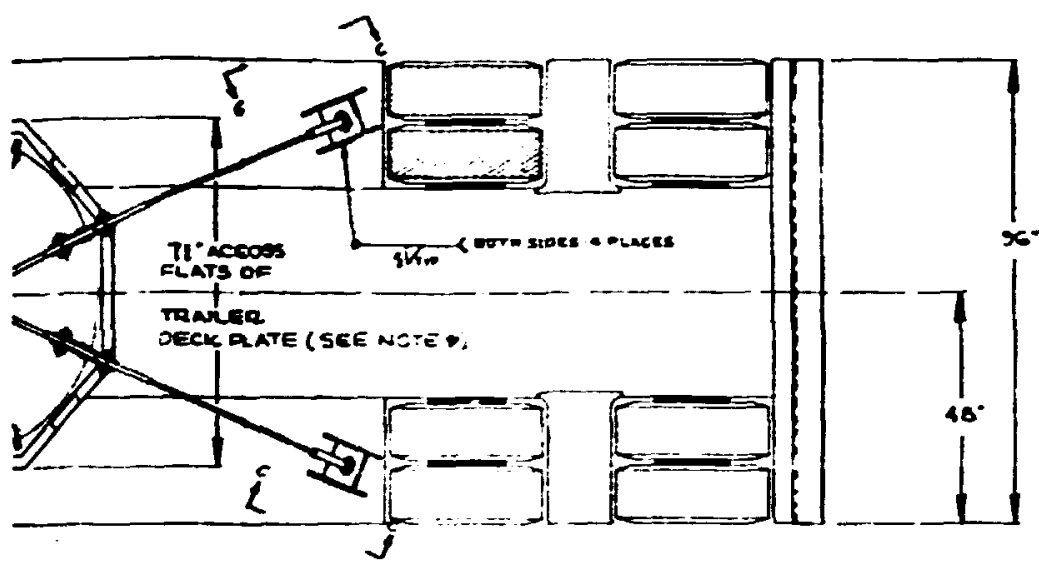

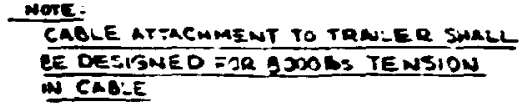

MOTE: THE COWNS SABLE NUTS AND ANCHOC DOTS

SHAL EE TIGHTENED TO 330 ET LES T2R?

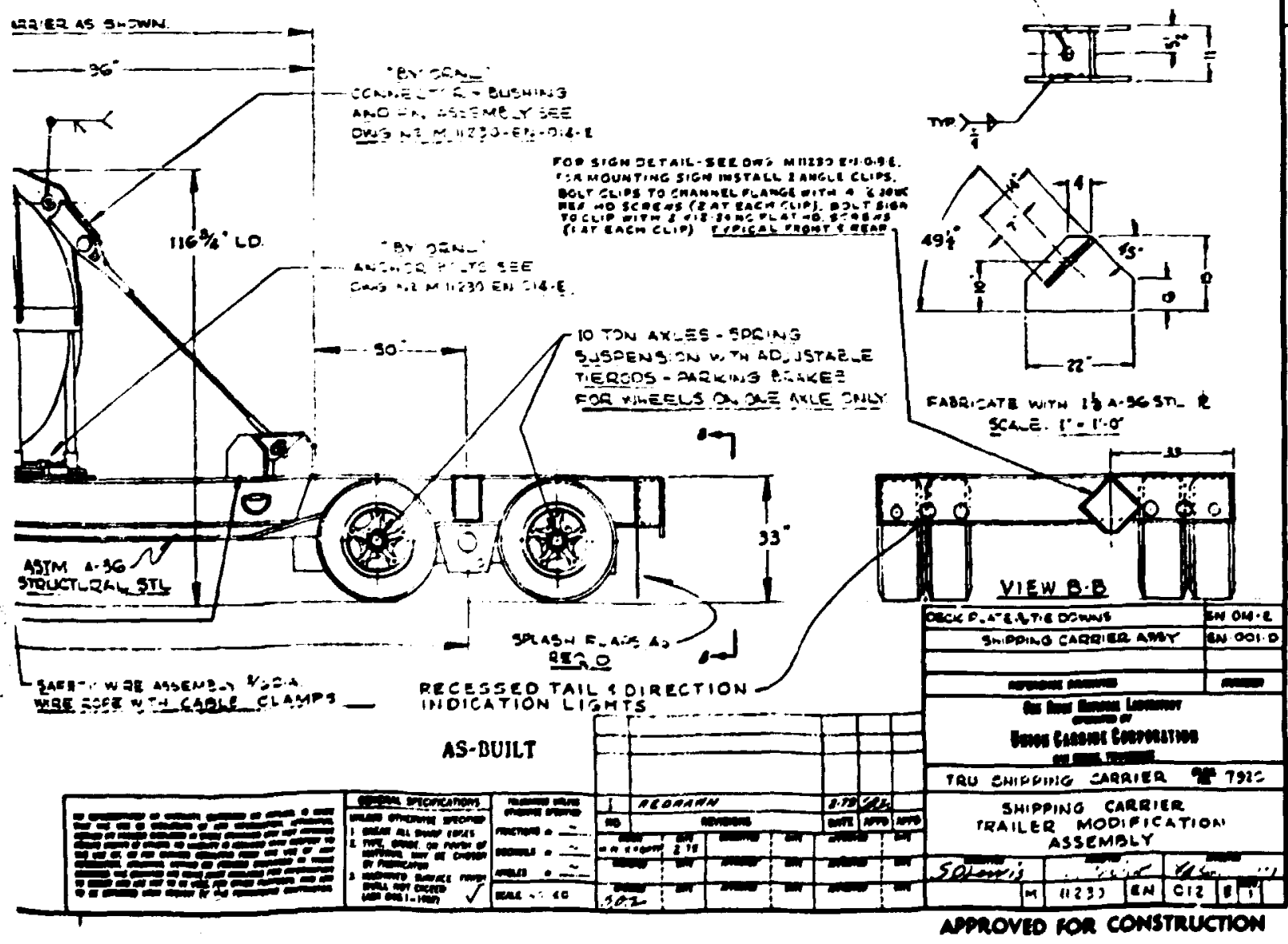



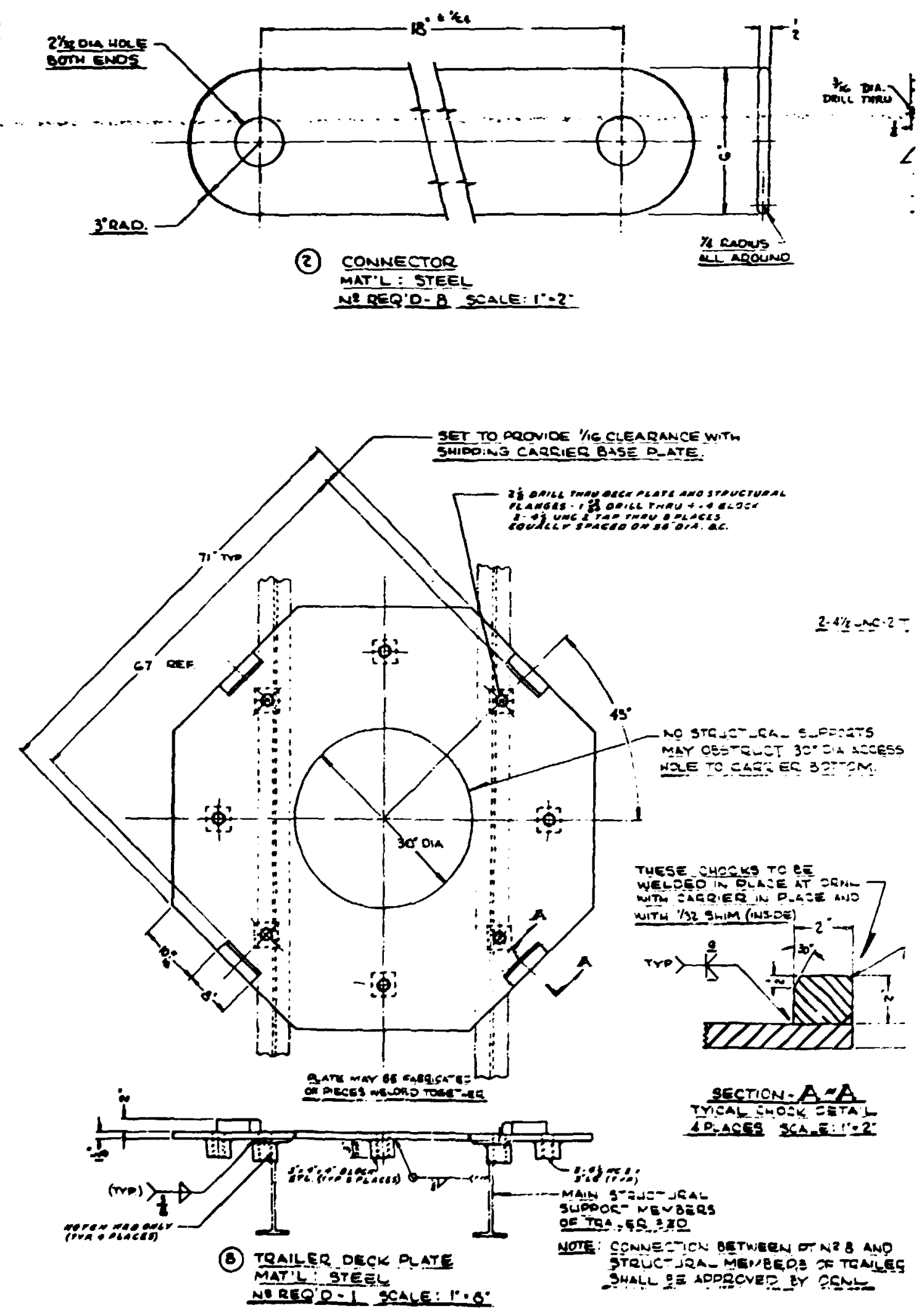

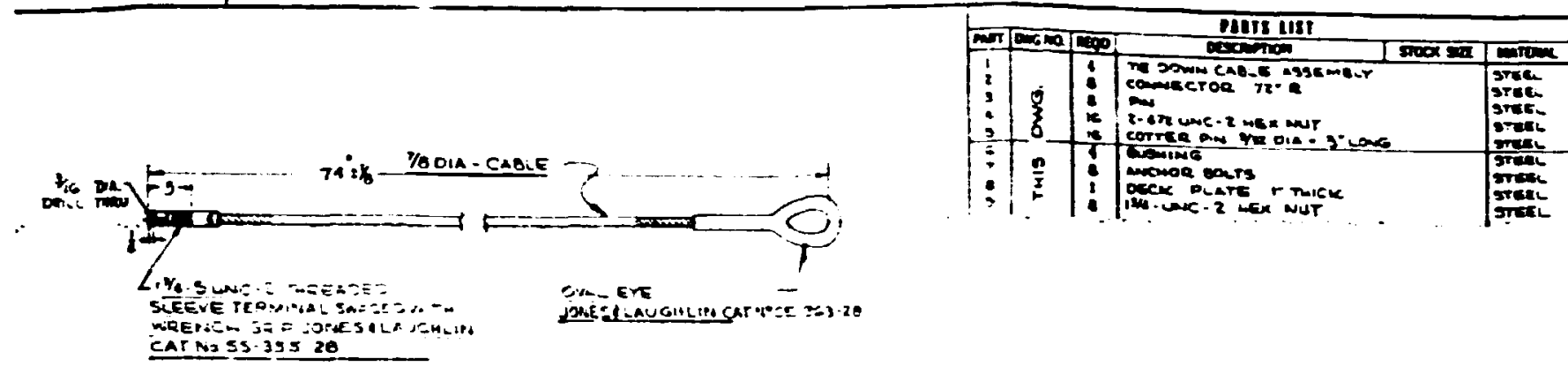
(1) TEDewn $=x z-\equiv$
MAT L STEE

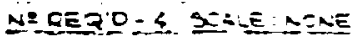
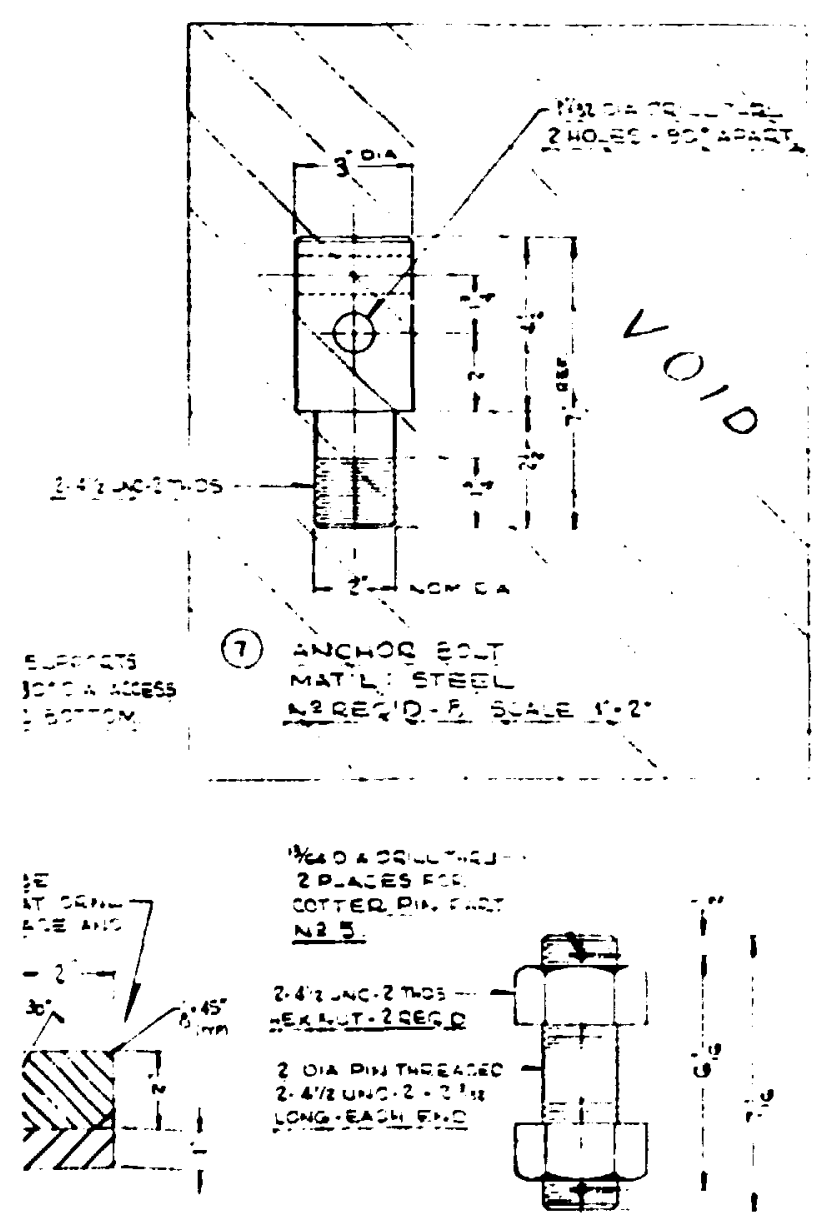

$\frac{C-x}{x=-4}$

$x+x=2$

(3) Din Asseprastr MATL - MLE STEENERESD. 8 SELE. T.?

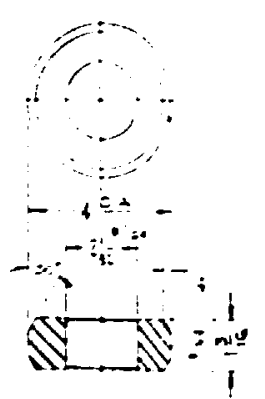

$6, \quad 34 h+3$

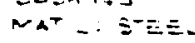

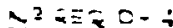

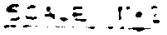

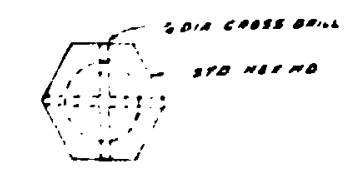

II TAUEe

er $251=$
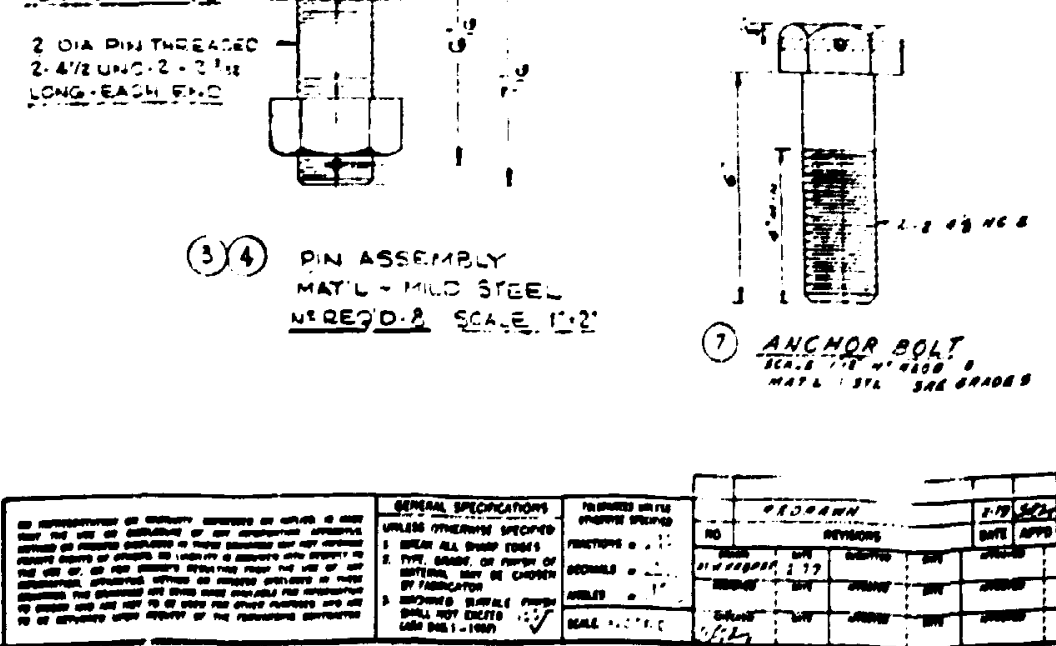

(1) ANCNOP soL?

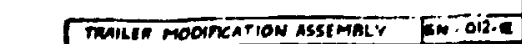




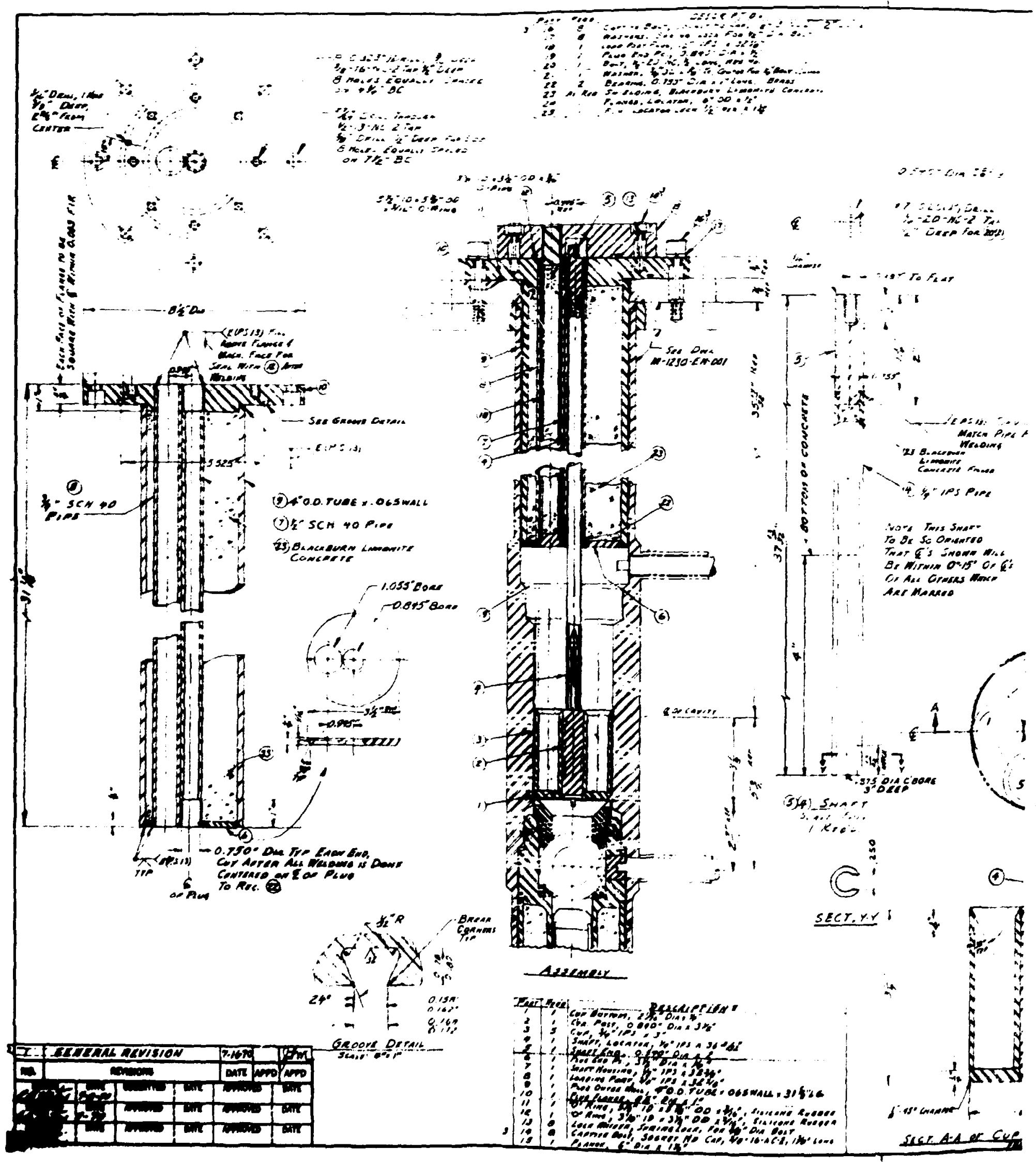




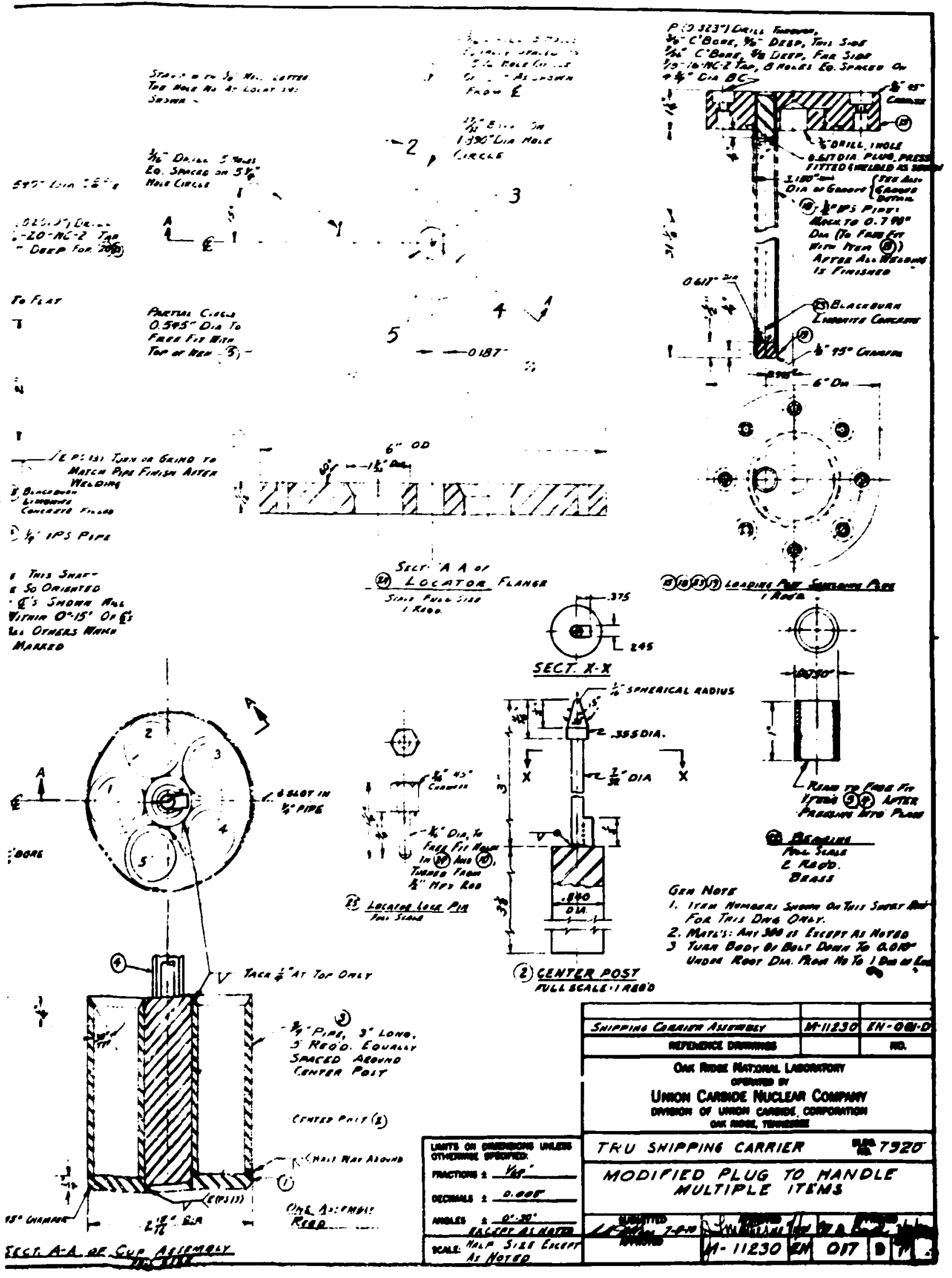




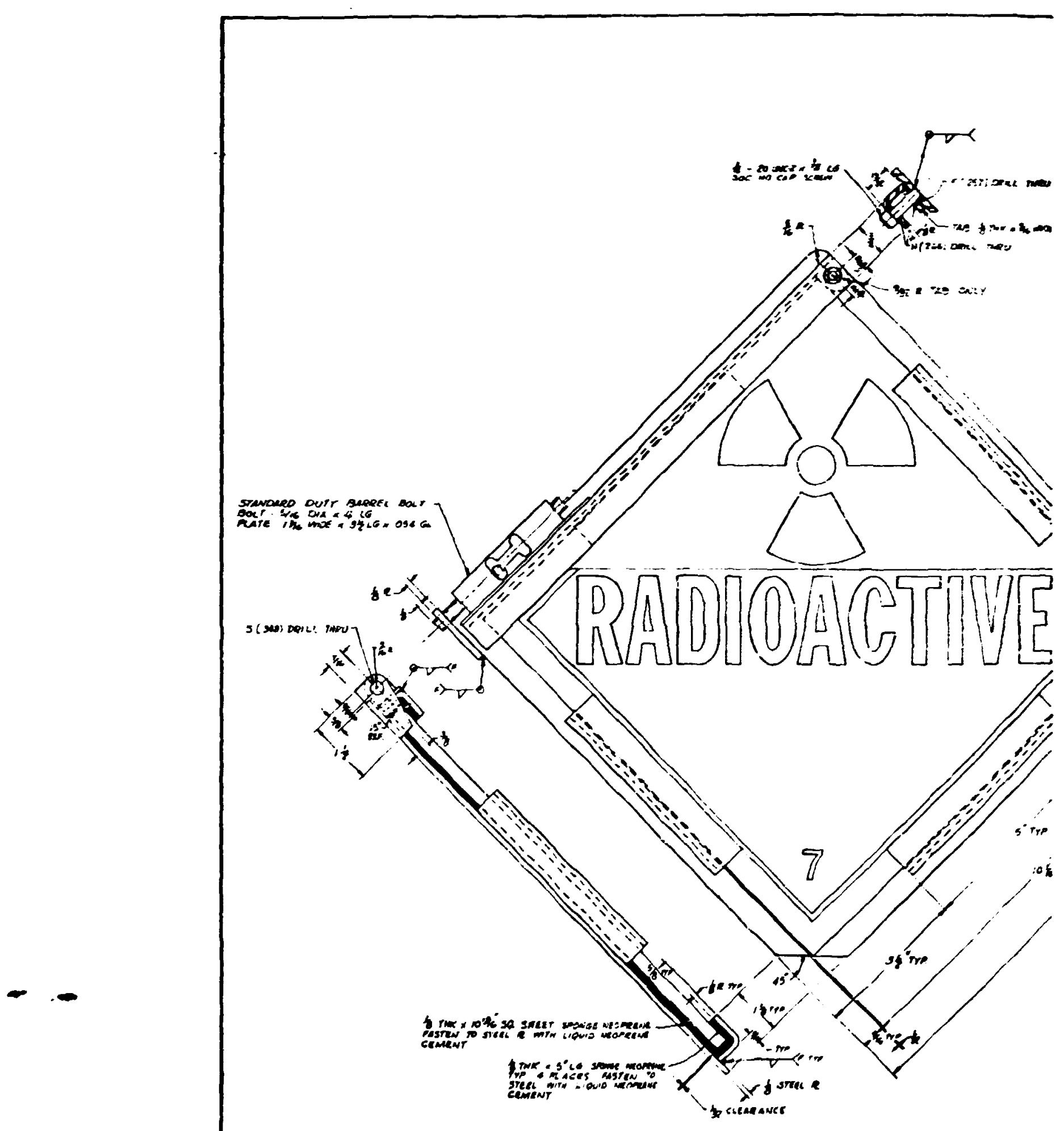




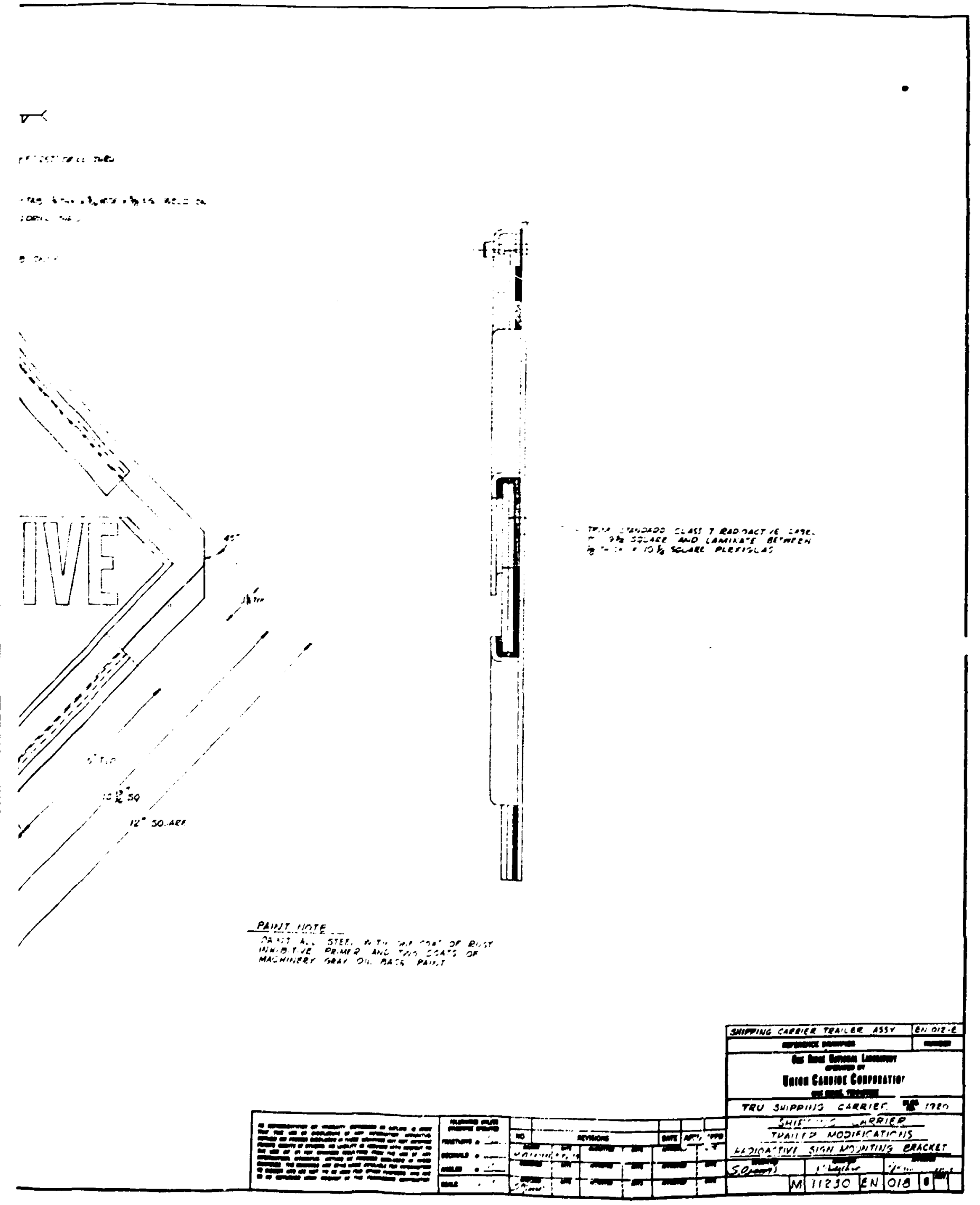




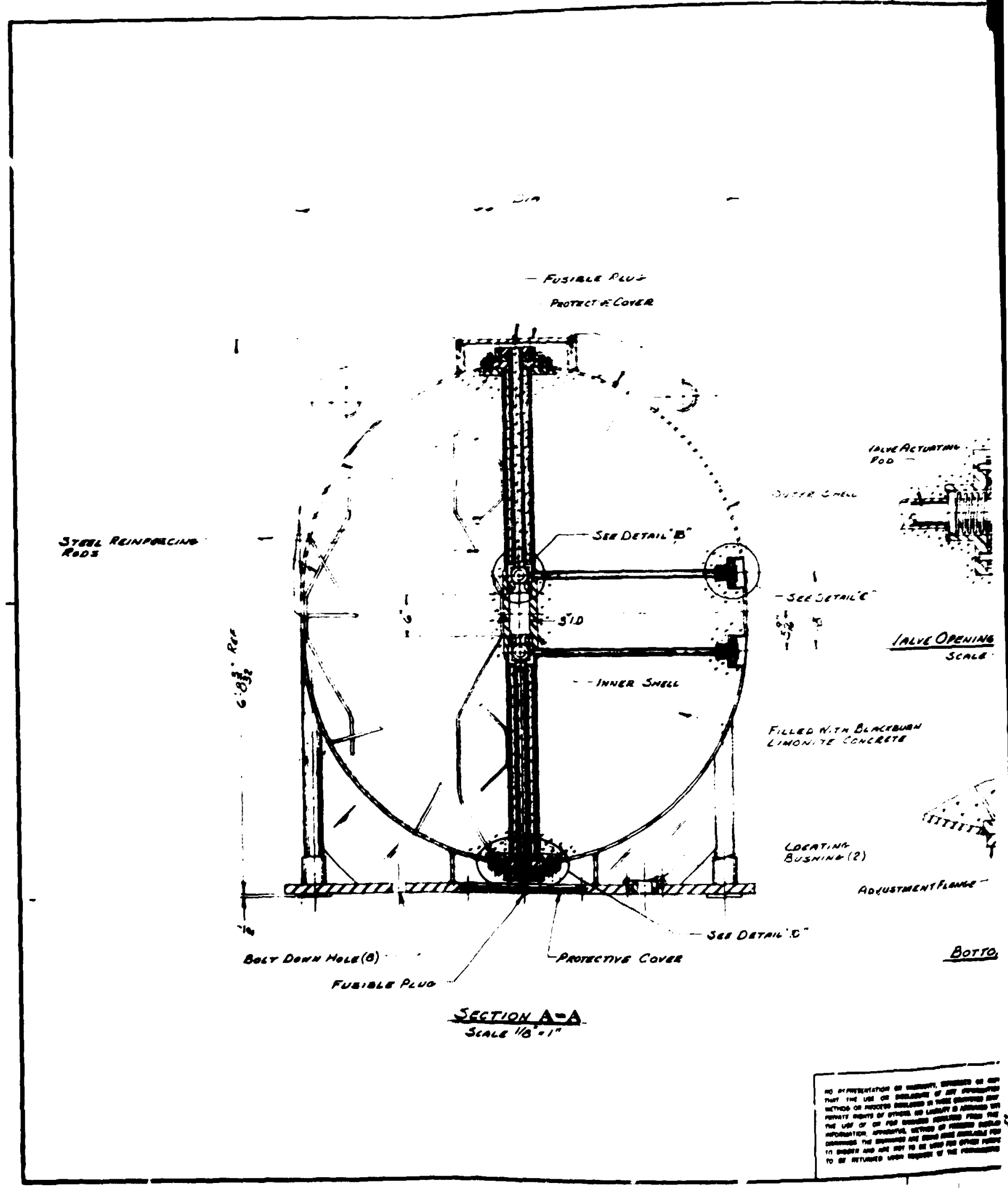




\subsection{Appendix B: Approval Documerits}

This appendix includes copies of the following:

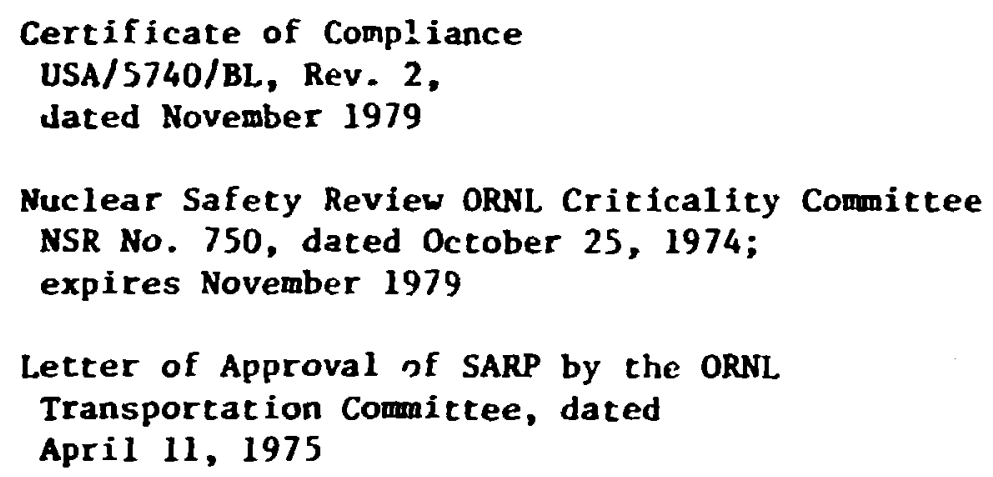




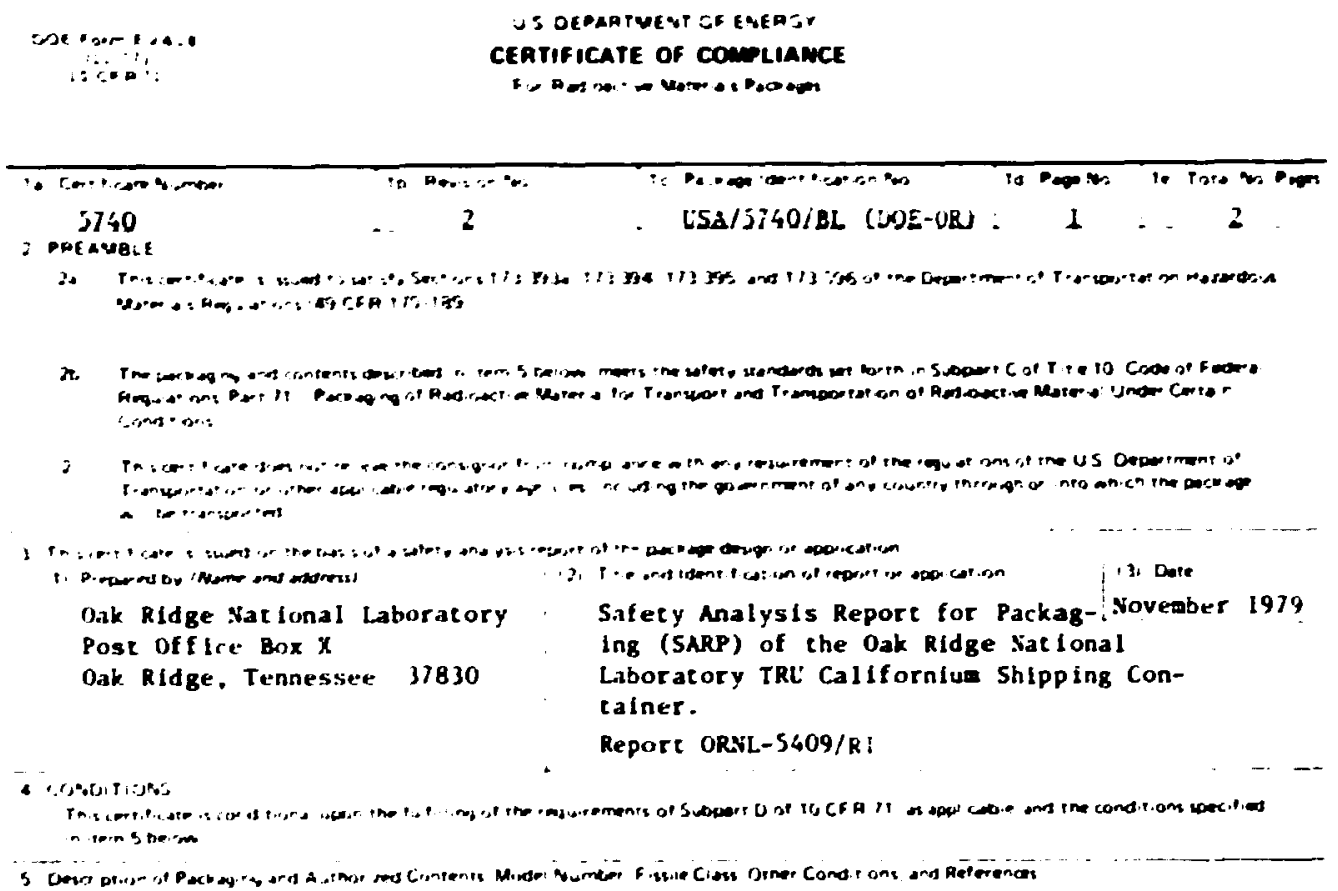

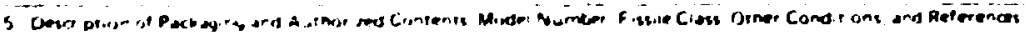

(a) Packaging

(1) Model: ORNL TRU Californium Shipping Container

(2) Description: A 304L stainless steel encased concrete stipping cask

The outer sheli consists of two $\xi-i n$. thick, 66-in. dianeter heaispherical heads joined by a 6-in. cylindrical section. The cylindrical cavity has a $1-i n$. thick stainless steel wall and is 3-in. diameter $\times 6-1 n$. iong. Shlelding consists of $30-i n$. Of Blackburn limonite concrete having a density of

lis $1 \mathrm{~h} / \mathrm{ft}^{3}$. Upper and lower level ball valves located at the end of concretefllled plugs define, isolate, and seal the cavity. Both of these plugs uhich utllize 0-ring seals are bolted in place and are frotected with a gasketed cover plate. Fuslble plugs in the cover plates and the shell will welt to permit steam release in event of thermal exposure.

The top ball valve and plug ay be replaced by other plugs for multiple source shipments. Sources are contained in Dot Specification $2 R$ or speclalform containers.

The cask is wounted onto a l-in. thlck steel base place by eloht steel $2 f-i n$. NPS Schedule 40 plpe strits. The cask is transported on tis own special iraller. The gross welghe of the cask $1823,500 \mathrm{lb}$.

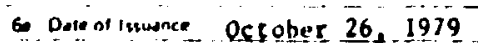

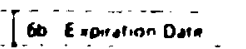

BOATEY US DEPARTMENT CSE ENERGY

1. Antroms int DoE lisuing onirol

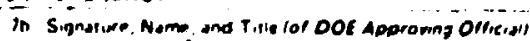

U. S. Department of Energy

Pont office Box $\varepsilon$

Oak Ridge. Tennessee 37830

Whan

Willias H. Travis, Director

Safety \& Environmental Control Division 
Certificate 5740, Revision No. 2 - Page 2

(3) Drawings:

The package and special trailer are constructed in accordance with Oak Ridge National Laboratory (ORNL) Drauings M-11230-ENO01-D through 008-D, 012-E, 014-E, 017-D, 018-E, and M-12166CD-019-D.

(b) Contents

(1) Type and Form of Material

The contents consist of isotopes of Americium (Am), Curiun (Co), Berkelium (Bk), Californium (Cf), Elnsteinium (ES), and Permium (Pm) as a solid (metal, oxide, oxysulfate, or dry salt) that is contained in a DOT Specification $2 R$ inner container(s) or in a spectal form capsule(s).

(2) Maximum Quantity of Material Per Package

3g. (large quantity).

(3) Other Limitations

(1) Maximum heat load - 5W.

(2) External radiation dose rates - Iimited to DOT Regulations, 49 CFR 173.393. 


\section{MECUEST FOR MUCLEAR SAFETY REVIEW}

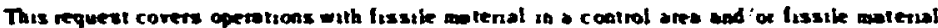

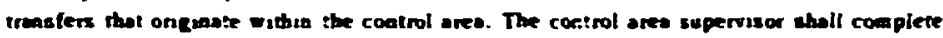

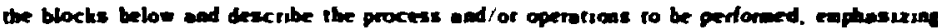

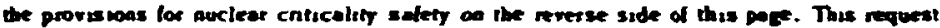

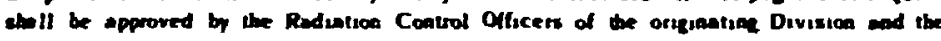
Division(s) to thich fiscile materal wall be transferred.

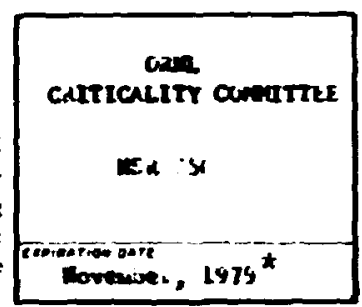

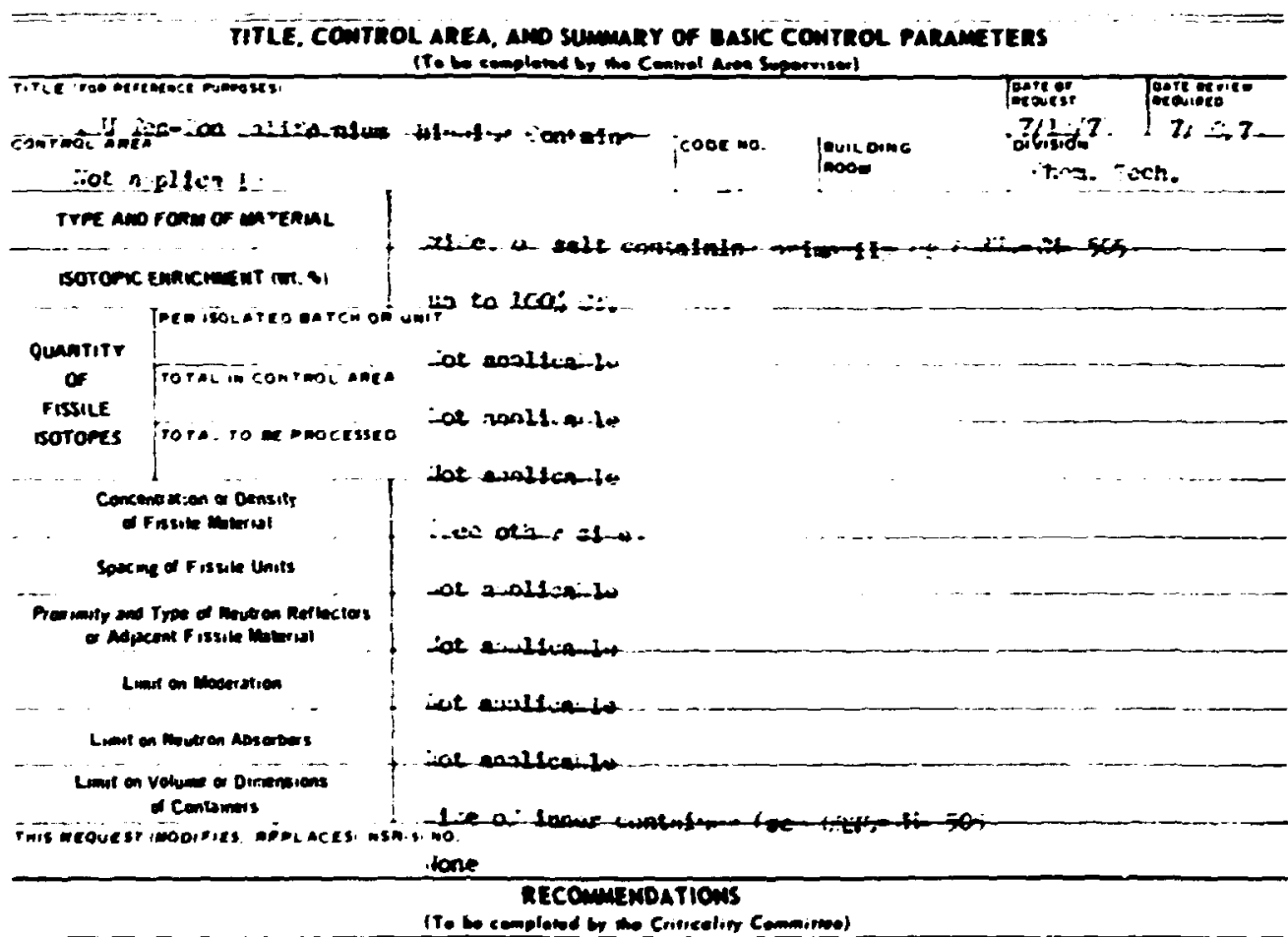

This epdosement is bosed on ous present understending of the operation (whether scquired verbally of in wising) and is tubject to reviet and cencellation.

This request is epproved cuoject to the following conefuerat fons:

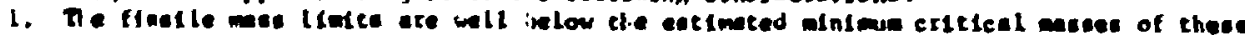
ectinide leocopes under cooditions of optinal wo.erecion ent retlection.

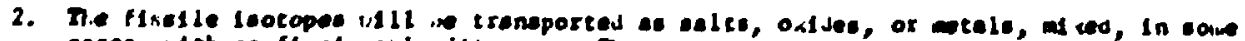
ceres, ith nonflestonable dimento. Hese consilione tenc to furtier increace tie oinimin critical mese hithin thif cesk.

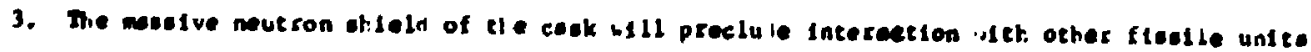

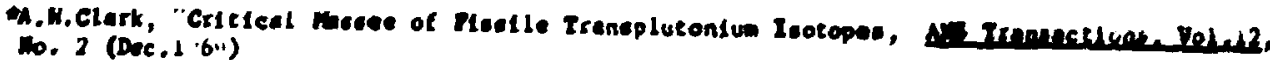




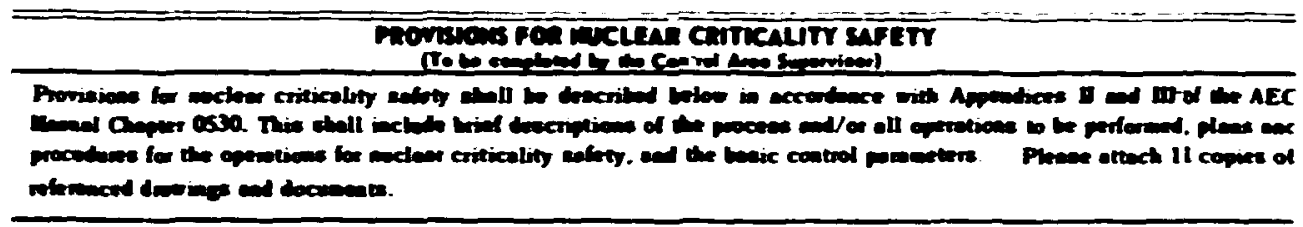

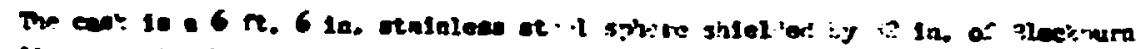

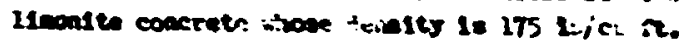

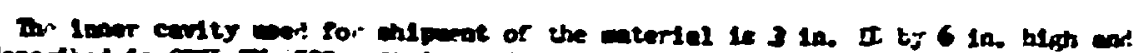

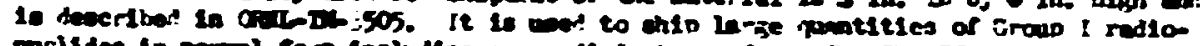

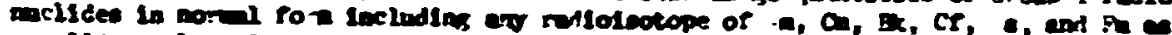

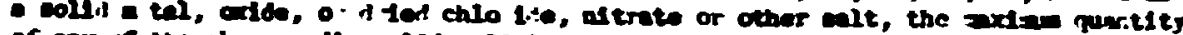

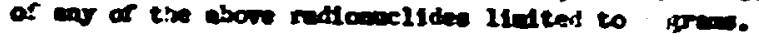

arin

currealis conidrex

in 750

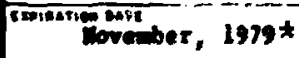

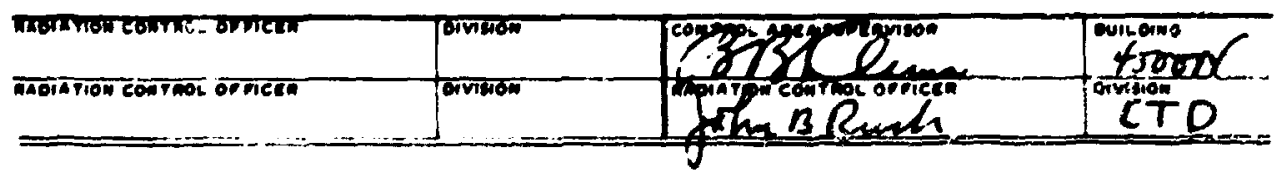

*The explration date for thts NSR has been extended to November 1984. 


\title{
INTRA-LABORATORY CORRESPONDENCE OAK RIDGE MATIONAL LABORATORY
}

\author{
Apri1 11, 1975
}

To:
B. B. Klima
L. B. Shappert
M. C. Jurgensen

From: Transportation Committee

Subject: Approval of SARP of the ORNL TRU Californium Shipping Container

The ORM Transportation Committee has reviewed your submission of the subject SARP to fulfill the requirements ( $n$ icrnal review) of paragraph B of AEC Immediate Action Directive 5201-3. Particular attention was given the five areas of structural integrity, the rmal resistance, radiation shielding, nuclear criticality safety, and quality assurance.

The results of the evaluation show that the container meets the requirements of AECI 0529 and the SARP is approved for submission to the ERDA for request of a Certificate of Compliance for approval of the cask for use for of fsite shipments of fissile and radioactive materials.

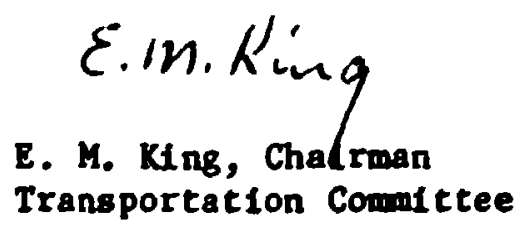

EAR:bb

cc: Transportation Coumittee 
9.3 Appendix (: Computer Program for 30)-ft I)rop (Onto the Iop and

Bottom of the TRI Californium Shipping

Container - Progran 1014 Cask

Derilation of Eyuation,

The model shown in Fig. 9.1 illustrates the general case of a cask equipped with an energ! abrorber which deforms in pure compression. If the force-deformation curve for the absorber is taken as shown in Fig. 9.2. the expression

$$
C L_{n}=F_{n}\left(X_{n}-X_{n-1}\right)=F_{n} \delta_{n}
$$

represcnts the energy expended as the cask moves from $X_{0}$ to $X_{n}$ and detorms the absorber an amount $\delta_{n}$. It follows that

$$
i_{n}=\sum_{n=0}^{n=n} \dot{C}^{i}=\sum_{n=0}^{n} .
$$

The summation may be simplified hy taking $\delta$ constant and satisfying the expression.

$$
i \delta=X_{n}
$$

The deformation $X_{n}$ may be written

$$
x_{n}=\epsilon_{n} l .=N \delta .
$$

Solving for $t_{n}$, we have

$$
t_{n}=N \delta 1 .
$$

There is an expression, $\sigma_{t}=f\left(t_{t}\right)$. where $n=$ stress, psig, and $t=$ strain, in. in., for the material from which the energy absorter is constructed. The force can then be determined from the following expression:

$$
\mathbf{F}=\boldsymbol{\sigma A} \text {. }
$$

where

$$
A=\text { original cross-sectional area of the energy absorber, in. }{ }^{2} \text {. }
$$

These relationships form the hasis for the attached computer program. The absorber deformaiton is increased in steps of constant magnitude. Strain. stress, and force are computed for value of deformation and the energy for the step determined. The energy is added to the sum of that from previous steps and compared with the cask potential energy. When the dissipated energy equais the potential energy, the computations are complete.

The program is currently supplied with stress-strain equations. 
OFNL DWG 75-82
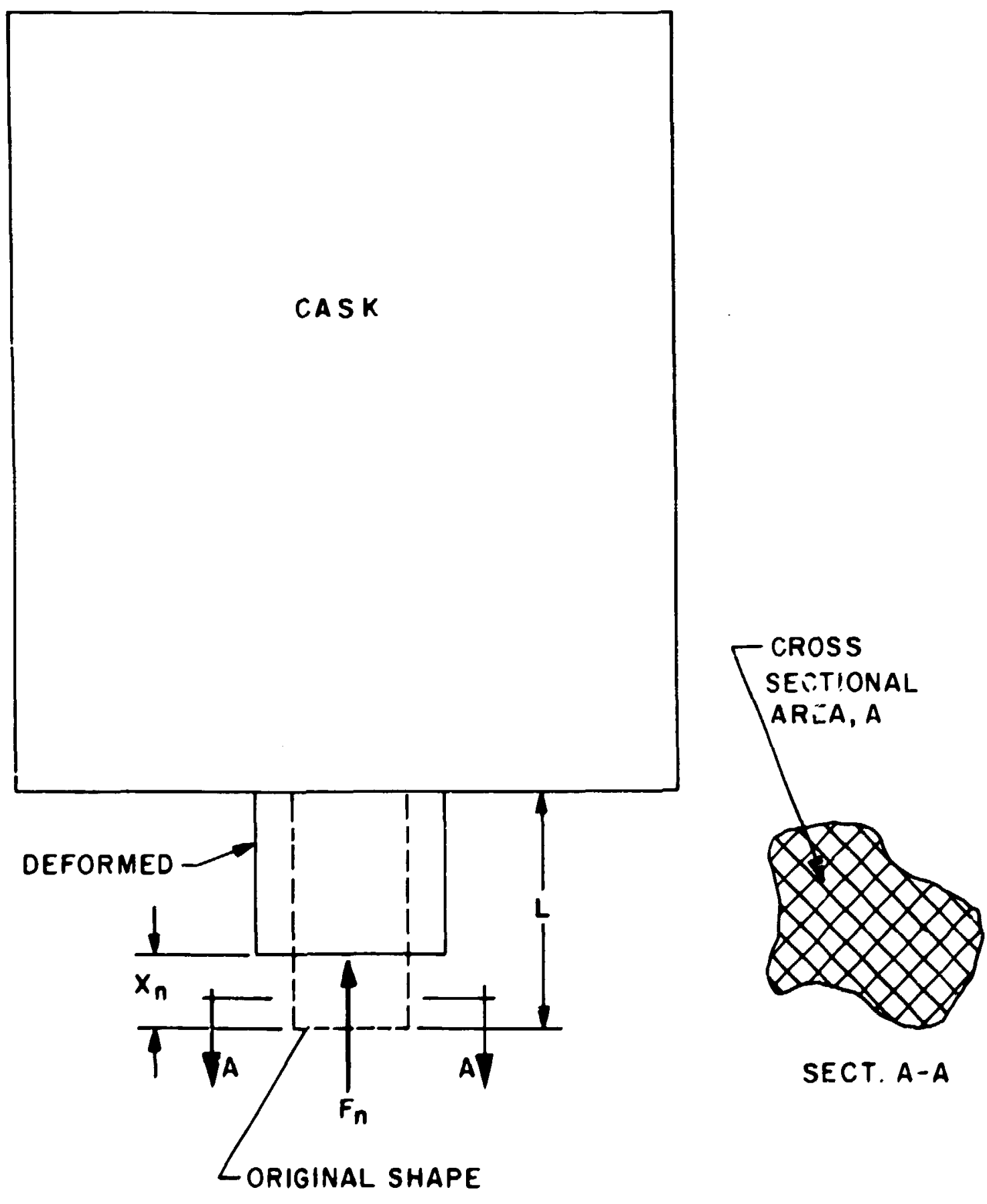

SECT. A-A

F1g. 9.1. Cask model. 
ORNL DWG 75-83

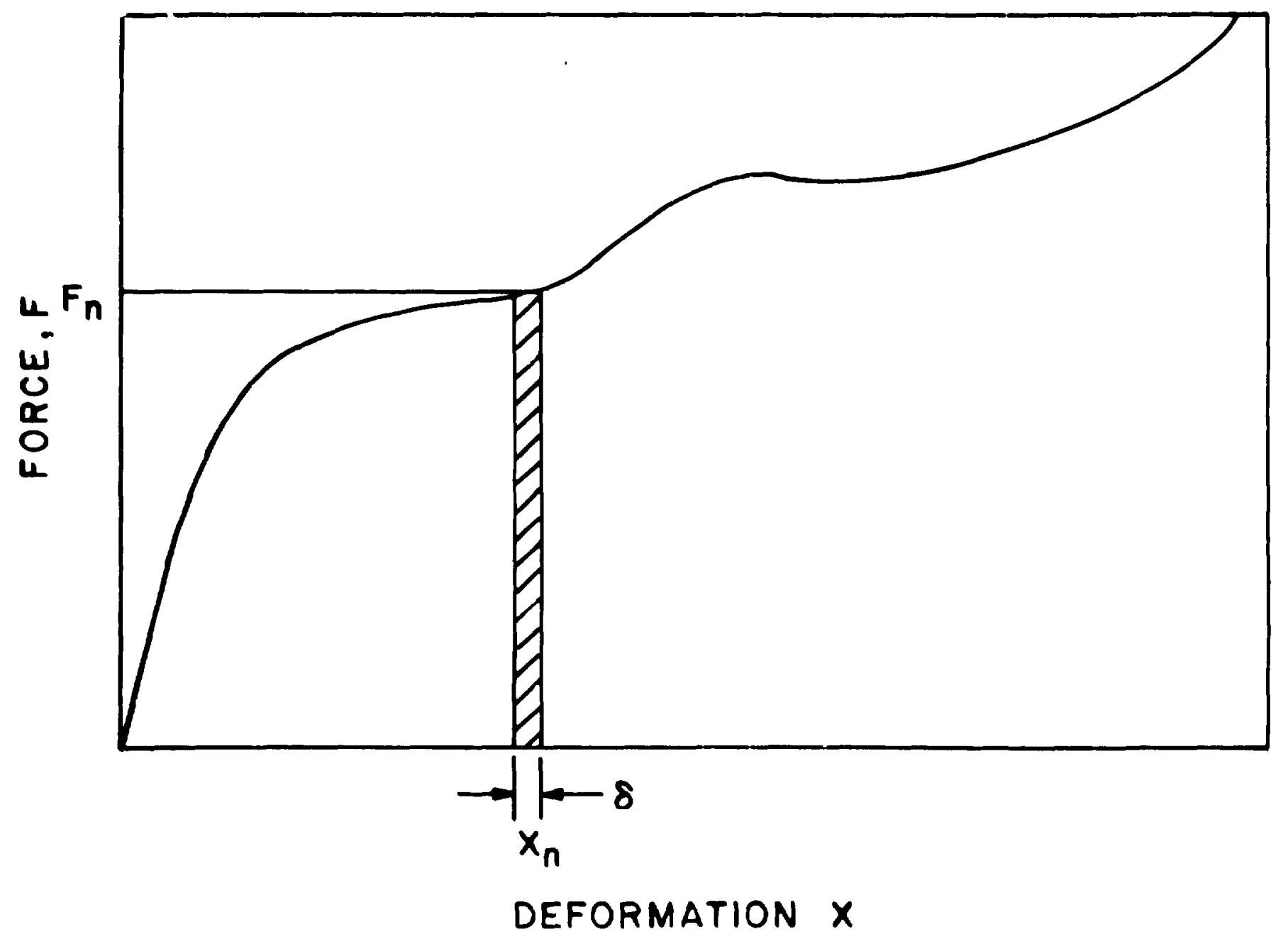

Fig. 9.2. General force deformation diagram. 


$$
\sigma=f(e) \text {. }
$$

for stainiess steel and mild steel. The program can be used for abuorbers having any crow-sestonal shape. It 1s equipped to compute the area ior cubular abourbers (wep Fig. 9.3a) and for rectangular ahsisiters having a constant thickness (see Figs. $9.3 \mathrm{~h}$ and $9.3 \mathrm{C}$ ). In the case of the tuhular atherrter. the sadiuv and thickness depth must be inserted in statement numbers 79, $7 \mathrm{i}$. and ?2. 1.er a rectangulaf absorker. the thickness. depth. and length must be inserted a) stitemient rumber, 71. 72, and 73. For absorbers of other georatetry. the area must be computed by hand in inpu: in statement 74. Those statements not applicable must be left as 0.0. In addition. the cask weight in pounas must be input in statement $8($ ). the drop material height in incties in statement 81 , and the material in statement 88 . The material in input is SSI for 30() annealed series stainless steel and STI. for mild steel If a finer or coarser mesh is desired. the value of DF: in statement 60 may be decreased or increased. The (OX)( format should be altered in identify the cask.

A glossary of terms used in the $10(x)$ format is listed belou:

$$
\begin{aligned}
& \text { AMATL = Material absorber is made of } \\
& \text { Wr }=\text { Weight of cask } \\
& \text { TLEN }=\text { Length of absorber } \\
& \text { RAD }=\text { Radius of absorber } \\
& \text { THK = Thickness of absorber } \\
& \text { DEPH = Depth of absorber } \\
& \text { DL = Incremental change in absorber depth } \\
& \text { AREA = Area of absorber before impact }
\end{aligned}
$$



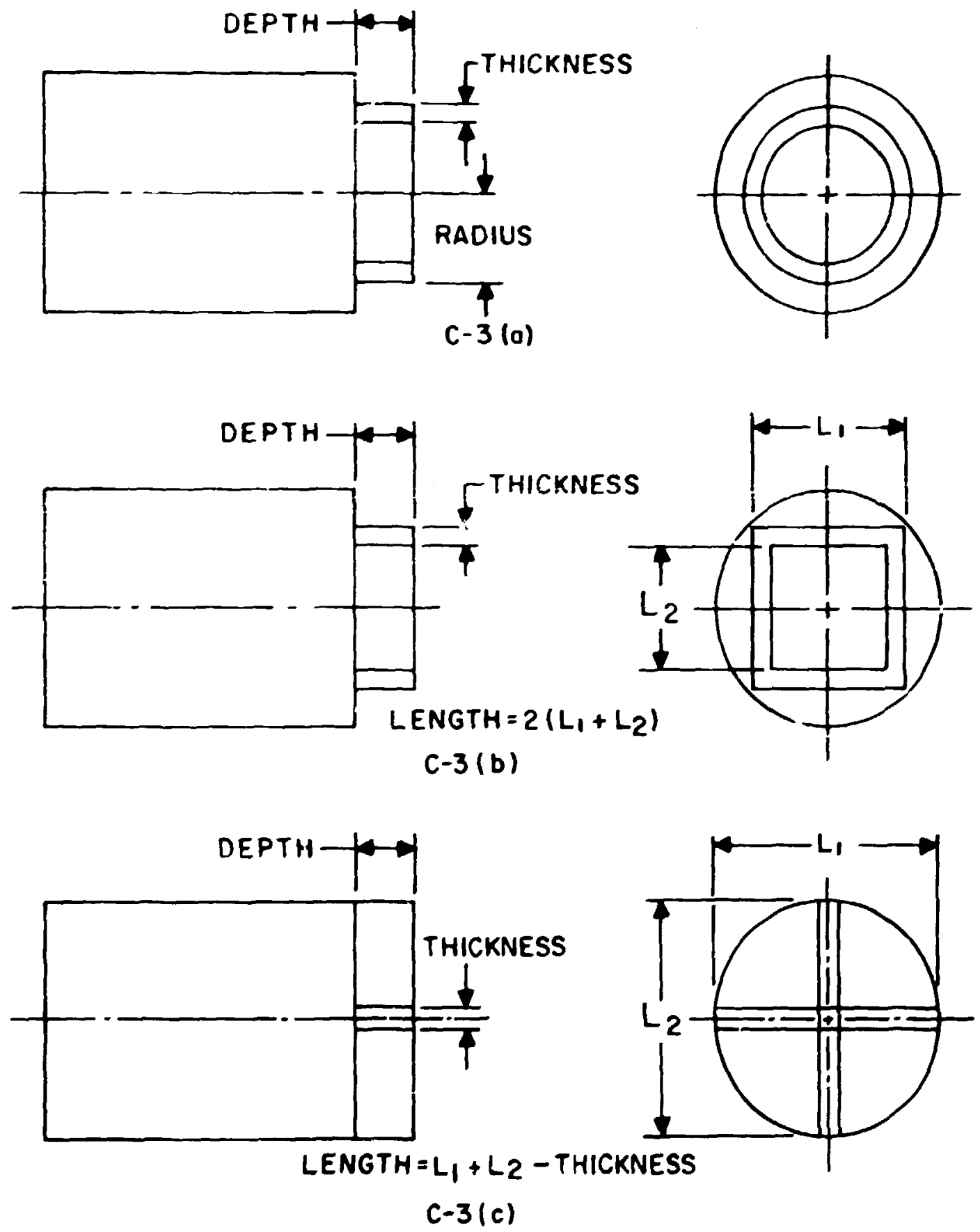

Fig. 9.3. Energy absorber configurations. 


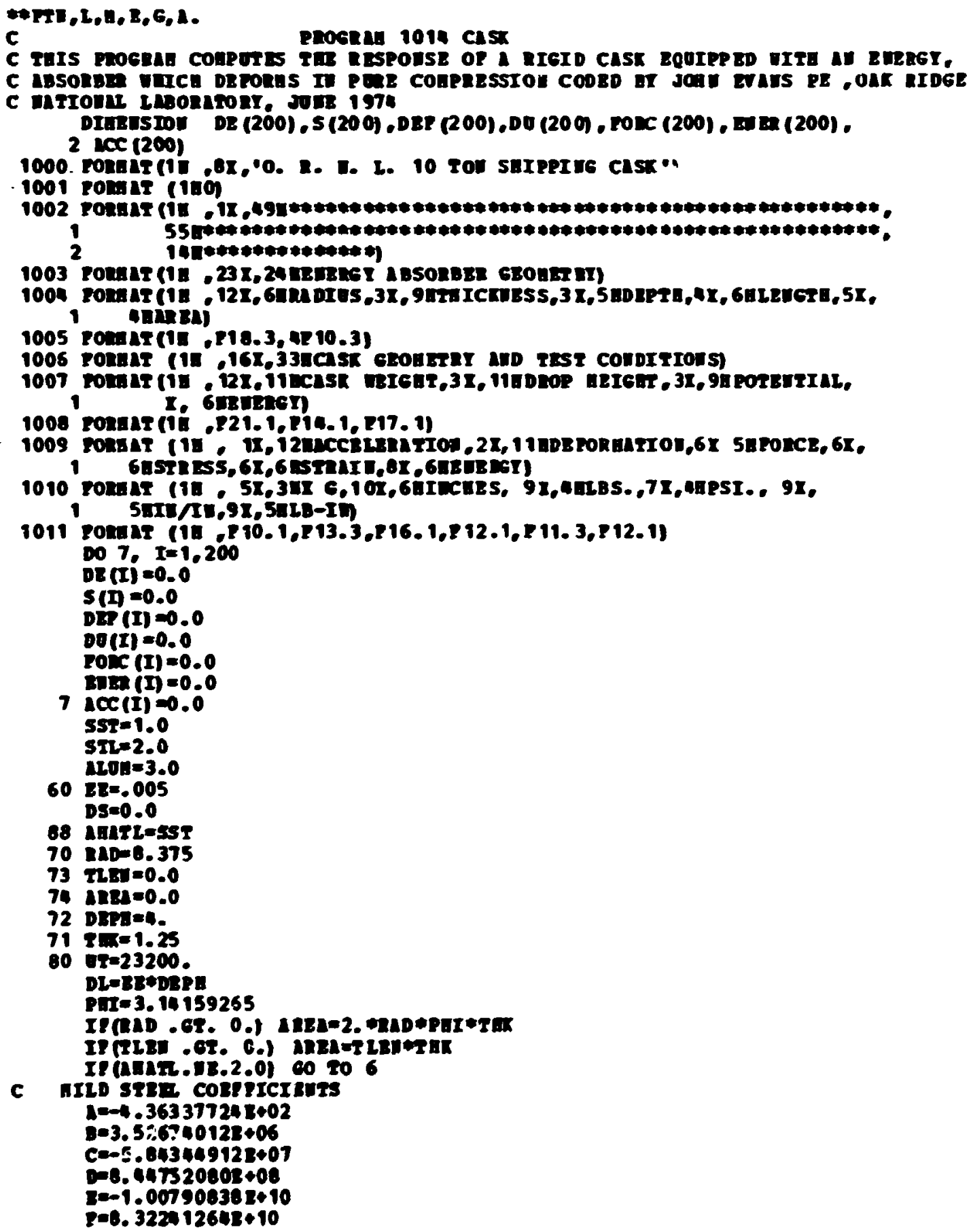




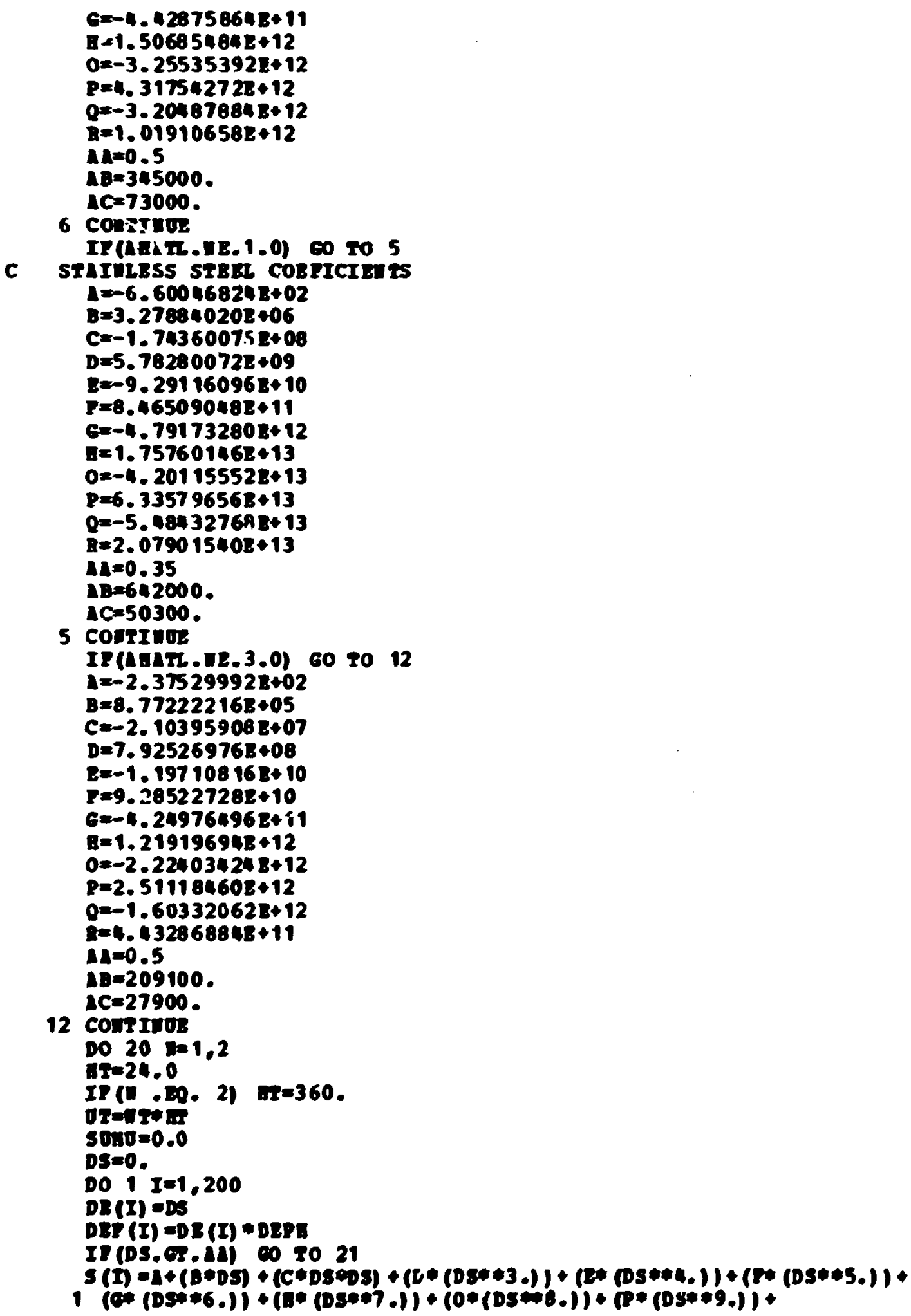


$2(Q *(D S * 10))+.(R *(D S * 11)$.

21 contrut

IP(DS.LE.AL) 60 TO 22

22 comr IU⿴囗十

$\operatorname{PORC}(I)=S(I) * 18 E A$

$\operatorname{LCC}(I)=\mathrm{FORC}(\mathrm{I}) / \mathrm{TT}$

DO(I) =ronC (I) *DL

SOAO $=50.0+D 0(I)$

EUER (I) $=5000$

DSADS+LE

IF(BDER(I).GE.0T 60 TO 2

1 conrirue

2 conritus

$J=I$

DRITE $(6,1002)$

DETrE $(6.1002)$

URTPE (6.1001)

unIIs $(5.1000)$

anis $(6.1001)$

DETSE (6.1002)

DRITE $(6,1002)$

TEITE $(6,1001)$

DRIT $(6,1003)$

DEITs $(6.1001)$

verrs $(6,1004)$

atres $(6,1001)$

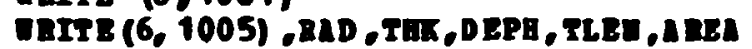

EIITE $(6,1001)$

TRITE $(6,1002)$

ERITE $(6,1001)$

maIrs $(6,1006)$

VIITE $(5,1001)$

TEIT $B(6,1007)$

DRITE $(6.1001)$

DIITE $(6,1008)$ DT, BT, 01

TRTTE $(6,1001)$

DAITE $(6,1002)$

URIIE $(6,1002)$

चmis $(6.1001)$

UITE (6. 1009)

DITE $(6,1001)$

DEITE $(6,1010)$

vRITE $(6,1001)$

Do $10 \quad I=1.200$

DRITE (6, 1011) , ACC (I) , DEE (I) , PORC (I) , S (I) ,DE (I) , BUER (I)

IF(I.GE.J) eo ro 11

10 conrruor

11 Conrinos

URITE $(6,1001)$

ERTre $(6,1001)$

URITE $(6,1002)$

URITE $(6,1002)$

verte $(6,1002)$

ancre $(6,1002)$

InITE $(6,1002)$

DRIT2 $(6,1002)$ 


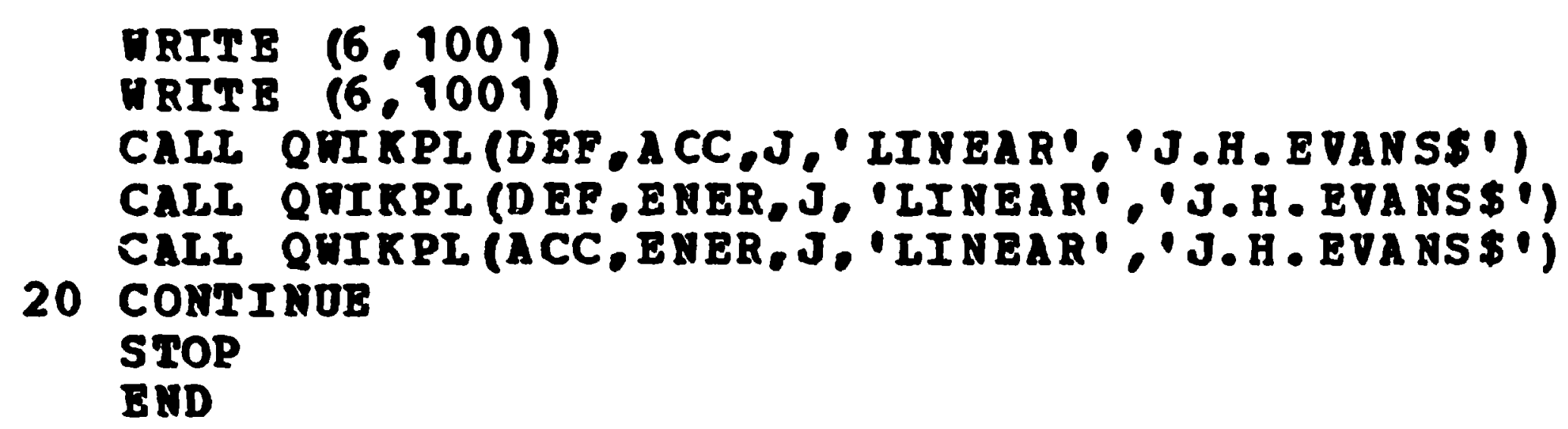

END 
9.4 Appendix D: Typical Operating and Irspection Procedures for TRU Californium Shipping Container 
Form TRU.. 5740-1

SHIPMENT PREPARATION SUMMARY

AEC-OR USA/5740/BL

DATE : TRU SHIPMENT NO.:

The following elements of shipment proparation have been properly completed, copies of the indicated forms are attached.

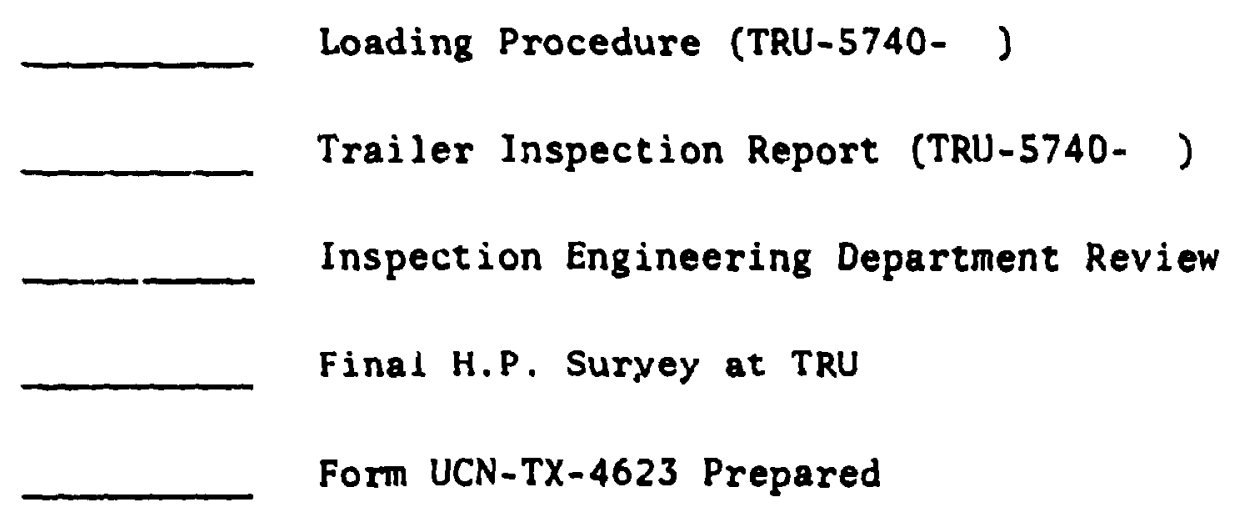


FORM TRU-5740-5

TRU CALIFORNIUM SHIPPING CONTAINER

Face 1 of 2

UNLOAD ING PROCEDURE

INCOMING SHIPPENTS

MULT IPLE BASKET ITEASS OR

SINGLE SHIPMIERT ITERS

AEC-OR USA; $5740 / \mathrm{BL}$

Date:

Material Received:

No. Packages:

Type Packages:

Shipper :

Radiation Data: H.P. Representative:

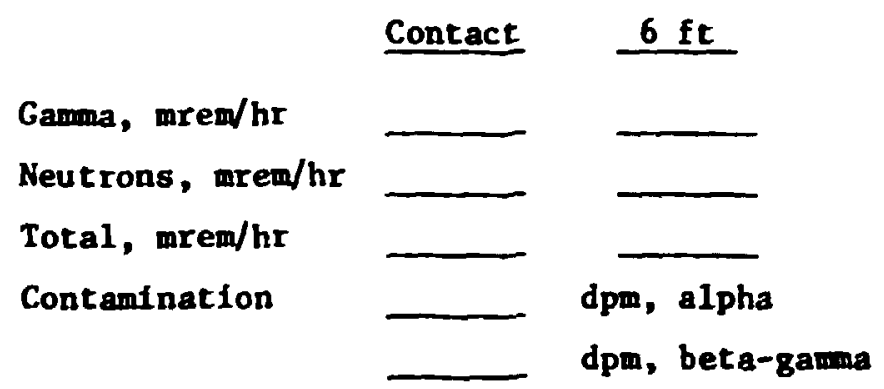

Date $\quad$ By

1.

Carrier moved from tratler into Bldg. 7920.

Items $\underline{2}$ through $\underline{13}$ require H.P. survelllance.

2.

Remove top cover plate.

3.

Remove bolts fros top valve actuator rod assy.

Pull assy. out 1 inch.

4.

Remove top plug - top loading port shield remains attached to top plug. 
Date By

FORM TRU $-5740-5$

Page 2 of 2

5.

Complete pre-move check on TDF:

A. Air, water, power disconnected:

B. Transfer line disconnected:

C. Slug chute closed - handle removed:

D. Valve in TDF ciosed:

6.

Hove TDF to stacion above carrier.

7.

Open valve in botton of TDF.

8.

Lower proper tool from TDF into carrier - engage basket or single item and lift into TDF.

9.

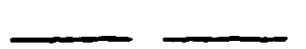

Close bottom valve on IDF.

10. Move TDF back to upper station.

11.

H.P. survey carrier to determine that carrier is empty.

12. Clean all carrier parts. Store in plestic bags.

13. Contamination levels after cleaning - dpm alpha

Top plug:

Carrier Intermals:

Spacers:

14.

Rewove old shipping labels from carrier.

15.

Cover opes top of carrier with plastic or blotter paper.

16.

Reinstall top valve actuator rod assy, and tighten boles. 
MULTIPIE SHIPMENT LCADING PROCEDURE

IRU CALIFORHIOM CONTAINER

AEC-OR USA/5740/BL

Date:

Materi. I to be Shipped:

TRU Shipment No.:

Number of Packages:

Type Packayes:

Date By

1.

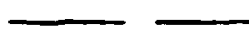

2.

3.
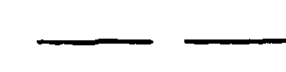

4.

5.

s. $+$
Contamination levels after cleaning carrier components.

$$
\text { dpm, alpha }
$$

Top loading port shield

Top plug

Basket

Carrier Internals

Transfer multiple shipping basket to decontamination factlity (TDE).

Load and record package positions:

$$
\text { dpa alpha smear }
$$

Position No. 1

Position No. 2

Position No. 3

Position No. 4

Position No. 5

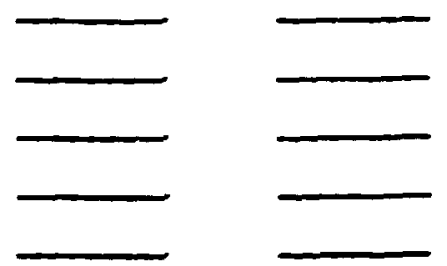

Disconnect air, water, porer, and transfer line frow TDF.

Chack that valve in slug chute is closed. 
Date By

6.

8.

9.

10.

11.

12.

13.

14.

15.

16.

17.

18.

19.

20.

.

.

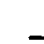

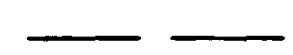

.$$
\text { . }
$$
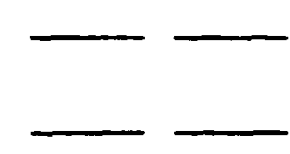

.

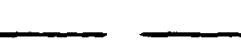

.

.

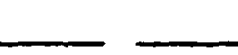

6.

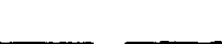

7.

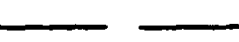

.

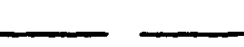

.

Install outer cover plate with lock washers in place.
Torque bolts to 100 in. Ib.

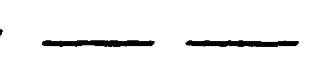

Remove handle from slug chute valve.

Check that valve in bottom of TDF is closed.

Have riggers move TDF to load-out station.

Open valve in bottom of TDF.

With H.P. survefllance, lower loaded basket into carrier cavity.

Hove TDF back to Cell 1 position.

Check condition of sealing surfaces and 0-ring on top inner plug.

Put top Inner plug into carrier, being certain to orient shaft to engage basket.

Torque top inner plug bolts to $100 \mathrm{in.} 1 \mathrm{bs}$.

Check sealing surfaces ati 0-ring on top loading port shielding plug.

Install top loading port shield plug.

Torque top loading port shield plug bolts to $80 \mathrm{in.} 1 \mathrm{bs}$.

Check condition of surfaces and gasket on outer cover plate. Comments:

1. General condition of carrier:
FOR: TFES $5, T+40-7$

Pate $20:$ i

2. Old shipping labele removed: 
FORM TRU 5740-7

Page 3 of 3

21. Radiation Data - Obtain and Resord - H.P. Representative:

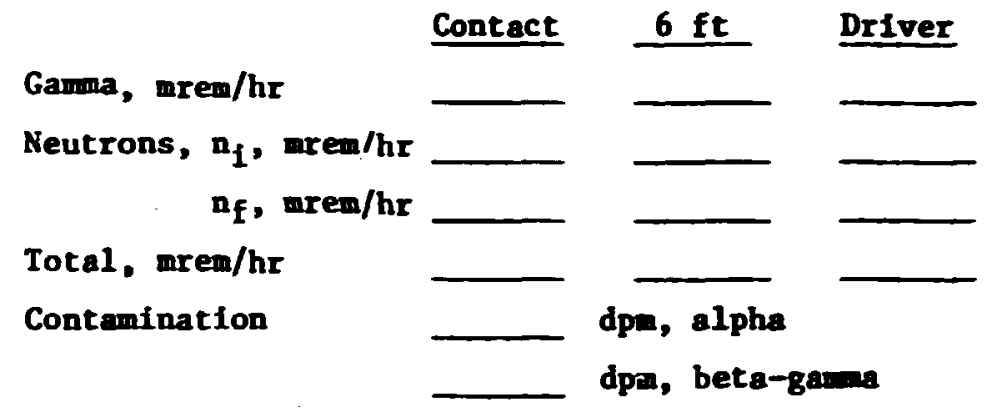

Date By

22.

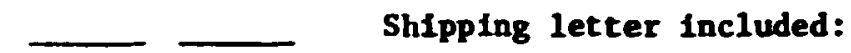

1. Inside carrier top cover:

2. Inside trailer tool box:

23. Cartier moved to trailer.

24. Install anchor bolts. Torque to $230 \mathrm{ft}-1 \mathrm{~b}$.

25. Install anchor bolt safety wres.

26. Install cables.

27. H.P. transfer tag attached to carrier.

28. Trafler tool box check 118t: 1. Source 11fting tool:

2. Index plate:

3. Tool box locked: 
FORM TRU-5740-8

Page 1 of 2

TRU TEN-TON CALIFORNEUM SHIPPING CONTAINER

BIEANIAL INSPECTION CHECK LIST

\section{CONTAINER}

1. Inspection of Welds (Visual):

Welds on spherfcal body:

Welds on top fins:

Welds on bottom fins:

Baseplate welds:

Welds needing more Inspection:

2. Pusible Plugs:

Top cover plate:

Botton cover plate:

Concrete pour opening:

3. Pressure Check:

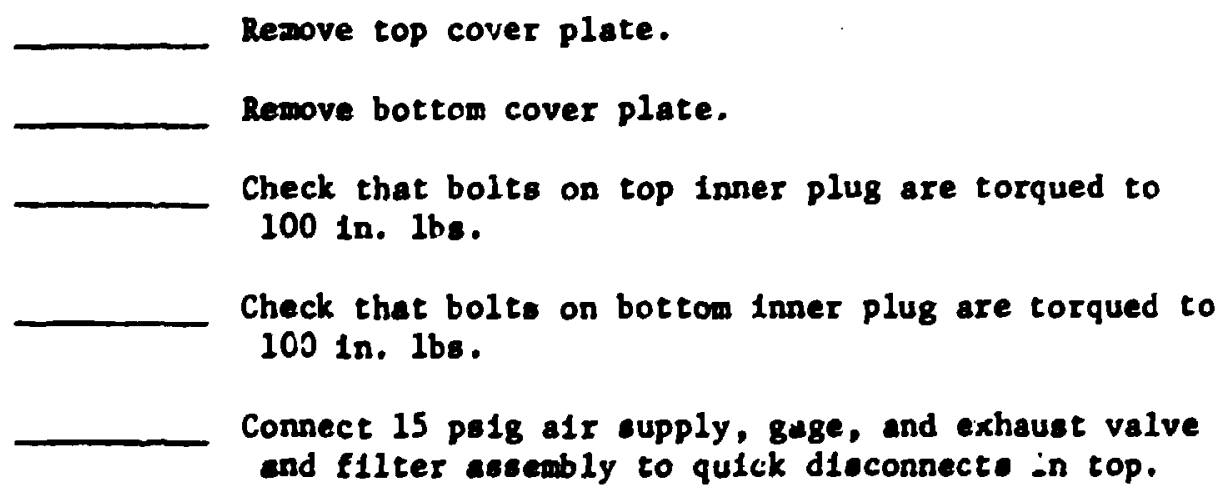


Apply 15 psig pressure to cavity and close inlet valve. After 30 min observe pressure: __ psig.

If pressure has dropped, check test equipment for leaks using soap solution.

If test equipment $1 \mathrm{~s} 0 . \mathrm{k}$., check top and bottom 0-ring seals.

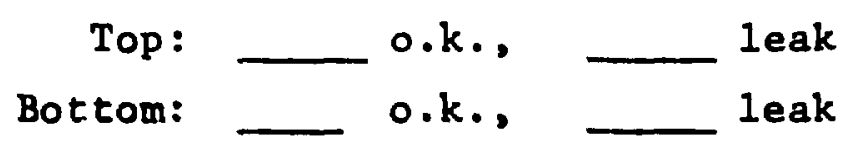

Release alr pressure from system.

Obtain H.P. assistance.

Remove top and/or bottom Inner plug.

Inspect $0-$ ring and sealing surfaces. Comments:

After making needed repalrs, obtain another copy of th1s form and repeat pressure test. 


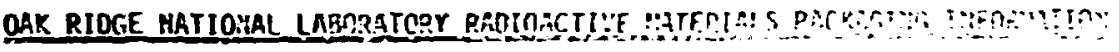

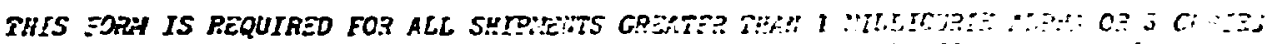

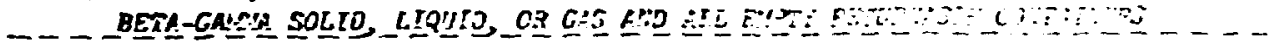
riseneral Information

1. Origin Cofvision

2. Destination

3. Mechod of Transport

4. Heigite

5. Special Instructions

Specisl instructiors Co.splied by

Padioactive Contents

1. MI major activities in curies and/or krams

2. Spectfy Gl boral Forb $\square$ (b) Special Form $\square$ Special form No.

CLI Pfasile

(d) Non-Fissile $\square$

3. Redianctive Materlal Pora: Solid $\square$ Liquid $\square$

4. Bent Load (ratce): Calculated

Gas $\square$

Estimered

By

Shipping Container

1. AEC Cerciffcate of Compliance No. AFC-OR-USA

2. Dor Specification to.

4. Container deternined proper for contents hy

3. Muclear Safety Revies lo. internal Conta iner

l. Internal Containsent: Glass Bottle $\square$ Plastic Bottle $\square$ "2R" $\square$ Conoseal $\square$ Welded Capsule (specify capsule materiel) $\square$ Oeher (explain) $\square$

2. Contaninateon level on Internal contafnet: fatimated

3. Rediation Ievel from Internal container: Measured

4. Gaskets or seals (valves) properly installed

5. Leak tests of internal concainer External Container.

1. Hoderator and neutroa sosorher present for fissile material? Yes

2. External conteiner examination

3. Gaskets or seals properly instajled

4. Leak cest

5. Doles torqued to

6. Tie down to skid checked

7. To uper seal tnetalled Radiation Survey

1. Surface contanlation level: Alpha

2. Extermal radiation level

3. Domestic shipments

4. Forelen shipmente

5. Bealth Physice Surveyor Simcesred

Date culared Truck Tle-Down and Shoring

1. Ile-down and shoring checked by (Insp ection Engincering)

Shiprent Approved By

Date

TX-4623 (Revised 9/74) 


\section{REHEREVICFS}

1. B. H Klıma and 1. B. Shappert. The TRL Ten-Ton Califormum Shyping Container. (OR.VI-35US Novemher 197i).

2 Conde ol leoderal Regulations. Title II). Part 71.

3. Ir)E. Manual. (napter 15529 IJune 14. 1973).

4. Conde al tederal Regularimm. Title 49. Pan 173.

5. Conle of Fideral Regulations. Title 49. Pan 173. paragraph 173.389(b).

6. Codt' of Ficderal Regulatiuns. Title 49. Pan 173. paragraph 173.393(j).

7. R. J. Roark and W. C. Young. Formulas for Siress and Sirain. Sth ed.. p. 97. Meciraw-Hill, Neu York. 1975.

x. Ihid. p. 216.

9. J. I. Oden. Mechanics of Filusiic Siructures. p. 87. McGraw-Hill, New York, 1967.

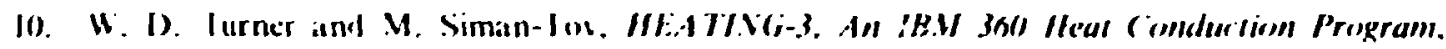
(IR.VI. IM-321) I ICbrtiary 1971).

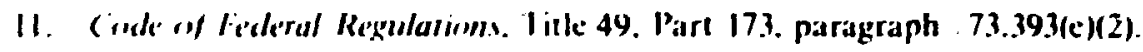

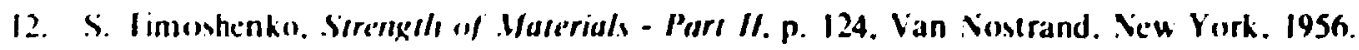

13. S. R. Pearsall. S. Majeski. and I.. (iemmell. "Design and Testing of a Shipping Contsiner for large Quantities of Radioactive Waste." pp. 634-36 in Proceedings of the fircomel !nernational Simposium on Packaging and Transportation of Radinortive Lateriests. CONF-681001 (1968).

14. J. H. Fanns. Design and Analysis of the New Brunswick Lahoralory High-l.evel Wasle (ask. OKNI. TM-4242 (June 1973). Appendix D.

15. (inde of ficderal Regulutioms. Title 10. Part 71. Appendix D).

16. Agcnt R. M. (iravianos Tariff No. 29. Hazardous Materials Regulations of the Departmenl of Transportation Including Sperifications for Shipping Containers lissued Dec. 15. 1974: effective Jan. 14. 1975). paragraph 178.34. 
17. E. D. Clayton. "The Nature of Firsion and the Criticality Process" (from Protactinium to Californium and Beyond). -Proceedings of Short Course on Nuclear Criticality Safert. Taos. New Mexico, May 7-J1. 1973. USAEC TID-26286 (1974). p.I.

18. R. D. Seagren. C. D. Watson, and W. D. Box. The Oak Ridge Notional Lahoratory Chemical Technolog! Division Quality Assurance Program for Radivactive Material Packagings. ORNL TM-647I (in preparation). 